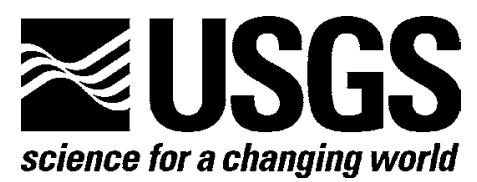

\title{
Helicopter Electromagnetic Survey of the Model Land Area, Southeastern Miami-Dade County, Florida
}

By David V. Fitterman, Maria Deszcz-Pan, and Scott T. Prinos

Open-File Report 2012-1176 


\section{U.S. Department of the Interior \\ KEN SALAZAR, Secretary}

\section{U.S. Geological Survey \\ Marcia K. McNutt, Director}

U.S. Geological Survey, Reston, Virginia 2012

For product and ordering information:

World Wide Web: http://www.usgs.gov/pubprod

Telephone: 1-888-ASK-USGS

For more information on the USGS-the Federal source for science about the Earth,

its natural and living resources, natural hazards, and the environment:

World Wide Web: http://www.usgs.gov

Telephone: 1-888-ASK-USGS

Suggested citation:

Fitterman, D.V., Deszcz-Pan, M., and Prinos, S.T., 2012, Helicopter electromagnetic survey of the Model Land Area, Southeastern Miami-Dade County, Florida: U.S. Geological Survey Open-File Report 2012-1176, 77 p.

Any use of trade, product, or firm names is for descriptive purposes only and does not imply endorsement by the U.S. Government.

Although this report is in the public domain, permission must be secured from the individual copyright owners to reproduce any copyrighted material contained within this report. 


\section{Contents}

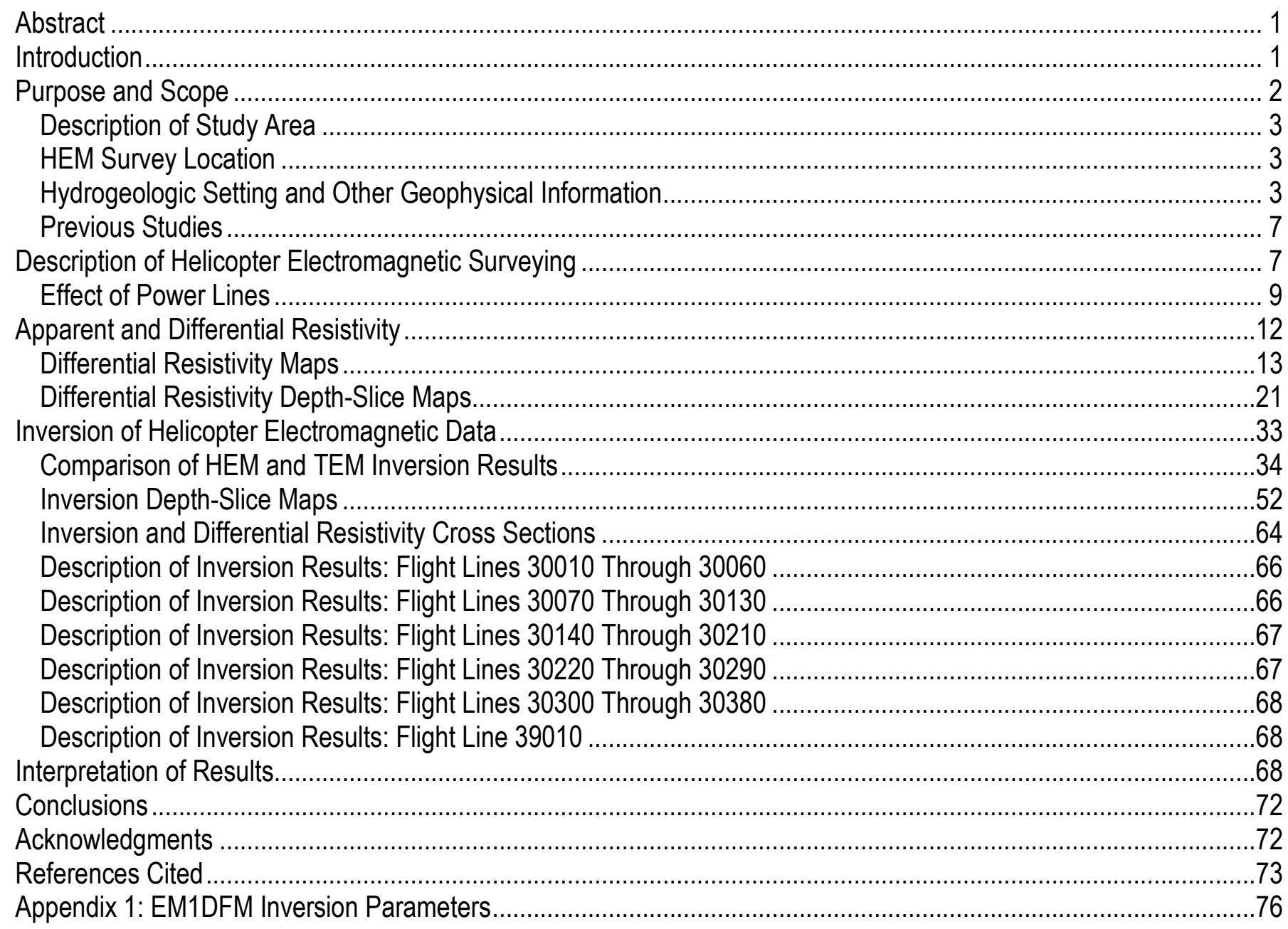

\section{Plates}

Plate 1. Line $30010 \mathrm{HEM}$ differential and inverted resistivity cross sections

Plate 2. Line $30020 \mathrm{HEM}$ differential and inverted resistivity cross sections

Plate 3. Line $30030 \mathrm{HEM}$ differential and inverted resistivity cross sections

Plate 4. Line $30040 \mathrm{HEM}$ differential and inverted resistivity cross sections

Plate 5. Line $30050 \mathrm{HEM}$ differential and inverted resistivity cross sections

Plate 6. Line $30060 \mathrm{HEM}$ differential and inverted resistivity cross sections

Plate 7. Line $30070 \mathrm{HEM}$ differential and inverted resistivity cross sections

Plate 8. Line $30080 \mathrm{HEM}$ differential and inverted resistivity cross sections

Plate 9. Line $30090 \mathrm{HEM}$ differential and inverted resistivity cross sections

Plate 10. Line 30010 HEM differential and inverted resistivity cross sections

Plate 11. Line $30011 \mathrm{HEM}$ differential and inverted resistivity cross sections

Plate 12. Line $30012 \mathrm{HEM}$ differential and inverted resistivity cross sections

Plate 13. Line $30013 \mathrm{HEM}$ differential and inverted resistivity cross sections 
Plate 14. Line 30014 HEM differential and inverted resistivity cross sections Plate 15. Line $30015 \mathrm{HEM}$ differential and inverted resistivity cross sections Plate 16. Line $30016 \mathrm{HEM}$ differential and inverted resistivity cross sections Plate 17. Line $30017 \mathrm{HEM}$ differential and inverted resistivity cross sections Plate 18. Line $30018 \mathrm{HEM}$ differential and inverted resistivity cross sections Plate 19. Line 30019 HEM differential and inverted resistivity cross sections Plate 20. Line $30020 \mathrm{HEM}$ differential and inverted resistivity cross sections Plate 21. Line $30021 \mathrm{HEM}$ differential and inverted resistivity cross sections Plate 22. Line $30022 \mathrm{HEM}$ differential and inverted resistivity cross sections Plate 23. Line 30023 HEM differential and inverted resistivity cross sections Plate 24. Line $30024 \mathrm{HEM}$ differential and inverted resistivity cross sections Plate 25. Line $30025 \mathrm{HEM}$ differential and inverted resistivity cross sections Plate 26. Line $30026 \mathrm{HEM}$ differential and inverted resistivity cross sections Plate 27. Line $30027 \mathrm{HEM}$ differential and inverted resistivity cross sections Plate 28. Line $30028 \mathrm{HEM}$ differential and inverted resistivity cross sections Plate 29. Line $30029 \mathrm{HEM}$ differential and inverted resistivity cross sections Plate 30. Line $30030 \mathrm{HEM}$ differential and inverted resistivity cross sections Plate 31. Line $30031 \mathrm{HEM}$ differential and inverted resistivity cross sections Plate 32. Line $30032 \mathrm{HEM}$ differential and inverted resistivity cross sections Plate 33. Line $30033 \mathrm{HEM}$ differential and inverted resistivity cross sections Plate 34. Line $30034 \mathrm{HEM}$ differential and inverted resistivity cross sections Plate 35. Line $30035 \mathrm{HEM}$ differential and inverted resistivity cross sections Plate 36. Line $30036 \mathrm{HEM}$ differential and inverted resistivity cross sections Plate 37. Line $30037 \mathrm{HEM}$ differential and inverted resistivity cross sections Plate 38. Line 30038 HEM differential and inverted resistivity cross sections Plate 39. Line 39010 HEM differential and inverted resistivity cross sections

\section{Figures}

Figure 1. Location of the study area and 2001 helicopter electromagnetic survey ........................................... 4

Figure 2. Location of the helicopter electromagnetic survey and time-domain electromagnetic soundings............ 5

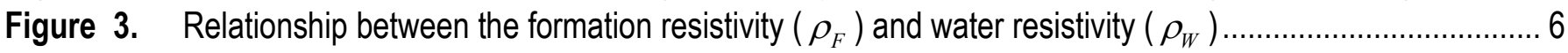

Figure 4. Relationship between water resistivity $\left(\rho_{W}\right)$ and chloride content..................................................... 6

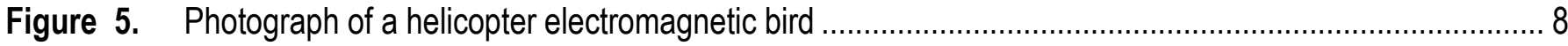

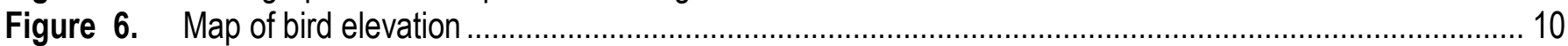

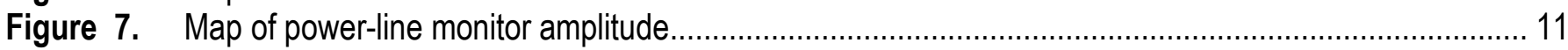

Figure 8. Model Land 100-kHz HEM differential apparent resistivity map .................................................. 16

Figure 9. Model Land 25-kHz HEM differential apparent resistivity map ..................................................... 17

Figure 10. Model Land 6,200-Hz HEM differential apparent resistivity map ................................................... 18

Figure 11. Model Land 1,500-Hz HEM differential apparent resistivity map .................................................... 19

Figure 12. Model Land 400-Hz HEM differential apparent resistivity map .......................................................20

Figure 13. Model Land 5-meter depth differential resistivity depth-slice map ................................................22

Figure 14. Model Land 10-meter depth differential resistivity depth-slice map .............................................. 23

Figure 15. Model Land 20-meter depth differential resistivity depth-slice map ................................................. 24

Figure 16. Model Land 30-meter depth differential resistivity depth-slice map ................................................25

Figure 17. Model Land 40-meter depth differential resistivity depth-slice map ................................................. 26

Figure 18. Model Land 50-meter depth differential resistivity depth-slice map ............................................... 27

Figure 19. Model Land 60-meter depth differential resistivity depth-slice map ............................................. 28 
Figure 20. Model Land 70-meter depth differential resistivity depth-slice map ............................................2 29

Figure 21. Model Land 80-meter depth differential resistivity depth-slice map ................................................. 30

Figure 22. Model Land 90-meter depth differential resistivity depth-slice map ................................................. 31

Figure 23. Model Land 100-meter depth differential resistivity depth-slice map ............................................. 32

Figure 24. Comparison of HEM inversion for flight line 30010 and TEM sounding models MIA225, MIA207,

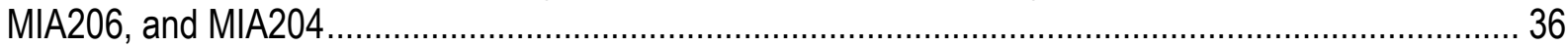

Figure 25. Comparison of HEM inversion for flight line 30020 and TEM sounding models MIA225, MIA207,

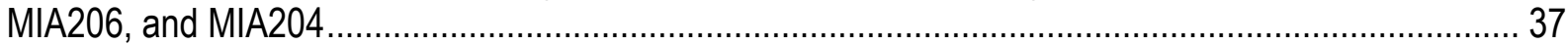

Figure 26. Comparison of HEM inversion for flight line 30030 and TEM sounding models MIA209, MIA208,

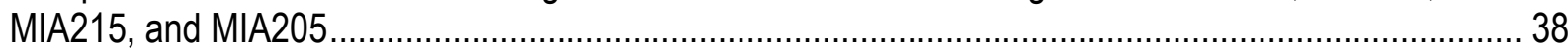

Figure 27. Comparison of HEM inversion for flight line 30040 and TEM sounding models MIA226, MIA209,

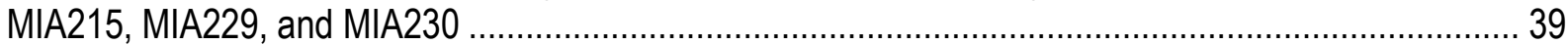

Figure 28. Comparison of HEM inversion for flight line 30050 and TEM sounding models MIA227, MIA210, MIA211, MIA214, MIA229, and MIA230

Figure 29. Comparison of HEM inversion for flight line 30060 and TEM sounding models MIA211, MIA228, and MIA213F

Figure 30. Comparison of HEM inversion for flight line 30070 and TEM sounding models MIA236 and MIA212F.. 42

Figure 31. Comparison of HEM inversion for flight line 30080 and TEM sounding models MIA234 and MIA231 ... 43

Figure 32. Comparison of HEM inversion for flight line 30090 and TEM sounding model MIA231 ......................44

Figure 33. Comparison of HEM inversion for flight line 30100 and TEM sounding model MIA233F.................... 45

Figure 34. Comparison of HEM inversion for flight line 30110 and TEM sounding model MIA233F................... 46

Figure 35. Comparison of HEM inversion for flight line 30130 and TEM sounding models MIA216, MIA235F, MIA232, MIA223, and MIA224

Figure 36. Comparison of HEM inversion for flight line 30140 and TEM sounding model MIA217 ......................48

Figure 37. Comparison of HEM inversion for flight line 30170 and TEM sounding models MIA222, MIA221, and MIA220

Figure 38. Comparison of HEM inversion for flight line 30180 and TEM sounding model MIA219F....................50

Figure 39. Comparison of HEM inversion for flight line 30270 and TEM sounding model MIA218F..................... 51

Figure 40. Model Land 5-meter depth inverted resistivity depth-slice map ...................................................... 53

Figure 41. Model Land 10-meter depth inverted resistivity depth-slice map ......................................................54

Figure 42. Model Land 20-meter depth inverted resistivity depth-slice map ...................................................... 55

Figure 43. Model Land 30-meter depth inverted resistivity depth-slice map ......................................................56

Figure 44. Model Land 40-meter depth inverted resistivity depth-slice map .................................................... 57

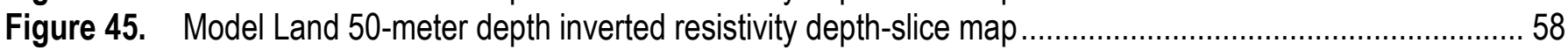

Figure 46. Model Land 60-meter depth inverted resistivity depth-slice map ..................................................5 59

Figure 47. Model Land 70-meter depth inverted resistivity depth-slice map .........................................................60

Figure 48. Model Land 80-meter depth inverted resistivity depth-slice map .......................................................61

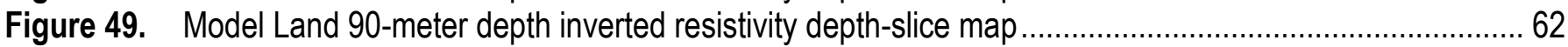

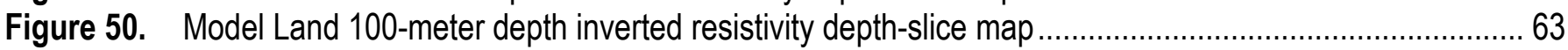

Figure 51. Description of HEM resistivity cross sections ........................................................................ 65

Figure 52. Map of Homestead area showing chloride concentration in canals in February, 1941, and June

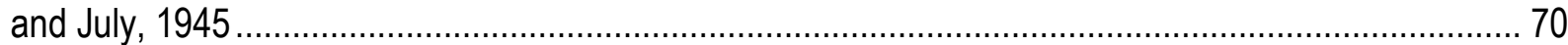




\section{Tables}

Table 1. Specifications of Fugro Airborne Surveys' RESOLVE bird ............................................................. 9

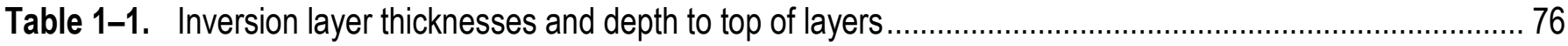

Table 1-2. Estimated noise in HEM data based on calibration-site measurements........................................... 77 


\section{Conversion Factors, Datum, Abbreviations, and Acronyms}

\section{SI to Inch/Pound}

\begin{tabular}{lll}
\hline \multicolumn{1}{c}{ Multiply } & \multicolumn{1}{c}{ By } & \multicolumn{1}{c}{ To obtain } \\
\hline Length & \\
millimeter $(\mathrm{mm})$ & 0.3937 & inch (in.) \\
meter $(\mathrm{m})$ & 0.03937 & inch (in.) \\
kilometer $(\mathrm{km})$ & 3.281 & foot (ft) \\
kilometer $(\mathrm{km})$ & 0.6214 & mile (mi) \\
meter $(\mathrm{m})$ & 0.5400 & mile, nautical (nmi) \\
\hline
\end{tabular}

\section{Electrical Conductivity and Electrical Resistivity}

\begin{tabular}{lcl}
\hline \multicolumn{1}{c}{ Multiply } & By & \multicolumn{1}{c}{ To obtain } \\
\hline Electrical conductivity & & \\
\hline siemens per meter $(\mathrm{S} / \mathrm{m})$ & 1,000 & millisiemens per meter $(\mathrm{mS} / \mathrm{m})$ \\
\hline siemens per meter $(\mathrm{S} / \mathrm{m})$ & 10,000 & microsiemens per centimeter $(\mu \mathrm{S} / \mathrm{cm})$ \\
\hline Electrical resistivity & & \\
\hline ohm-meters $($ ohm-m) & 0.001 & kiloohm-meters $(\mathrm{kohm}-\mathrm{m})$ \\
\hline
\end{tabular}

Electrical conductivity $\sigma$ in siemens per meter $[\mathrm{S} / \mathrm{m}]$ can be converted to electrical resistivity $\rho$ in ohm-meters [ohm-m] as follows: $\rho=1 / \sigma$. Electrical conductivity $\sigma$ in millisiemens per meter $[\mathrm{mS} / \mathrm{m}]$ can be converted to electrical resistivity $\rho$ in ohm-meters [ohm-m] as follows: $\rho=1,000 / \sigma$.

Electrical conductivity $\sigma$ in microsiemens per centimeter $[\mu \mathrm{S} / \mathrm{cm}]$ can be converted to electrical resistivity $\rho$ in ohm-meters [ohm-m] as follows: $\rho=10,000 / \sigma$.

Electrical resistivity $\rho$ in ohm-meters [ohm-m] can be converted to electrical conductivity $\sigma$ in siemens per meter [S/m] as follows: $\sigma=1 / \rho$. Electrical resistivity $\rho$ in ohm-meters [ohm-m] can be converted to electrical conductivity $\sigma$ in millisiemens per meter $[\mathrm{mS} / \mathrm{m}]$ as follows: $\sigma=1,000 / \rho$.

Electrical resistivity $\rho$ in ohm-meters [ohm-m] can be converted to electrical conductivity $\sigma$ in microsiemens per centimeter $[\mu \mathrm{S} / \mathrm{cm}]$ as follows: $\sigma=10,000 / \rho$.

Specific conductance SC refers to fluid electrical conductivity corrected to a temperature of $25^{\circ} \mathrm{C}$. The units of specific conductance are usually in microsiemens per centimeter $[\mu \mathrm{S} / \mathrm{cm}]$. The above conversions apply.

Horizontal coordinate information is referenced to the North American Datum of 1983 (NAD 83). 


\section{Abbreviations}

$\begin{array}{ll}\mathrm{ft} & \text { feet } \\ \mathrm{Hz} & \text { hertz } \\ \mathrm{km} & \text { kilometer } \\ \mathrm{m} & \text { meter } \\ \mathrm{mi} & \text { mile } \\ \mathrm{mg} / \mathrm{L} & \text { milligram per liter } \\ \mathrm{ohm}-\mathrm{m} & \text { ohm-meter } \\ \mathrm{ppt} & \text { parts per thousand }\end{array}$

\section{Acronyms}

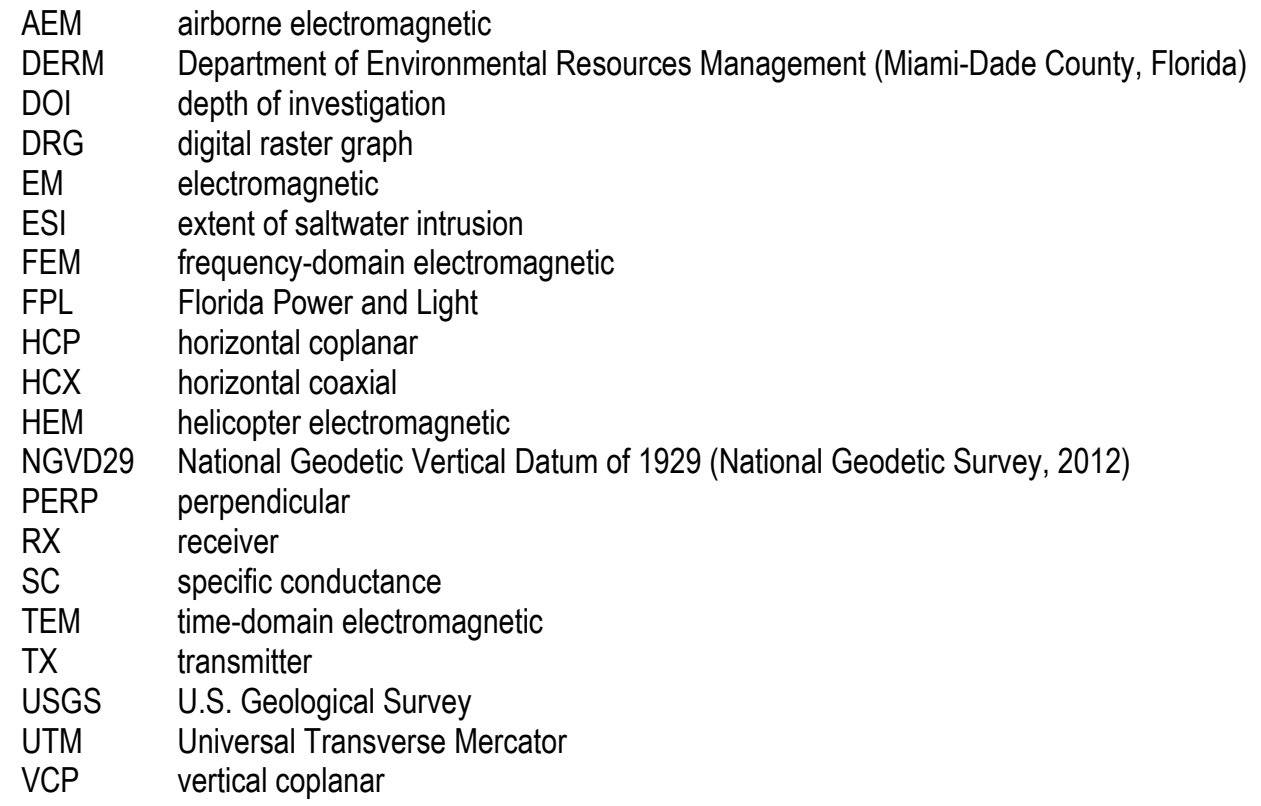




\title{
Helicopter Electromagnetic Survey of the Model Land Area, Southeastern Miami-Dade County, Florida
}

\author{
By David V. Fitterman'1, Maria Deszcz-Pan², and Scott T. Prinos²
}

\begin{abstract}
This report describes a helicopter electromagnetic survey flown over the Model Land Area in southeastern Miami-Dade County, Florida, to map saltwater intrusion in the Biscayne aquifer. The survey, which is located south and east of Florida City, Florida, covers an area of 115 square kilometers with a flight-line spacing of 400 meters. A five-frequency, horizontal, coplanar bird with frequencies ranging from 400 to $100,000 \mathrm{Hertz}$ was used. The data were interpreted using differential resistivity analysis and inversion to produce cross sections and resistivity depth-slice maps. The depth of investigation is as deep as 100 meters in freshwatersaturated portions of the Biscayne aquifer and the depth diminishes to about 50 meters in areas that are intruded by saltwater. The results compare favorably with ground-based, time-domain electromagnetic soundings and induction logs from observation wells in the area. The base of a high-resistivity, freshwater-saturated zone mapped in the northern 2 kilometers of the survey area corresponds quite well with the base of the surficial aquifer that has been determined by drilling. In general, saltwater in the survey area extends 9 to 12 kilometers inland from the coast; however, there is a long nose of saltwater centered along the Card Sound Road Canal that extends 15 kilometers inland. The cause of this preferential intrusion is likely due to uncontrolled surface flow along the canal and subsequent leakage of saltwater into the aquifer. Saltwater also extends farther inland in the area between U.S. Highway 1 and Card Sound Road than it does to the west of this area. Until 1944, a railroad grade occupied the current location of U.S. Highway 1. Borrow ditches associated with the railroad grade connected to Barnes Sound and allowed saltwater to flow during droughts and storm surges to within a few kilometers of Florida City. Relicts of this saltwater that settled to the bottom of the Biscayne aquifer can be seen in the helicopter electromagnetic data. The area to the west of U.S. Highway 1 is more resistive in the upper 10 meters than the area to the east of the road; this reflects the influence of surface-water flows that are blocked by U.S. Highway 1. Between Card Sound Road and U.S. Highway 1, resistivities are slightly lower compared to adjacent areas. In the southern portion of the survey area, the surficial aquifer underlying the Biscayne aquifer is more resistive; this indicates that it contains fresher water than that found at the base of the Biscayne aquifer.
\end{abstract}

\section{Introduction}

The encroachment of saltwater in the Biscayne aquifer of southeastern Florida poses a threat to the principal source of drinking water in Miami-Dade County (Miller, 1990). The Florida Keys' sole source of potable water also comes from the Biscayne aquifer from a well

\footnotetext{
${ }^{1}$ U.S. Geological Survey, emeritus

${ }^{2}$ U.S. Geological Survey
} 
field west of Florida City, Florida (Fla.). Seawater began encroaching into the Biscayne aquifer early in the $19^{\text {th }}$ century when aquifer water levels decreased as a result of drainage efforts. Parker and others (1955) report that the drainage canals also allowed seawater ${ }^{3}$ to travel long distances landward and then to percolate to the base of the Biscayne aquifer. Early examples of this were in the New River Basin at Ft. Lauderdale, Fla., in 1907 and in the Miami Canal in 1909. More recent instances have been reported, including contamination of one of Miami's newer well fields 6.5 miles (mi) inland from Biscayne Bay near the Miami River (Parker, 1945). The extraction of water from the Biscayne aquifer by well fields can locally accelerate the landward movement of the saltwater front.

Monitoring the location of the saltwater front near well fields is important because managers use this information to help protect water-supply wells. Monitoring has traditionally been done with wells situated between the supply wells and the ocean. Periodic sampling of the monitoring wells to determine chloride content in screened intervals has been the usual monitoring technique. In the last ten years, the use of induction logs in monitoring wells has been used to supplement sampling. The advantages of using the induction log are that it gives continuous information, sampling extends outward beyond the well bore, and the data are not confined to a screened interval of the well.

Surface geophysical measurements can also be used to map the extent of saltwater encroachment. Fitterman and others (1999) and Fitterman and Prinos (2011) have used timedomain electromagnetic (TEM) soundings to map the location of the freshwater-saltwater interface (FWSWI) in the Biscayne aquifer. This technique is less expensive than drilling monitoring wells and thereby allows collection of more data to generate a map of saltwater encroachment. The technique works best when calibrated against monitoring wells that have induction logs and water-quality information.

Another electromagnetic geophysical technique that has been used in south Florida to map the FWSWI is helicopter electromagnetic (HEM) surveying (Fitterman and Deszcz-Pan, 1998, 2002, 2003). Measurements are made with geophysical sensors that are slung below a helicopter. The method is described in more detail below. The survey area is covered with parallel flight lines typically spaced 400 meters (m) or less, and a measurement is made every 0.1 second (s) along flight lines corresponding to a spatial sampling interval of approximately $3 \mathrm{~m}$. This high sampling interval provides detailed information which is not feasible over large areas with ground-based methods. This makes HEM surveying a valuable tool for mapping saltwater intrusion over large areas.

\section{Purpose and Scope}

This report describes the collection, processing, and interpretation of HEM data in a portion of coastal Miami-Dade County in southeastern Florida often referred to as the Model Land ${ }^{4}$. The results are summarized and compared with other geophysical measurements. The report discusses the implications of the results for mapping the landward extent of saltwater in the Biscayne aquifer.

\footnotetext{
${ }^{3}$ The term seawater is used herein to refer only to water whose source is the ocean and has the same chemical composition as ocean water. Seawater that has mixed with freshwater in the canals or in the aquifer is considered to be saltwater because of dilution and chemical interaction with the rock matrix.

${ }^{4}$ The term Model Land refers to all the wetlands in the area on both sides of Card Sound Road and south of SW 344

Street (Palm Drive, see northern edge of figure 2) (C.K. Grossenbacher, Miami-Dade County Department of Environmental Resources Management (DERM), written commun., 2010).
} 


\section{Description of Study Area}

The HEM survey discussed in this report is part of a larger saltwater-intrusion study that was the focus of a TEM survey located primarily in the eastern portion of Miami-Dade County within approximately 15 kilometers $(\mathrm{km})$ of the coast in the southern part of the county, and within approximately $5 \mathrm{~km}$ of the coast in the northern part (Fitterman and Prinos, 2011). Figure 1 shows the location of the HEM survey, which is in the southernmost region of the saltwaterintrusion study. The HEM study area is primarily undeveloped land with some exceptions in the northern part (near Florida City).

\section{HEM Survey Location}

The HEM survey location and flight lines are shown in fig. 2. The northern boundary of the survey is located about $1 \mathrm{~km}$ south of Florida City and extends $13 \mathrm{~km}$ to the east in the direction of the Florida Power and Light (FPL) Turkey Point nuclear power plant. The western boundary of the survey is a line parallel to and $1.5 \mathrm{~km}$ to the west of U.S. Highway 1 . The eastern boundary of the survey is a line starting at the intersection of U.S. Highway 1 and canal C-111 and proceeding northeast at an azimuth of about $28^{\circ}$ towards the western side of the Turkey Point power plant cooling canals near canal L-31E. The north-south extent of the survey is $14.8 \mathrm{~km}$. Flight line spacing is $400 \mathrm{~m}$. Thirty-eight east-west lines were flown as well as one north-south tie line.

\section{Hydrogeologic Setting and Other Geophysical Information}

Fish and Stewart (1991) describe in detail the surficial aquifer system of Miami-Dade County, which includes the Biscayne and gray limestone aquifers. The Biscayne aquifer consists of the Pleistocene aged Pamlico Sand, Miami and Key Largo Limestones, as well as the Anastasia and Ft. Thomson Formations, and in some areas the Pliocene aged Tamiami Formation. The Biscayne aquifer is wedge shaped and thins to the west in Miami-Dade County. It is about 180 feet (ft) deep in eastern Miami-Dade County. In the HEM survey area, the depth to the base of the Biscayne aquifer varies from 55 to $100 \mathrm{ft}$ (Fish and Stewart, 1991). The Biscayne aquifer is underlain by the gray limestone aquifer. These aquifers are separated by the semiconfining upper clastic unit of the Tamiami Formation (Fish and Stewart, 1991). The gray limestone is generally not used for public water supply in Miami-Dade County.

Electromagnetic induction logs collected in Miami-Dade County indicate that the freshwater saturated materials of the Biscayne aquifer have an average resistivity of $80 \mathrm{ohm}$ meters (ohm-m) and range from about 35 to $220 \mathrm{ohm}-\mathrm{m}$. This wide variation in resistivity is related primarily to changes in porosity of limestones in the Biscayne aquifer or changes in lithology (Cunningham and others, 2006 and 2009). When freshwater is replaced by saltwater in the Biscayne aquifer, its resistivity decreases dramatically. Figure 3 shows the relation of aquifer resistivity to pore-water resistivity in the Biscayne aquifer determined by comparing electromagnetic induction log data to water-sample resistivities. The ratio of formation (aquifer) resistivity $\left(\rho_{F}\right)$ to pore water resistivity $\left(\rho_{W}\right)$ is called the formation factor (Archie, 1942):

$$
F=\rho_{F} / \rho_{W} .
$$

For the Biscayne data, we estimate $F$ to be 5.1. The formation factor derived from these data is quite valuable and provides a means of estimating the pore-water resistivity from geophysically determined formation resistivities. For a given formation resistivity, the uncertainty in the water 


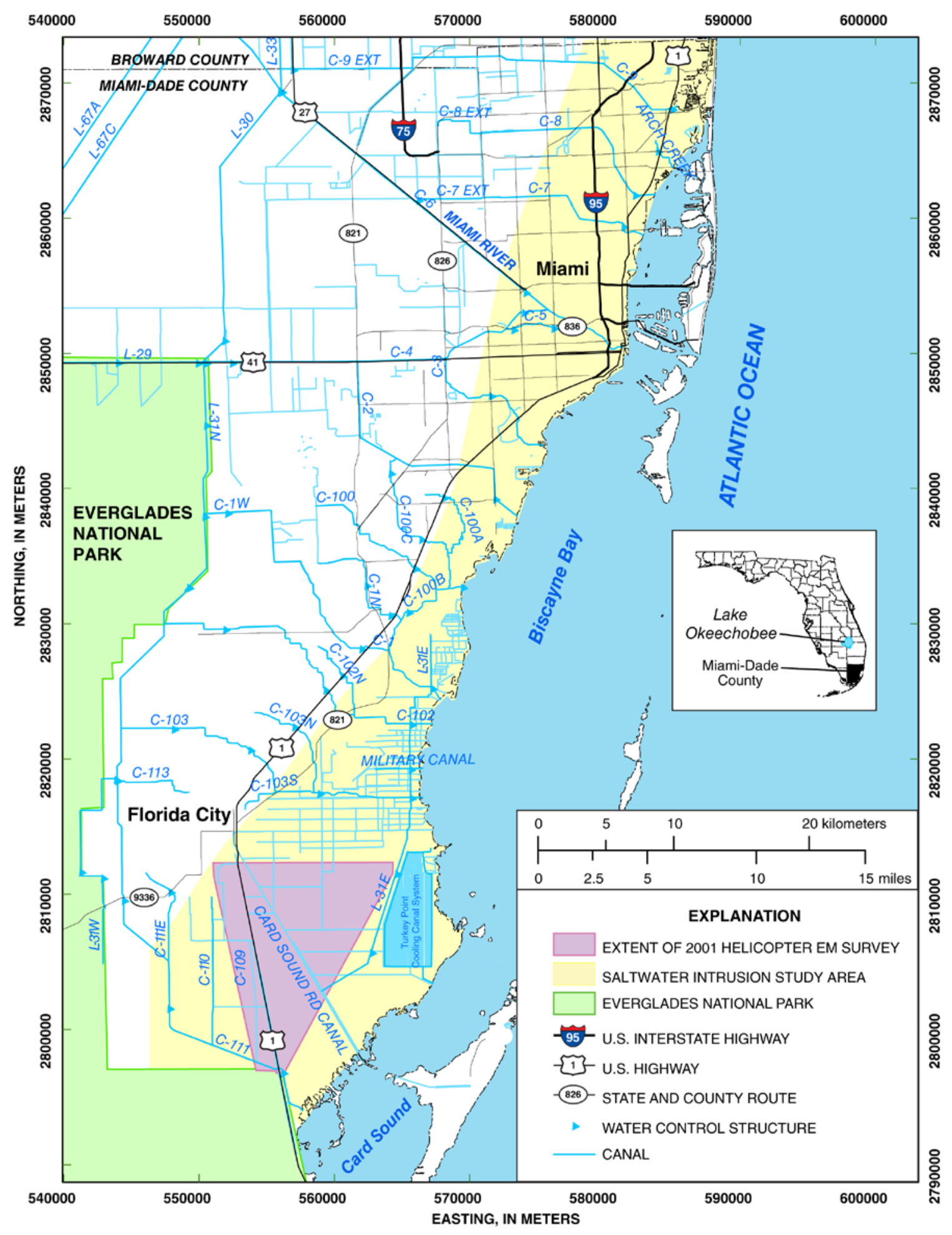

Figure 1. Location of the study area and 2001 helicopter electromagnetic survey. 


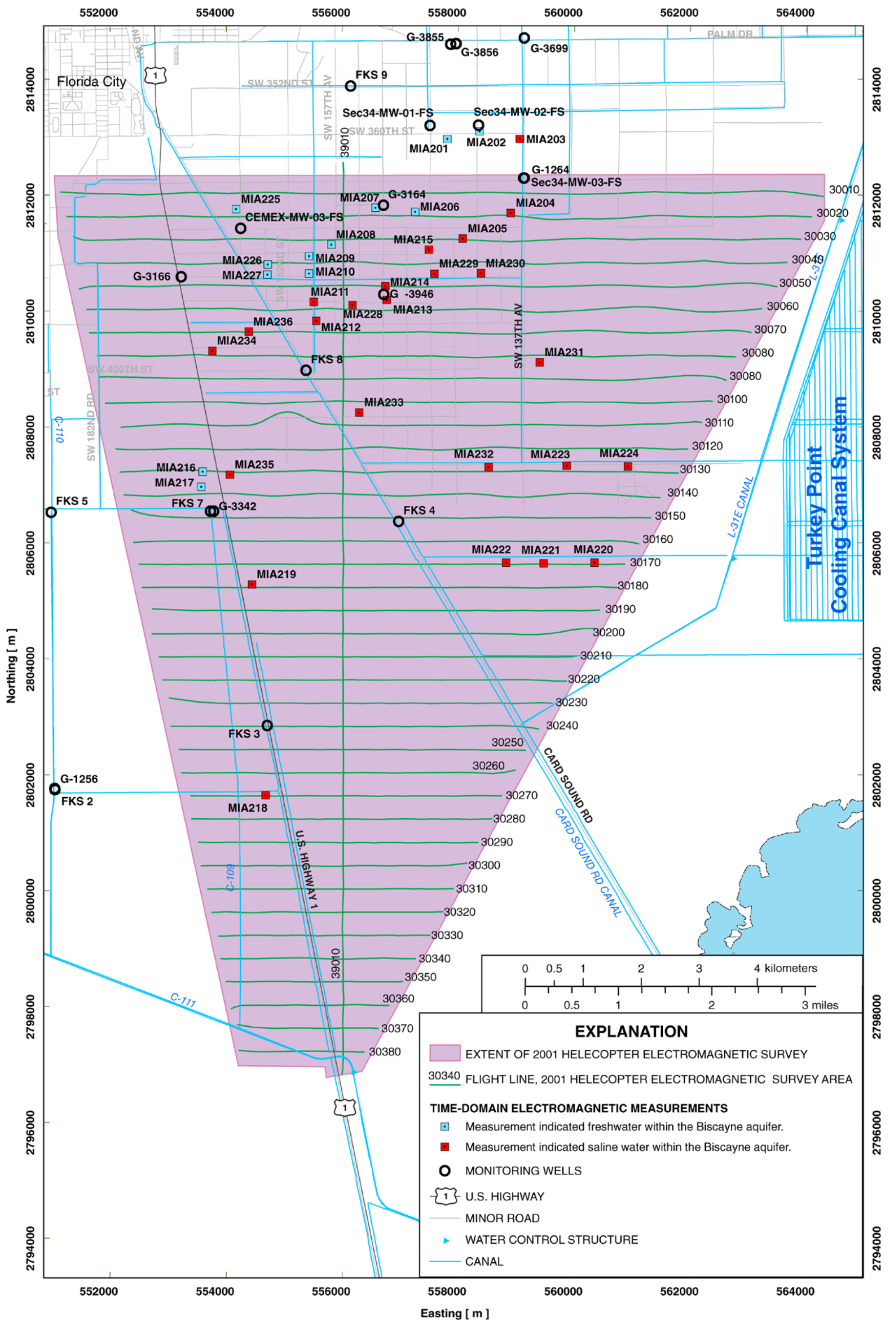

Figure 2. Location of the helicopter electromagnetic survey and time-domain electromagnetic soundings. Helicopter electromagnetic survey was flown in October 2001, and time-domain electromagnetic soundings were made in 2009 (Fitterman and Prinos, 2011). 


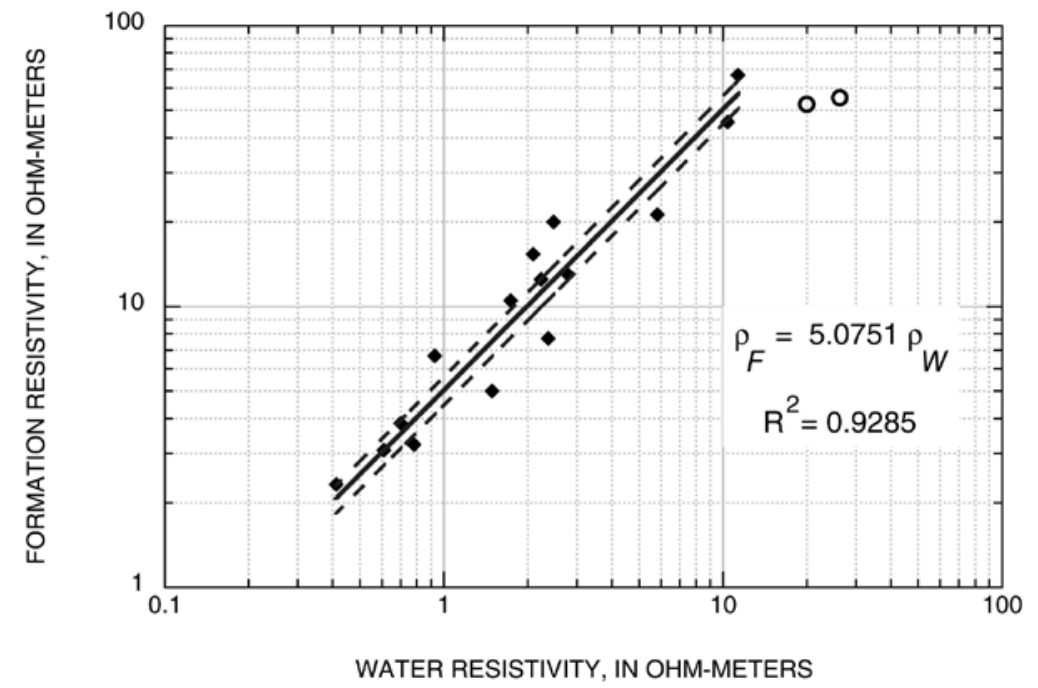

Figure 3. Relationship between the formation resistivity $\left(\rho_{F}\right)$ and water resistivity $\left(\rho_{W}\right)$. Water samples were collected in monitoring wells in Miami-Dade County and the bulk aquifer (formation) resistivity was measured by induction logs in the screened intervals of the same well. The two data points plotted as open circles were not used in the analysis. The equation describing the relationship is shown as a solid line. The 95-percent confidence interval is shown as dashed lines. $R^{2}$ is the coefficient of determination.

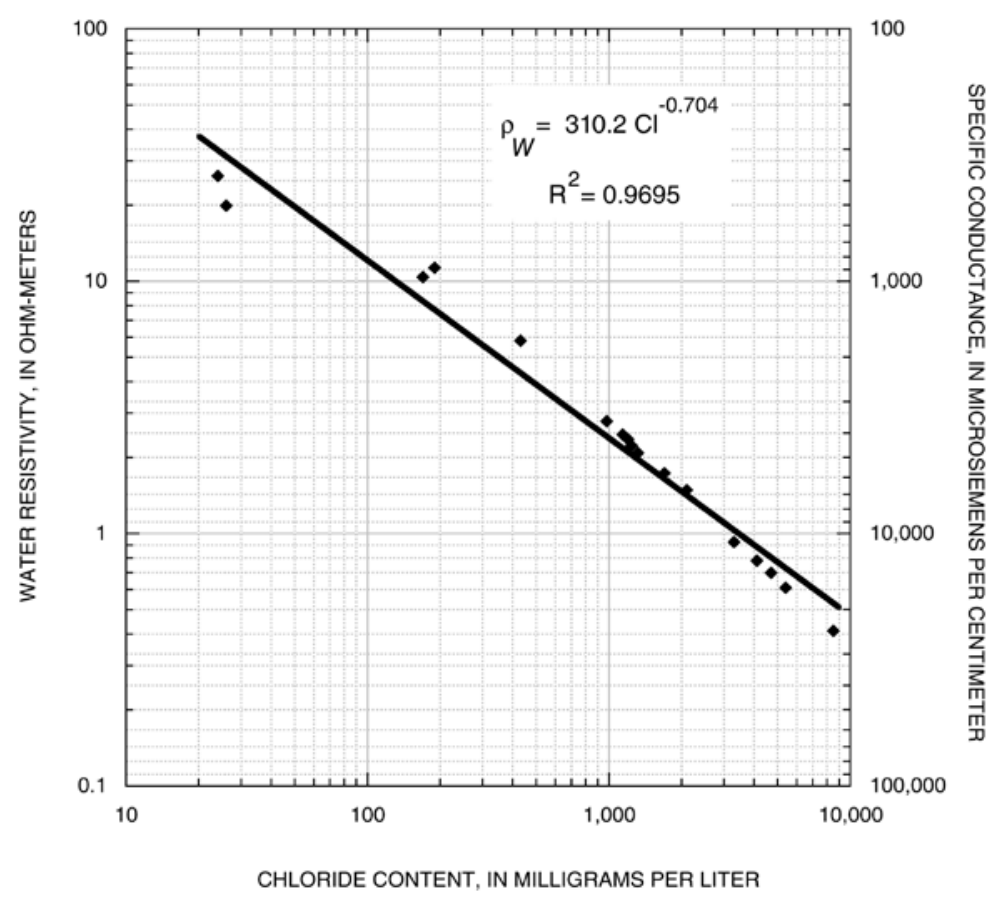

Figure 4. Relationship between water resistivity ( $\rho_{W}$ ) and chloride content. Water samples were collected in monitoring wells in Miami-Dade County. The equation describing the relationship is shown along with the coefficient of determination $\mathrm{R}^{2}$. 
resistivity estimate is about 12 percent based on the 95-percent confidence interval shown in figure 3. Figure 4 shows the relation between water resistivity and chloride content determined from water samples collected in Miami-Dade County. Based on this information, the resistivity of the Biscayne aquifer containing saltwater with a chloride concentration of 1,000 milligrams per liter $(\mathrm{mg} / \mathrm{L})$ would have a formation resistivity of approximately $10 \mathrm{ohm}-\mathrm{m}$. Geophysically determined resistivities of $10 \mathrm{ohm}-\mathrm{m}$ or less are generally interpreted to be contaminated with saltwater.

\section{Previous Studies}

The U.S. Geological Survey (USGS) has been studying the water resources of southeastern Florida in cooperation with the cities of Miami, Miami Beach, and Coral Gables, as well as Dade County, since 1939. The extent and causes of saltwater encroachment in MiamiDade County have been the subject of numerous reports (Brown and Parker, 1945; Parker, 1945; Hoy, 1952; Parker and others, 1955; Klein, 1957; Leach and Grantham, 1966). Later work focused on the extent of seawater intrusion in the Biscayne aquifer in Miami-Dade County in 1951 (Hoy, 1952), 1978 (Swayze, 1980), 1984 (Klein and Waller, 1985), and 1995 (Sonenshein, 1997). Klein and Ratzlaff (1989) and Sonenshein and Koszalka (1996) evaluated changes in the extent of saltwater intrusion in the Biscayne aquifer. Sonenshein's (1997) investigation used TEM measurements to augment monitoring well data; however, there was little information in extreme southeastern Miami-Dade County south of Florida City. As a result, Sonenshein could only approximate the extent of saltwater encroachment in this area.

TEM and HEM methods have been used in Everglades National Park to evaluate seawater encroachment (Fitterman and Deszcz-Pan, 1998; Fitterman and others, 1999). A companion study by Fitterman and Prinos (2011) reported on TEM soundings in Miami-Dade and Broward Counties. Some of their TEM soundings were specifically collected in the Model Land area to help the interpretation of the HEM survey reported herein (see fig. 2).

A detailed study of chloride content in USGS monitoring wells in the Biscayne aquifer sampled from 1974 to 1999 is reported in Prinos and others (2002). They reported on long-term trends found in these wells. By 2008, the USGS monitoring network included 81 monitoring wells in the Biscayne aquifer that were sampled to evaluate chloride content. Thirty-five of these wells were also logged annually to evaluate bulk conductivity of the materials in the aquifer. The results of this monitoring are provided to the public in several national (USGS Annual Water Data Reports: http://wdr.water.usgs.gov/, USGS Water Data for the Nation:

http://waterdata.usgs.gov/nwis) and local Web sites (Groundwater conditions in south Florida: http://www.sflorida.er.usgs.gov/edl_data/index_qw.html).

\section{Description of Helicopter Electromagnetic Surveying}

Airborne electromagnetic (AEM) methods are similar to ground-based electromagnetic (EM) methods except that the EM transmitter and receiver are located above the ground and are flown over the survey area by an aircraft. The aircraft can be an airplane or helicopter. As with ground-based EM methods, there are two broad categories of AEM methods: frequency-domain electromagnetic (FEM) and TEM. The survey described in this report is a frequency-domain, helicopter electromagnetic survey. Specifics of the methods are given below.

FEM measurements are made using an electromagnetic transmitter (TX) or source, which in ground-based surveys is typically a large rectangular loop or a multi-turn coil that is driven by 
a sinusoidally varying current source. The frequency of excitation can be varied. The receiver (RX) is a multi-turn coil located at a known distance from the transmitter. In ground-based EM measurements, the transmitter-receiver coil separation is sometimes varied, while for airborne EM measurements it is fixed. Airborne TX and RX coils are usually small and circular with a diameter of less than $1 \mathrm{~m}$. The coils are housed in a torpedo-shaped cylinder called a bird. Birds are commonly $10 \mathrm{~m}$ long with a diameter of 50-75 centimeters $(\mathrm{cm})$ and a mass of 200250 kilograms $(\mathrm{kg})$. The bird is carried on a sling about $30 \mathrm{~m}$ below the helicopter (see fig. 5). While surveying, the altitude of the bird is maintained at an elevation of $30 \mathrm{~m}$ above the terrain or tree canopy. Fraser (1972) gives a very good description of an early HEM system with only one TX-RX coil pair. Modern HEM systems can have as many as six coil pairs.

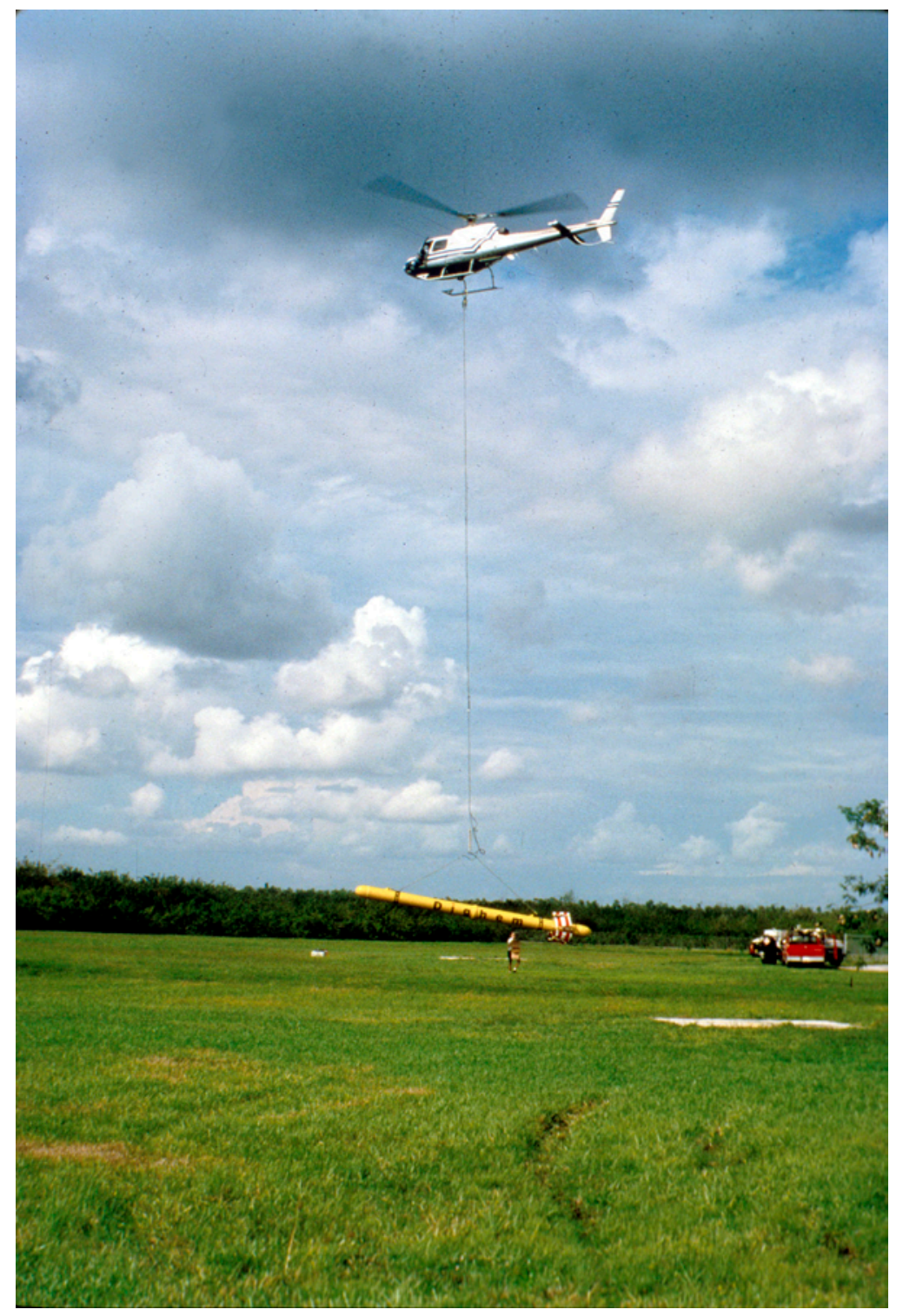

Figure 5. Photograph of a helicopter electromagnetic bird. Helicopter is lifting off from a site near the Daniel Beard Center in Everglades National Park, Fla. The transmitter and receiver coils are housed in the yellow, torpedo-shaped bird at the end of the sling. 
Because of the small coil size and the fact that they are circular, the normal to the plane of any HEM coil can be oriented inside the bird along one of three axes: parallel the bird's longitudinal axis, vertical and perpendicular to the longitudinal axis, or horizontal and perpendicular to the longitudinal axis. There are four coil-pair orientations that are typically analyzed for exploration purposes. Referred to by the orientation of the plane of the coils, they are: horizontal coplanar (HCP), vertical coplanar (VCP), horizontal coaxial (HCX), and perpendicular (PERP) (Wait, 1951, 1955, 1982; Keller and Frischknecht, 1966; Kaufman and Keller, 1983; Fitterman and Labson, 2005).

The signal measured by the receiver is divided into components which are inphase and $90^{\circ}$ out of phase with the transmitted signal. These are referred to as the "inphase" and "quadrature" components. The reported inphase signal has the primary field removed, so it is in fact the secondary inphase signal. Both the inphase and quadrature components are typically reported in parts per million (ppm) of the primary signal.

The Model Land HEM survey was flown by Fugro Airborne Surveys of Mississauga, Ontario, Canada. The HEM system used was an early version of Fugro's RESOLVE bird. This bird contained five horizontal coplanar coil pairs operating at nominal frequencies of 400; 1,500; 6,$400 ; 25,000$; and 100,000 Hz. The bird also had a vertical coaxial coil pair capable of operating at about $3,300 \mathrm{~Hz}$; however, for this survey it was disabled because of noise problems. The bird specifications are given in table 1.

Table 1. Specifications of Fugro Airborne Surveys' RESOLVE bird. All intercoil separations are 7.9 meters.

\begin{tabular}{ccccc}
\hline $\begin{array}{c}\text { Coil } \\
\text { Pair }\end{array}$ & $\begin{array}{c}\text { Coil } \\
\text { Geometry }\end{array}$ & $\begin{array}{c}\text { Nominal } \\
\text { Frequency [Hz] }\end{array}$ & $\begin{array}{c}\text { Actual } \\
\text { Frequency [Hz] }\end{array}$ & $\begin{array}{c}\text { Sensitivity } \\
{[\mathrm{ppm}]}\end{array}$ \\
\hline 1 & HCP & 400 & 340 & 0.13 \\
2 & HCP & 1,500 & 1,529 & 0.13 \\
3 & HCP & 6,200 & 6,227 & 0.25 \\
4 & HCP & 25,000 & 27,340 & 0.44 \\
5 & HCP & 100,000 & 106,200 & 0.44 \\
\hline
\end{tabular}

\section{Effect of Power Lines}

Power lines along the flight path affect HEM data in two ways. First, the helicopter must fly high enough so that the bird is not snagged on the cables. The increase in altitude will show up in the bird altitude trace of the flight line data when a power line is crossed. Increased altitude over the power lines decreases the amplitude of anomalies and reduces the depth of investigation. Second, if the power line is carrying current, the power-line monitor channel will increase as the power line is traversed. The increased electromagnetic noise due to the current flow will increase the uncertainty in the data interpretation near the power line.

The locations of power lines are shown in the various maps contained in this report based on aerial photographs and visual observation by driving along roads. The bird elevation and power-line monitor amplitude (see figs. 6 and 7, respectively) give a better assessment of where the power lines are and which ones are noise sources. The nominal bird elevation was $30 \mathrm{~m}$. For over 51 percent of the survey, the bird elevation was under $32 \mathrm{~m}$, and for 37 percent of the survey, the bird was in the range of 32 to $37 \mathrm{~m}$. Linear regions of increased elevation, exceeding $42 \mathrm{~m}$ in places, are seen along U.S. Highway 1 south of $2810000 \mathrm{~N}$, along the northern half of SW 137th Avenue, along a curved path between U.S. Highway 1 and Card Sound road near $2808500 \mathrm{~N}$ associated with the CEMEX quarry, a short north-south zone north of the CEMEX 
quarry (555000 E), and along the eastern and western survey boundaries where the helicopter started gaining altitude to make a turn. Looking at the power-line monitor amplitude map we see linear features, most of which are aligned with roads and correspond to increased altitude features.

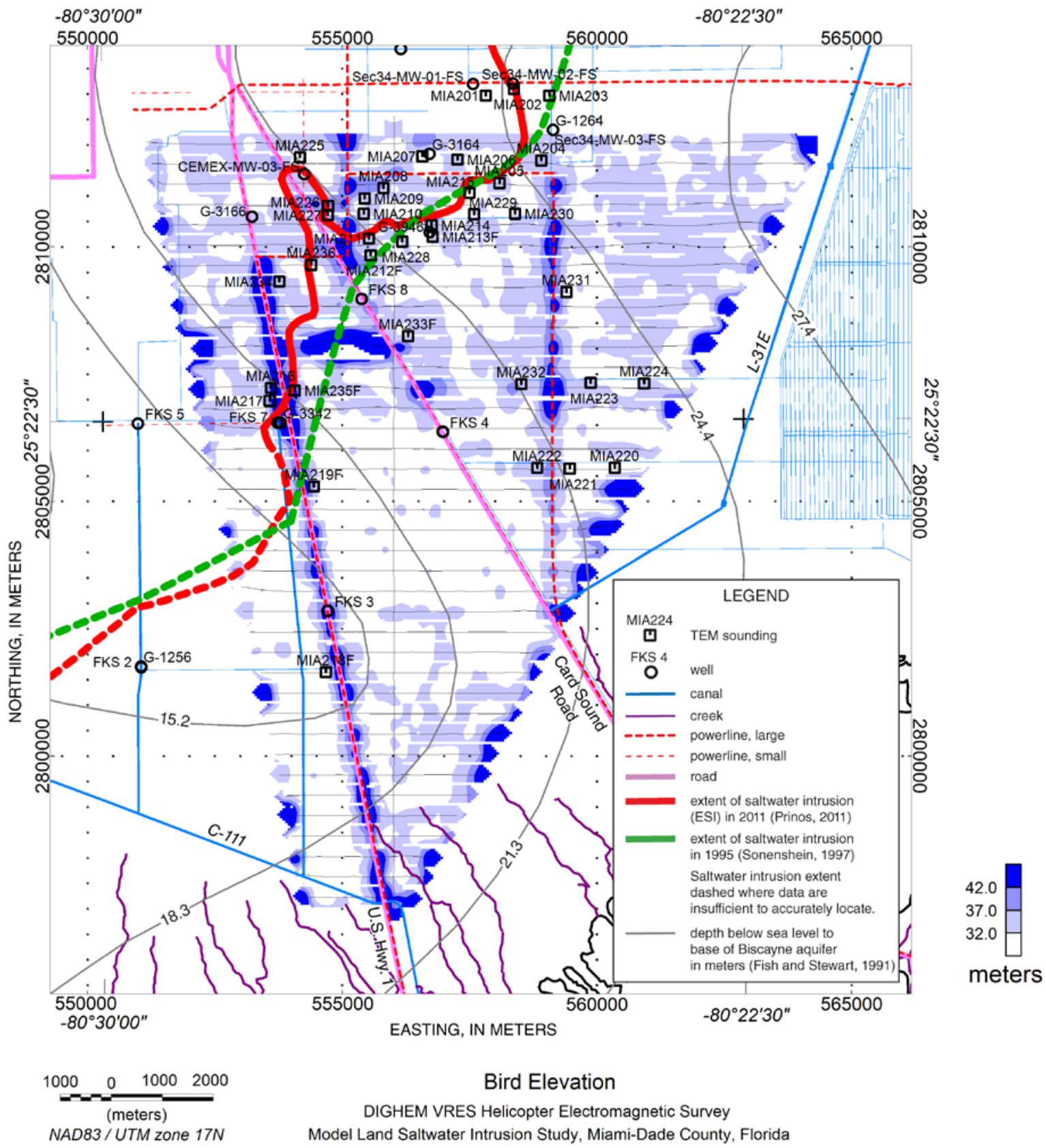

Figure 6. Map of bird elevation. Nominal bird height is 30 meters. 


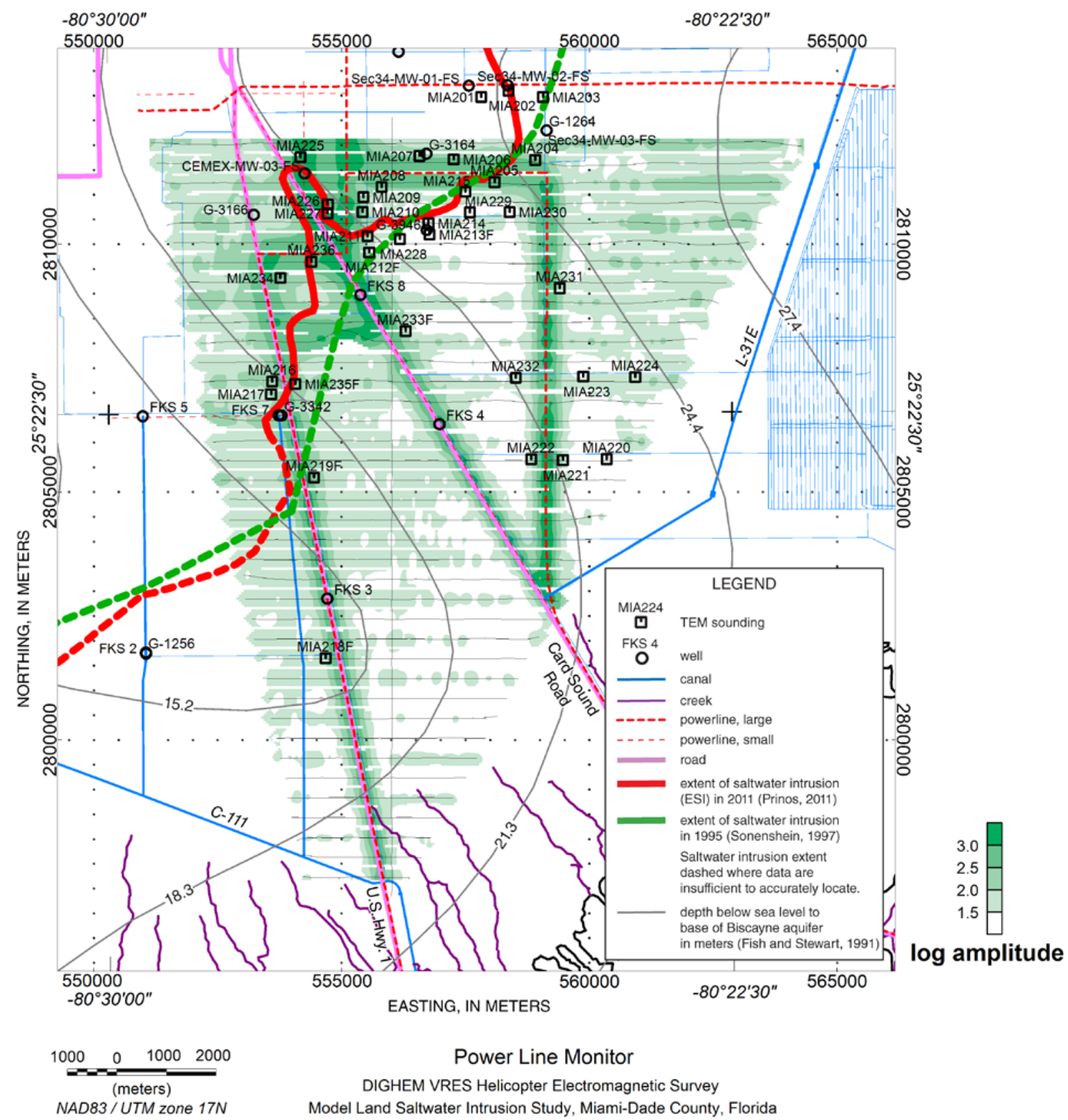

Figure 7. Map of power-line monitor amplitude. Amplitude is displayed using an uncalibrated logarithmic scale. 
The U.S. Highway 1 power-line feature extends the entire length of road, save for the portion north of 2810000 N. The Card Sound Road and SW 137st Avenue power-line features extend over the entire survey area. There is a quasi-rectangular region starting near the CEMEX quarry running between U.S. Highway 1 and Card Sound Road to the north about $4 \mathrm{~km}$ to the northern boundary of the survey where power-line noise is high.

The segment of the U.S. 1 power line north of the CEMEX plant did not require the helicopter to climb to avoid it. Also, the lack of signal in the power-line monitor indicates that this segment of the lines does not carry significant current. The Card Sound Road power line also did not require altitude gain to cross; however, it is carrying enough current to show up on the power-line monitor.

As will be seen later when the HEM cross sections are discussed, the presence of power lines often leads to conductive, linear features in the interpretation. Because these features can be confused with or hide similar conductive anomalies associated with saltwater flowing along canals that parallel the roads and then into the aquifer, it is important to know the locations of the power lines and whether or not they are generating electromagnetic noise.

\section{Apparent and Differential Resistivity}

The actual electromagnetic fields measured by electromagnetic geophysical methods do not lend themselves to easy comparison of measurements made at different locations. For HEM surveys, this is due primarily to differences in elevation as the survey is flown. One solution to this problem is to convert the measured fields to apparent resistivities (Fitterman and Labson, 2005). Conversion to apparent resistivity is done by answering the following question: What would the resistivity of a homogeneous half-space have to be to produce the measured electromagnetic fields given the same TX-RX configuration (intercoil spacing, coil elevation, excitation frequency, coil size, current)? The required resistivity is called the apparent resistivity because the ground appears to have this value. The apparent resistivity at a single site will usually vary for different transmitter parameters, such as excitation frequency. The apparent resistivity usually does not equal the actual ground resistivity; however, it gives the interpreter a rough idea of the ground resistivity. By comparing apparent resistivities at different frequencies, the interpreter can get an idea of how the actual resistivity changes with depth, because lower frequencies produce currents that penetrate deeper into the ground.

There are a number of methods for converting the measured EM fields to apparent resistivity for HEM data. Fraser (1978) developed the pseudo-layer half-space model, which has been used extensively. The inphase and quadrature components of the electromagnetic field are used to estimate the half-space resistivity and the thickness of a highly resistive pseudo-layer that rests on top of the half-space. HEM measurements are very sensitive to bird altitude, which is routinely measured with a radar altimeter. The altimeter information may contain errors due to the tree canopy reflecting the radar signal or the radar antenna not pointing directly downward due to changes in helicopter orientation. The tree canopy errors bias the altimeter reading downward, while the orientation errors usually bias the altimeter reading upward. The pseudolayer thickness accommodates these errors to produce a robust estimate of apparent resistivity.

While apparent resistivity maps are very informative and comparison of differences between maps can be used to infer relative resistivity changes with depth, apparent resistivity maps do not provide quantitative information about how the true resistivity of the ground varies with depth. A method of assigning depths to the various apparent resistivity values corresponding to the centroid depth of the induced current system was developed by Sengpiel 
(1988). The apparent-resistivity centroid-depth data are then used to produce cross sections along flight lines. These so called "Sengpiel sections" are then sliced horizontally to produce estimated resistivity at selected depths. This method is essentially a data transformation and not a true inversion. One of its drawbacks is that the depth estimates tend to be too shallow (Huang and Fraser, 1996)

As HEM systems improved and the number of transmitter frequencies and coil pairs increased, other interpretational possibilities became viable. One of these is the differential resistivity method of Huang and Fraser (1996) which expands on the earlier work of Sengpiel. The differential resistivity method assigns an effective depth to each frequency datum, which is based on the skin depth and apparent depth of the top of the Fraser pseudo-layer associated with the frequency. An apparent conductance, defined as the ratio of the effective depth to the apparent pseudo-layer resistivity, is computed. Next, a differential resistivity is computed as the change in effective depth divided by the change in apparent conductance going from one frequency datum to the next. The differential resistivity is then plotted at the effective depth at each measurement point. A spline function is used to interpolate the resistivity-depth function. The resulting resistivity-depth functions have been found to provide a very good estimate of the true resistivity-depth function in layered-earth model studies. We have used the resistivity-depth functions from the differential resistivity analysis to produce depth-slice maps and to create resistivity cross sections along flight lines. These results are discussed below and compared to cross sections produced using an inversion method.

The differential apparent resistivity maps for the Model Land survey are shown in figures 8 through 12 . These maps were created by gridding and contouring the differential apparent resistivity data. The grid interval is $25 \mathrm{~m}$. Shown on the maps are well and TEM sounding locations (Fitterman and Prinos, 2011), the extent of saltwater intrusion $\left(\mathrm{ESI}^{5}\right)$ in the Biscayne aquifer (Prinos, 2011), and the elevation below sea level of the base of the Biscayne aquifer (Fish and Stewart, 1991). The base of the Biscayne aquifer was mapped using a $10 \mathrm{ft}(3.05 \mathrm{~m})$ contour interval. In this report, these contours are labeled in meters below sea level. The HEM survey area forms a triangular region whose eastern boundary is subparallel to the coast. Resistivities are lower along this survey boundary and increase in the landward direction perpendicular to the eastern survey boundary. This general pattern holds for all five differential resistivity maps, though there are other features specific to each map.

\section{Differential Resistivity Maps}

The 100-kilohertz (kHz) map (fig. 8) shows a peculiarly shaped low resistivity (12-35 ohm-m) feature between TEM soundings MIA233F and MIA216, which resembles an upside down head of an elephant with its ears flared. This feature, which is more than three times as conductive as the surrounding area, is located over the CEMEX Card Sound Quarry and corresponds to three large rectangular pits aligned east-west and a single long, narrow pit oriented north-south. The presence of the pits lowers the formation factor from a value of about 5 to a value of 1 , thereby decreasing the bulk resistivity to that of the water which fills the pits. There is no correspondence seen between the differential apparent resistivity and the ESI because the ESI is mapped at the base of the Biscayne, and the 100-kHz HEM signal does not penetrate deep enough to sense it.

\footnotetext{
${ }^{5}$ When not otherwise specified, the ESI is the extent of saltwater intrusion as of 2011 from Prinos (2011).
} 
A resistivity anomaly is aligned with U.S. Highway 1 . The apparent resistivity along and adjacent to U.S. Highway 1 is anomalously lower than the surrounding areas. This anomaly is evident between TEM soundings MIA217 and MIA219F and becomes more obvious in the lower frequency differential resistivity maps. South of TEM sounding MIA218F along U.S. Highway 1 the apparent resistivity is higher to the west of the highway than the east by almost a factor of 2 .

Another road-related feature is seen along Card Sound Road southwest of well FKS-4 where the resistivity is very low on the western side of the road, especially in the $1.5-\mathrm{km}$ interval northwest of the intersection with canal L-31E. Like the anomaly along U.S. Highway 1, this anomaly is more prominent in terms of magnitude and areal extent in the lower frequency differential resistivity maps.

Both U.S. Highway 1 and Card Sound Road are raised above the marsh they traverse. The Card Sound Road Canal was installed on the west side of the Card Sound Road. U.S. Highway 1 has drainage ditches on both sides of the roadway (Parker and others, 1955). These ditches, canals, and roads undoubtedly influence the movement of surface water, and thus impact the groundwater resistivity.

In the $25-\mathrm{kHz}$ map (fig. 9), the low resistivity zone (less than $12 \mathrm{ohm}-\mathrm{m}$ ) has moved farther landward (northwest) and the resistivity gradient has become much sharper. The steepest gradient is in good agreement with the location of the ESI. The features near the CEMEX plant have been overridden by the regional northwestward advance of the low resistivity zone. The previously discussed low resistivity anomaly aligned with the Card Sound Road Canal extends northwest of well FKS-8 to well CEMEX-MW-03-FS. This feature will be discussed in more detail later. Along the eastern boundary of the survey a very low resistivity zone is located north of sounding MIA224 near the Turkey Point power plant cooling canals. The resistivity in this zone is 3 to 6 times lower than along the rest of the eastern boundary. A linear resistivity gradient oriented perpendicular to U.S. Highway 1 between well FKS-7 and TEM sounding MIA219F suggests the influence of the road and adjacent canal. At the south end of U.S. Highway 1, south of sounding MIA218F, a low resistivity zone is seen to the west of the road.

At first glance the 6,200-Hz map (fig. 10) looks similar to the $25-\mathrm{kHz}$ map with the map being divided by the ESI line into a bluish high-resistivity zone and an orange-red low-resistivity zone. Closer inspection reveals some features specific to this map. First, the resistivity of the region seaward of the ESI is lower by a factor of 2 than the resistivity in the $25-\mathrm{kHz}$ map. Second, the region between U.S. Highway 1 and Card Sound Road has slightly higher resistivity than the regions to either side of the roads. The region to the west of U.S. Highway 1 may have been influenced by seawater coming up the C-111 canal at some time in the past (Klein, 1965). The area northeast of Card Sound Road may be influenced by hypersaline water in the Turkey Point power plant cooling canals. Third, along the ESI line there are apparent resistivity variations from one map to the next. For example, about $1 \mathrm{~km}$ north of sounding MIA236 the resistivity is higher (green area) than in the $25-\mathrm{kHz}$ map (yellow-orange area). Five hundred meters north of sounding MIA229 the resistivity is lower (yellow area) than in the 25-kHz map (green-blue area).

In the 1,500-Hz map (fig. 11) the correspondence between the ESI and the steepest resistivity gradient no longer exists because the $1,500-\mathrm{Hz}$ data are sensing below the base of the Biscayne aquifer. While the regional resistivity gradient is greatly reduced, a significant gradient is seen along U.S. Highway 1 north of sounding MIA219F. To the west of U.S. Highway 1, the resistivity is in the $50-70 \mathrm{ohm}-\mathrm{m}$ range, whereas in the $6,200-\mathrm{kHz}$ map, it was greater than 70 
ohm-m. On the east side of U.S. Highway 1, the apparent resistivities are higher in the $1,500-\mathrm{Hz}$ than in the $6,200-\mathrm{Hz}$ map, particularly in the region defined by a polygon going through the locations of MIA218F, FKS-4, FKS-8, and MIA234. This may be due to fresher water in the deeper portion of surficial aquifer system that lies below the base of the Biscayne aquifer, as pointed out by Fish and Stewart (1991, p. 47, fig. 23). The very low resistivity zone associated with the cooling canals is no longer different from the background resistivity values, and the influence of the Card Sound Road Canal on the apparent resistivities noted in the higher frequency maps is less obvious because the background resistivity level has decreased.

The lowest frequency $(400 \mathrm{~Hz})$ map (fig. 12) has a gradual decrease in resistivity in the landward direction. There is a small conductivity anomaly aligned with U.S. Highway 1 north of sounding MIA219F; however, it may be due in part to noise from the power line. The only unusual feature is a $50 \mathrm{ohm}-\mathrm{m}$ circular zone located about $1.4 \mathrm{~km}$ to the west-southwest of sounding MIA219F. The feature is defined by a single flight line; however, because of its $800-\mathrm{m}$ east-west dimension, it is probably real. 


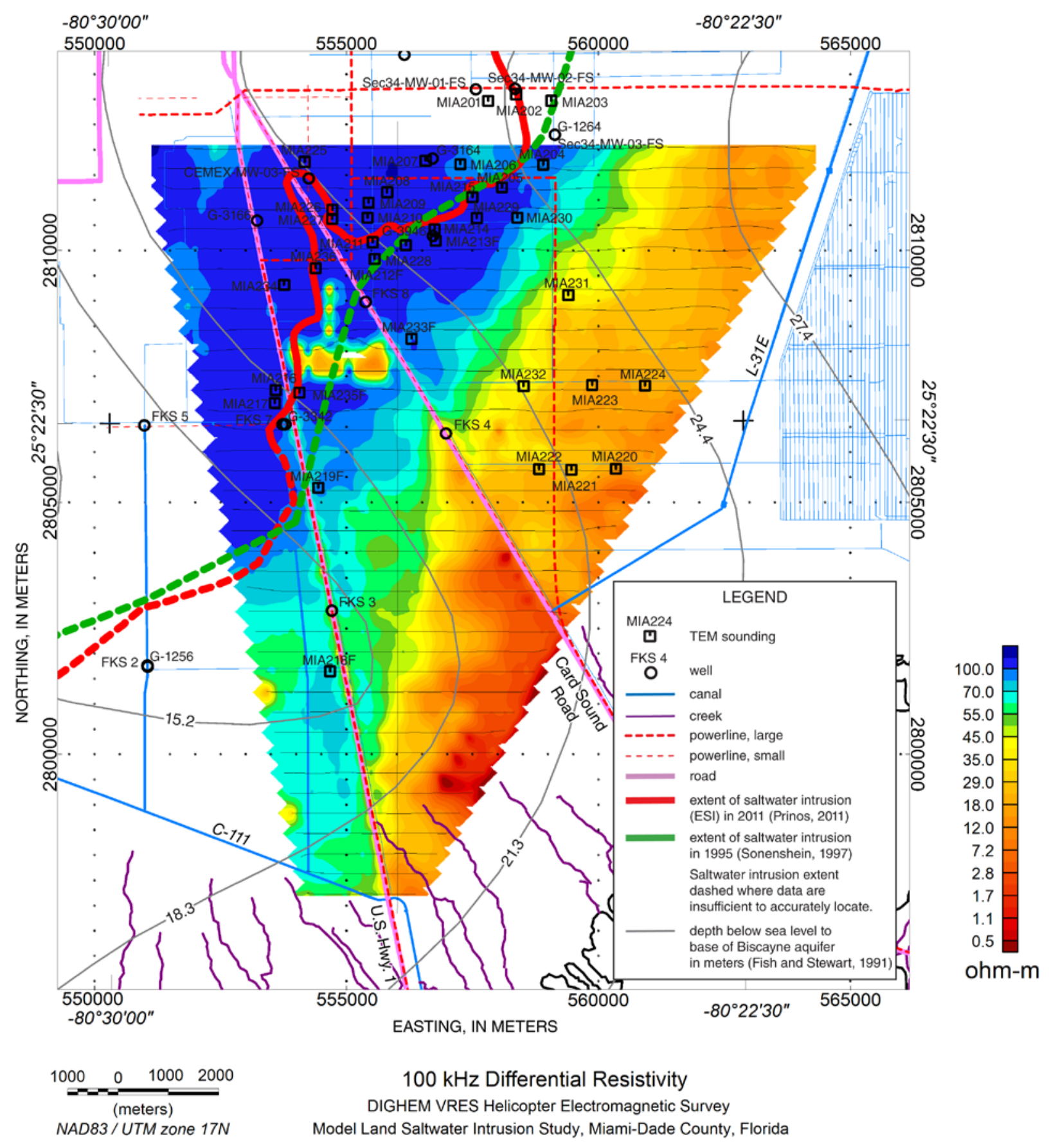

Figure 8. Model Land 100-kHz HEM differential apparent resistivity map. Contours of the depth to the base of the Biscayne aquifer (Fish and Stewart, 1991) and the extent of saltwater intrusion (Sonenshein, 1997; Prinos, 2011) are shown. 


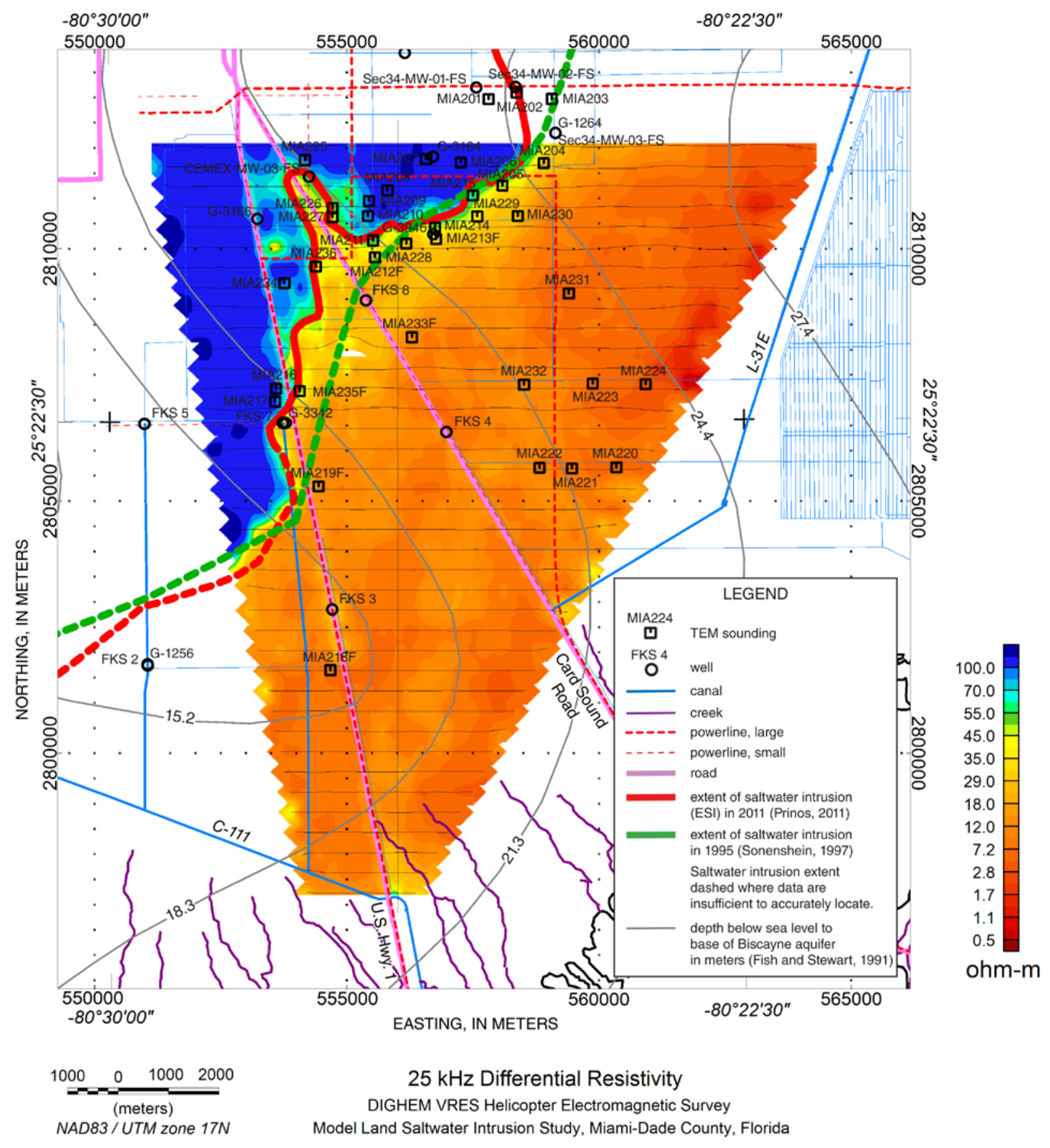

Figure 9. Model Land 25-kHz HEM differential apparent resistivity map. 


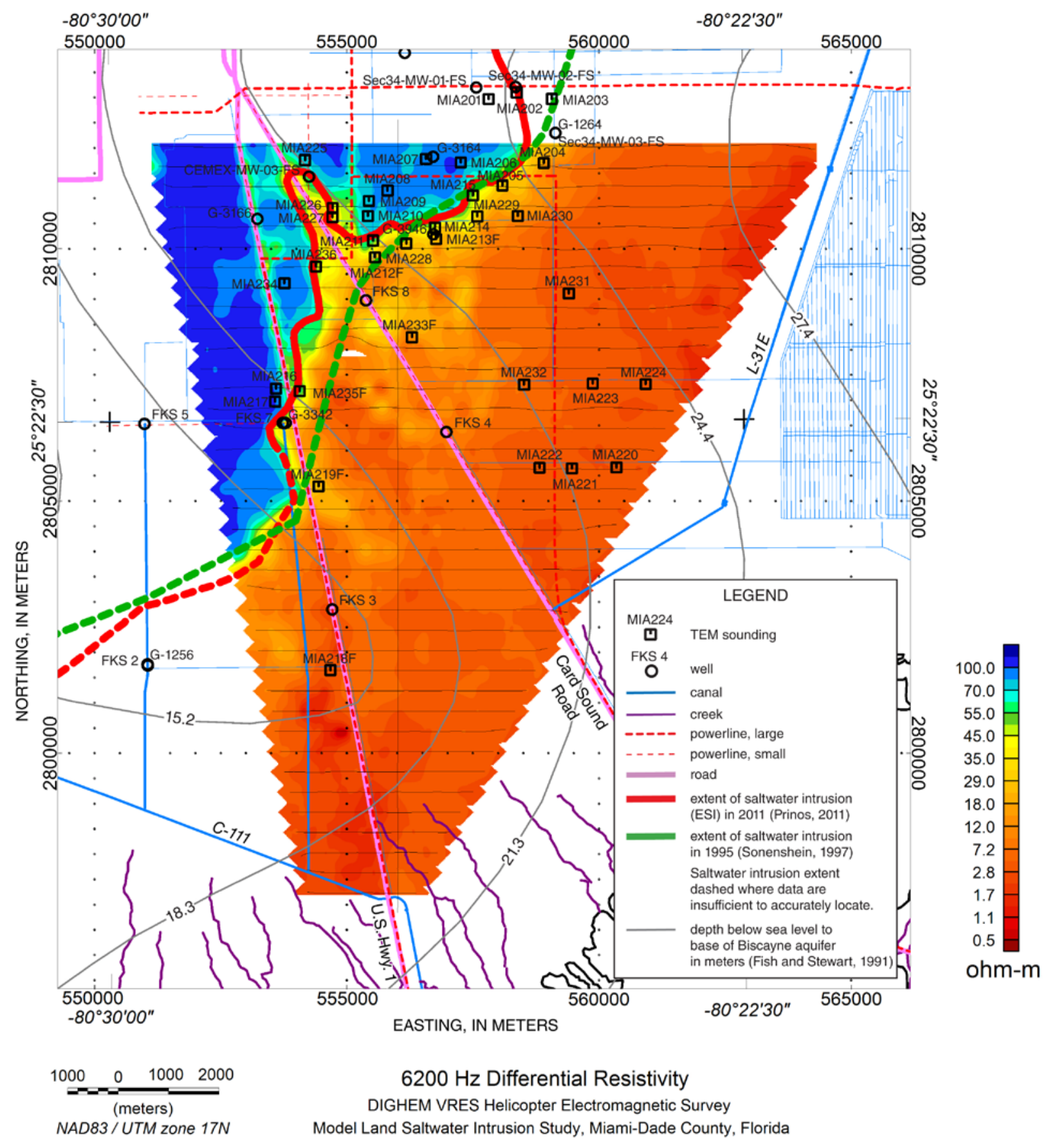

Figure 10. Model Land 6,200-Hz HEM differential apparent resistivity map. 


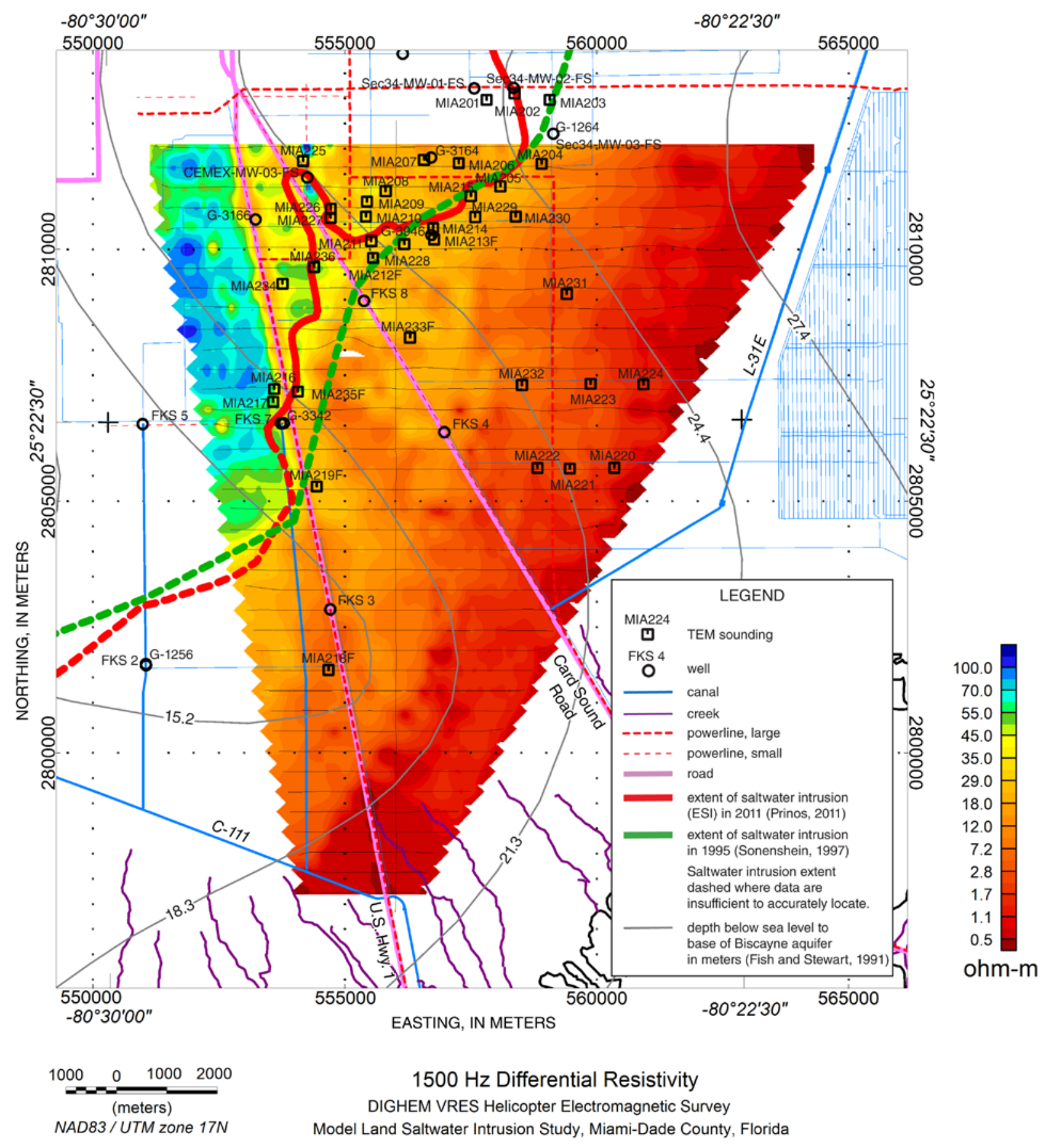

Figure 11. Model Land 1,500-Hz HEM differential apparent resistivity map. 


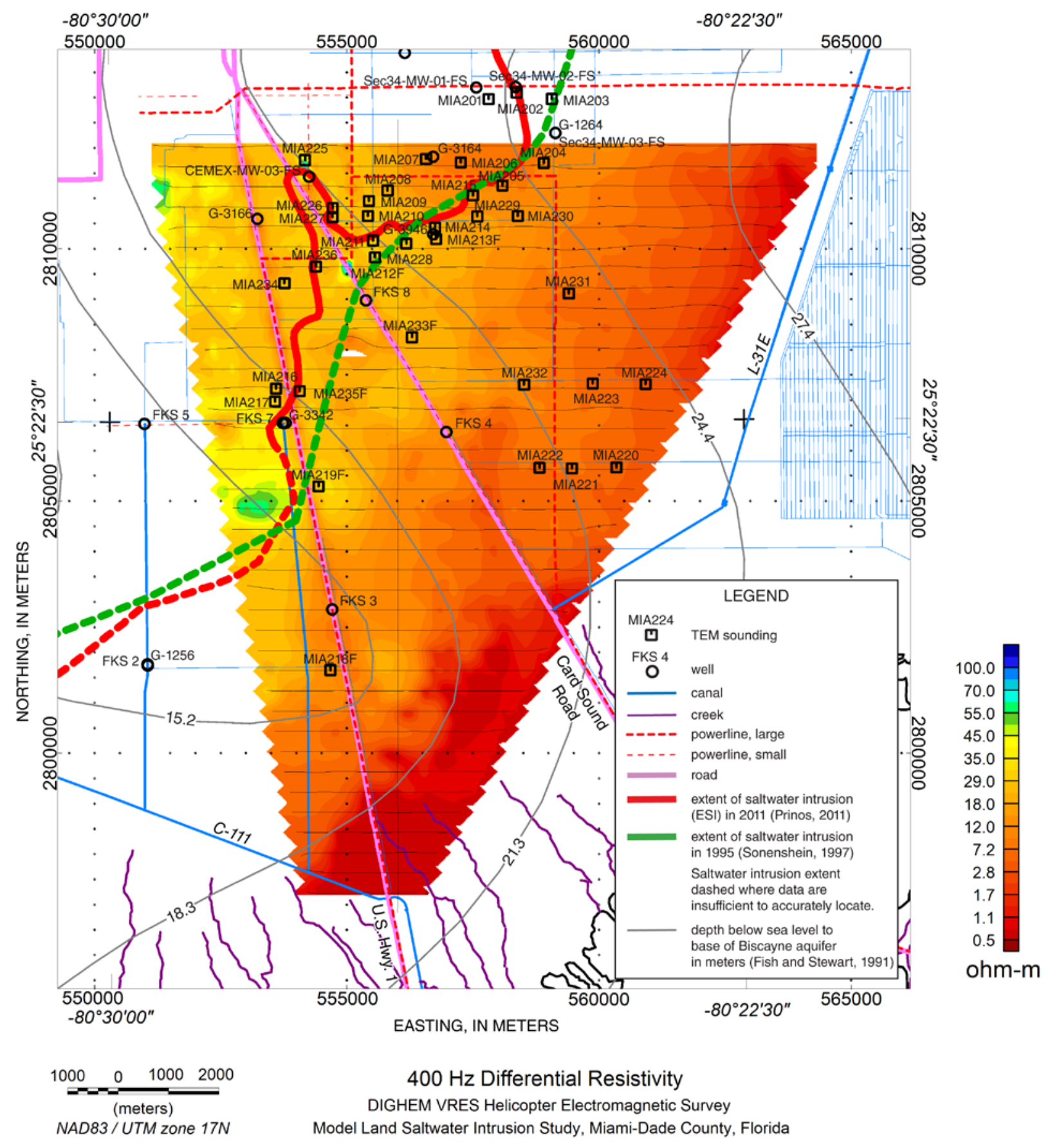

Figure 12. Model Land 400-Hz HEM differential apparent resistivity map. 


\section{Differential Resistivity Depth-Slice Maps}

Using the resistivity-depth functions obtained from the differential resistivity-depth analysis method of Huang and Fraser (1996), we created resistivity depth-slice maps ranging in depth from 5 to $100 \mathrm{~m}$; they are shown in figures 13 through 23. As with the differential apparent resistivity maps, the ESI line and the structural contours on the base of the Biscayne aquifer are shown for reference.

The 5-m depth-slice map is shown in figure 13. The most significant feature is the transition between 35 and 55 ohm-m which strikes NNE and aligns roughly with a line through well FKS-4 and TEM soundings MIA232 and MIA231. This transition proceeds SSW towards U.S. Highway 1, where it turns southward and follows the road. Card Sound Road between well FKS-4 and the eastern boundary of the survey separates a more conductive zone to the southwest from a slightly more resistive zone to the northeast. Both highways and the canals and ditches alongside them obviously influenced the flow of surface water and thereby changed the nearsurface resistivity. The other feature of note is the low-resistivity patches located between soundings MIA236, MIA233F, and MIA235F. As discussed previously, these low-resistivity zones correspond to the CEMEX quarries. There is no correspondence between the ESI and the resistivity values at this depth.

Figure 14 shows the 10-m depth-slice map. The main resistivity gradient has moved landward anywhere from 1.5 to $5 \mathrm{~km}$. The zone between U.S. Highway 1 and Card Sound Road is still more conductive than the adjacent areas. The area to the west of the Turkey Point cooling canals has become more conductive. The CEMEX quarry feature is still present.

At a depth of $20 \mathrm{~m}$, the picture has changed dramatically (fig. 15). The low-resistivity zone has moved northward to the ESI line, and the resistivity gradients across U.S. Highway 1 and Card Sound Road have disappeared. A prominent low-resistivity anomaly aligns with Card Sound Road from well FKS-8 north toward well CEMEX-MW-03-FS. The CEMEX quarry feature has been swallowed up by the saltwater front. The low-resistivity feature near the Turkey Point cooling canals can no longer be distinguished from the background resistivity values.

Depth slices from $30 \mathrm{~m}$ (fig. 16) and deeper have data gaps (white patches in the maps) starting along the eastern boundary of the survey, because conductive material, which reduces the depth on investigation, is encountered at shallower depths in this area than farther west in the survey area. With successively deeper depth slices, the area with data gaps expands to the west and north.

Starting with the 40-m depth slice (fig. 17), the resistivity seaward of the ESI starts to increase slightly because the HEM data are sensing the slightly more resistive material found beneath the Biscayne aquifer. This is most likely caused by the decrease in specific conductance of water in the deeper portion of the surficial aquifer system below the base of the Biscayne aquifer as determined by water samples from a well near the location of sounding MIA219F (Fish and Stewart, 1991).

In the depth range of $50 \mathrm{~m}$ to $100 \mathrm{~m}$ (figs. 17 through 23 ), the high-resistivity zone is found only to the west of U.S. Highway 1 north of sounding MIA219F. In the deeper maps, a lower resistivity linear feature (yellow and orange on maps) is seen aligned with the power lines suggesting that these are artifacts of power-line noise in the data. 


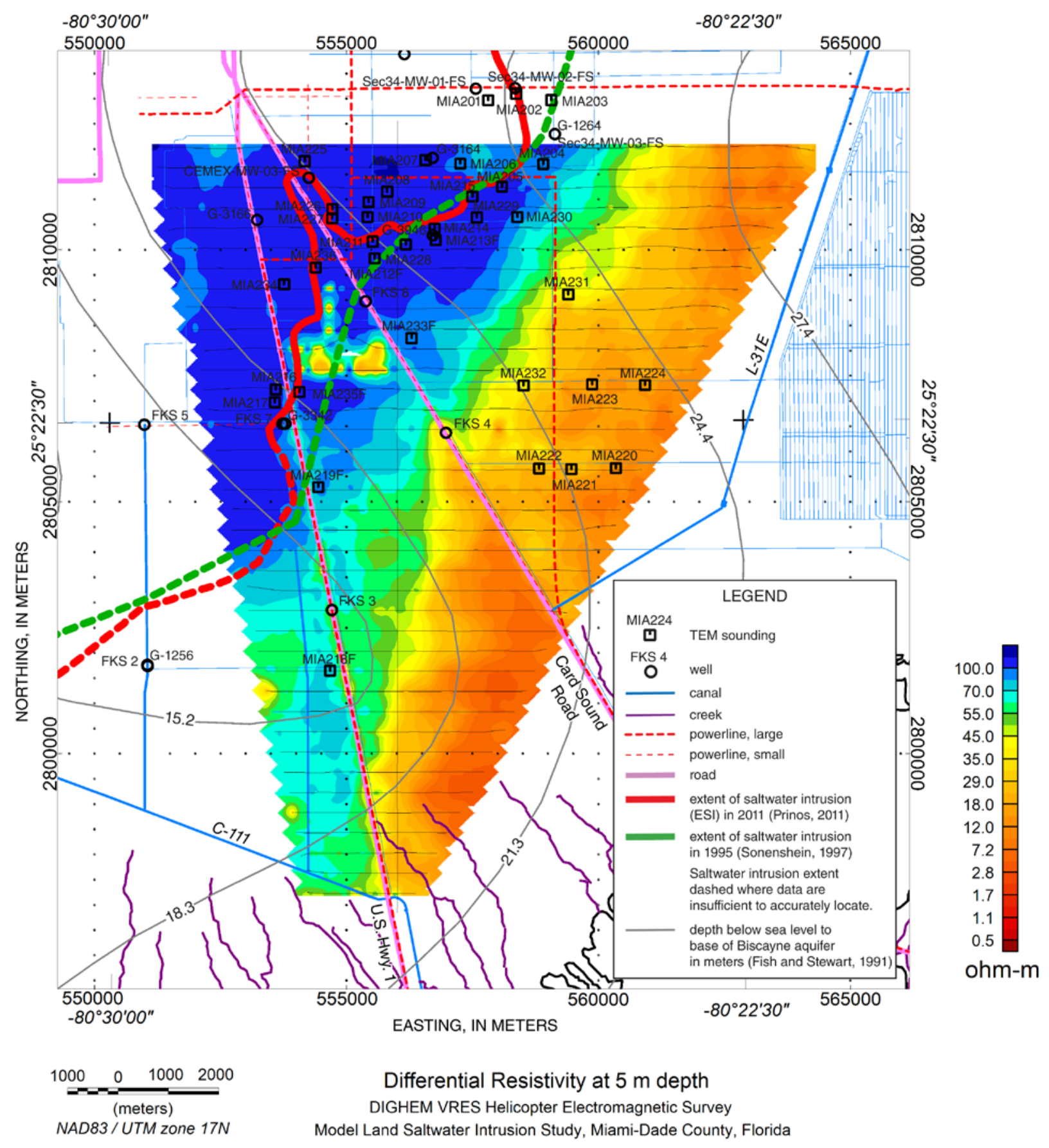

Figure 13. Model Land 5-meter depth differential resistivity depth-slice map. Contours of the depth to the base of the Biscayne aquifer (Fish and Stewart, 1991) and the extent of saltwater intrusion (Sonenshein, 1997; Prinos, 2011) are shown. 


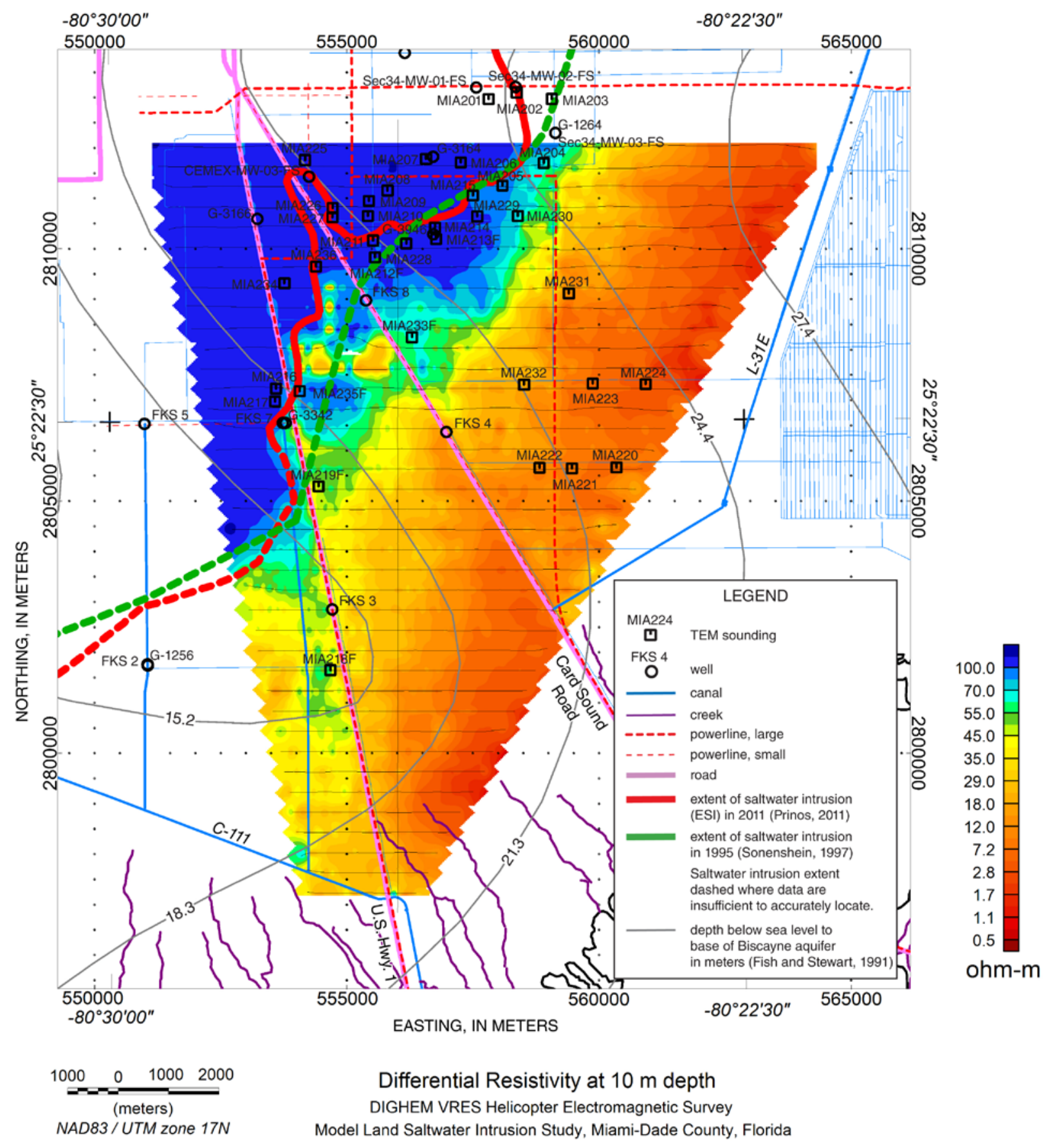

Figure 14. Model Land 10-meter depth differential resistivity depth-slice map. 


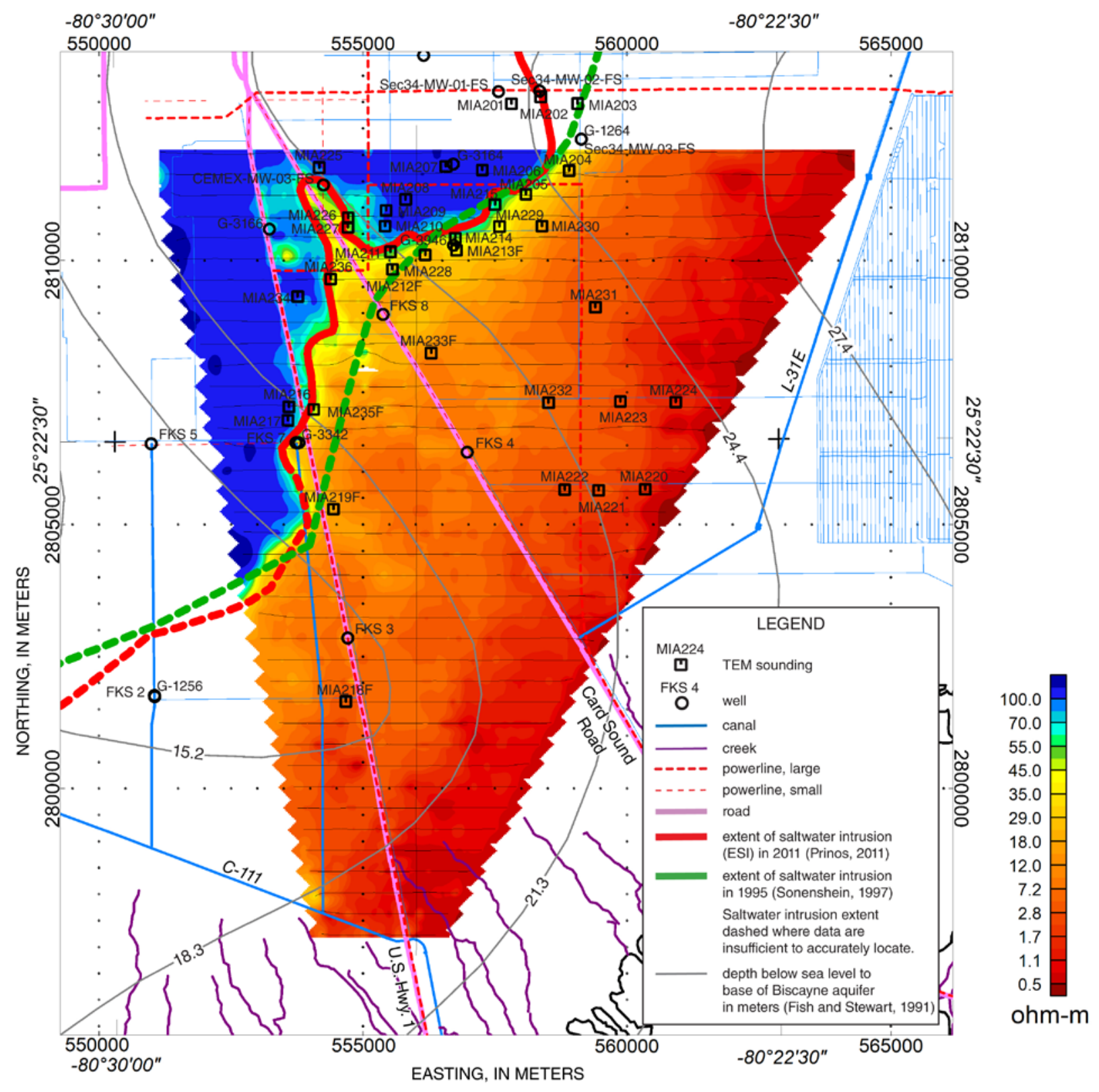

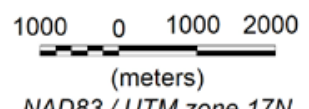

NAD83 / UTM zone $17 N$
Differential Resistivity at $20 \mathrm{~m}$ depth

DIGHEM VRES Helicopter Electromagnetic Survey

Model Land Saltwater Intrusion Study, Miami-Dade County, Florida

Figure 15. Model Land 20-meter depth differential resistivity depth-slice map. 


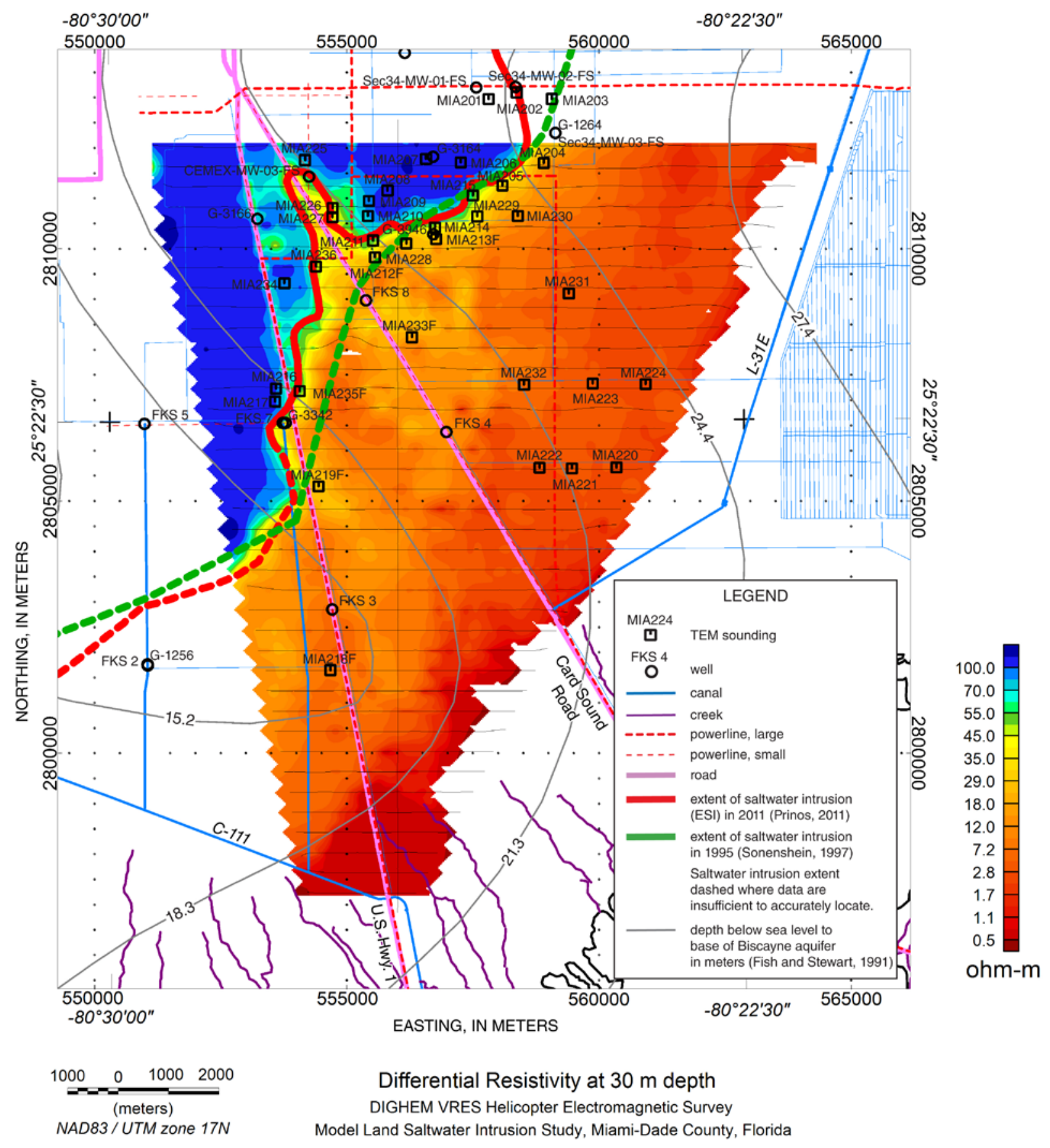

Figure 16. Model Land 30-meter depth differential resistivity depth-slice map. 


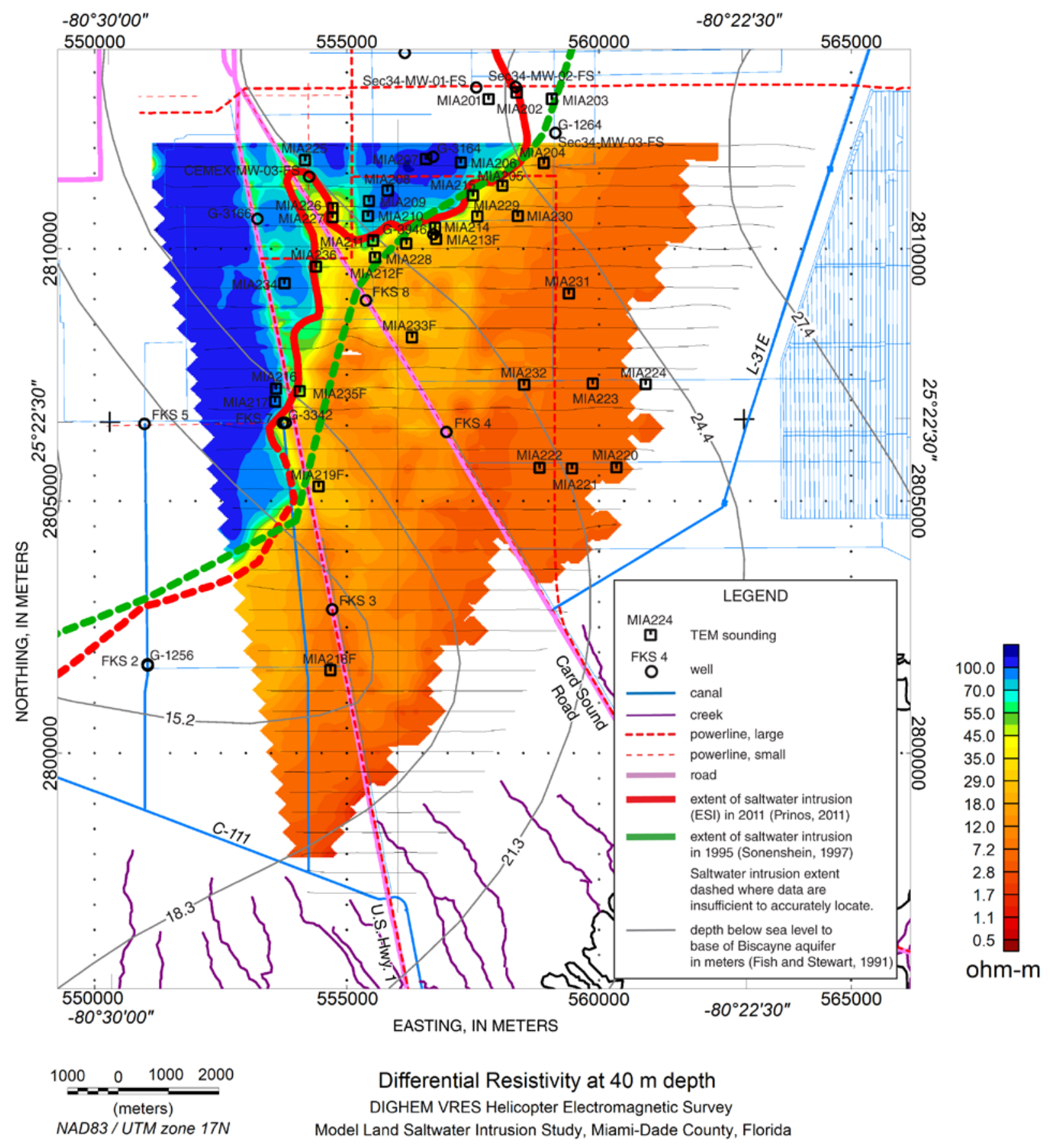

Figure 17. Model Land 40-meter depth differential resistivity depth-slice map. 


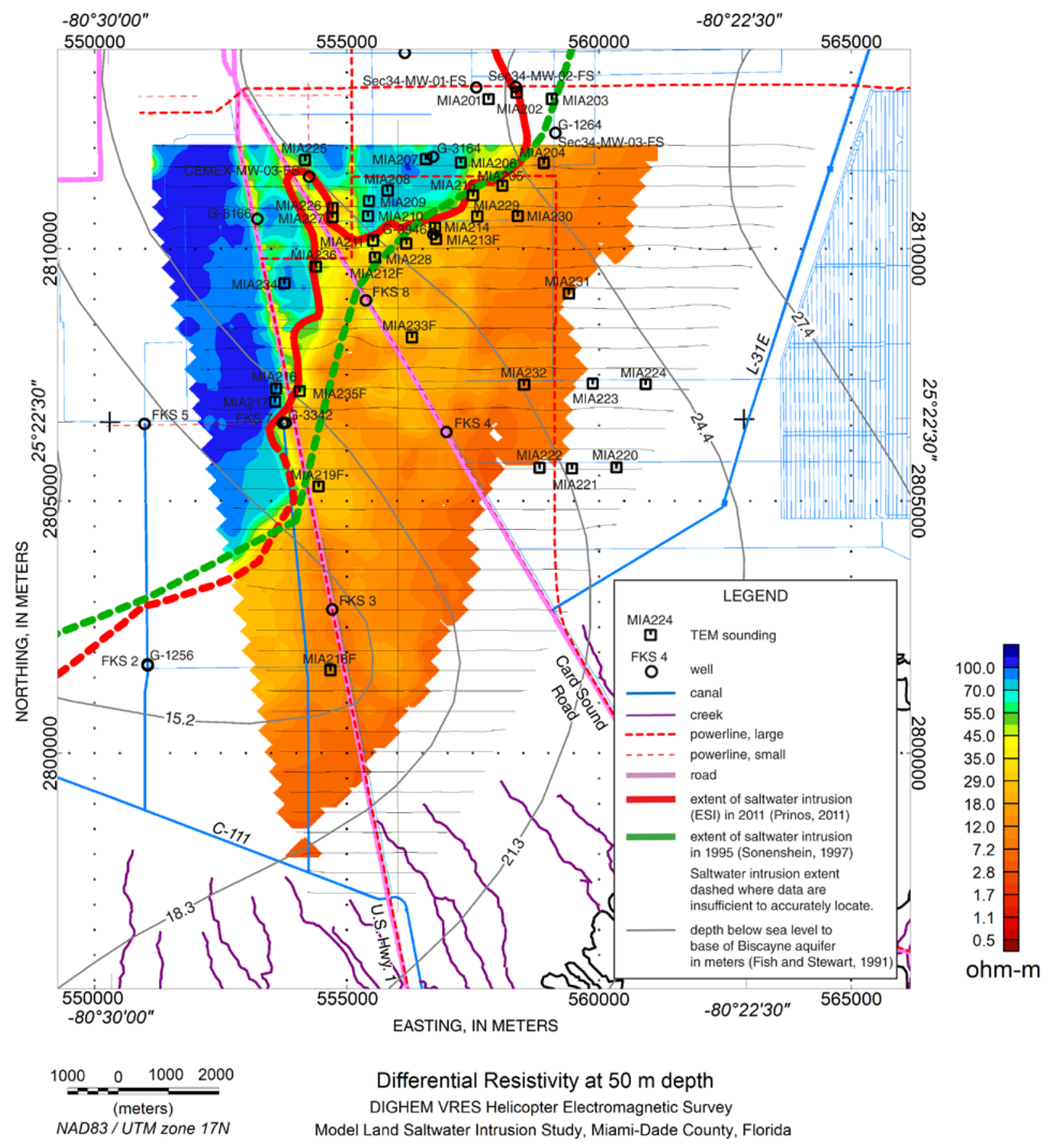

Figure 18. Model Land 50-meter depth differential resistivity depth-slice map. 


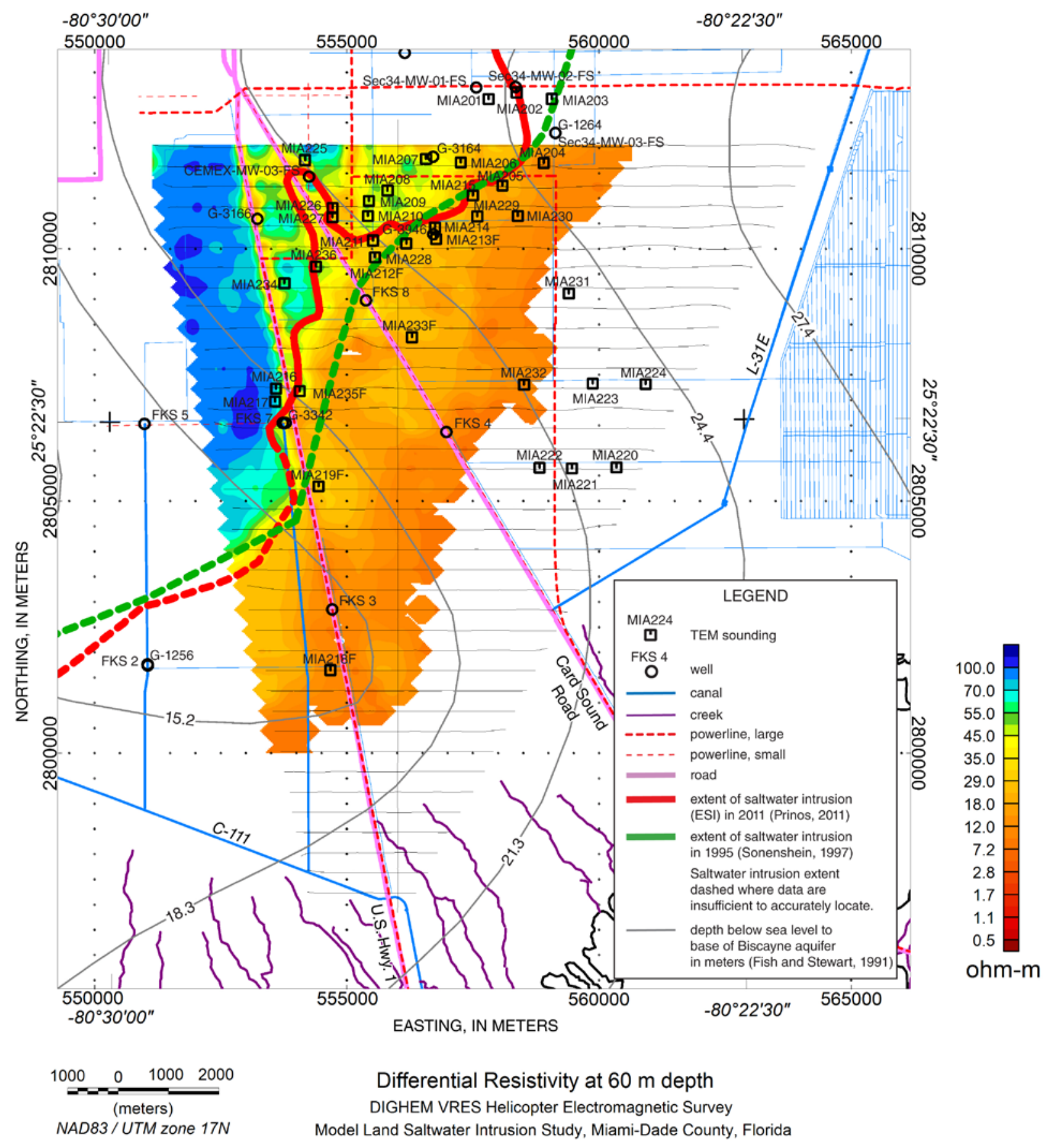

Figure 19. Model Land 60-meter depth differential resistivity depth-slice map. 


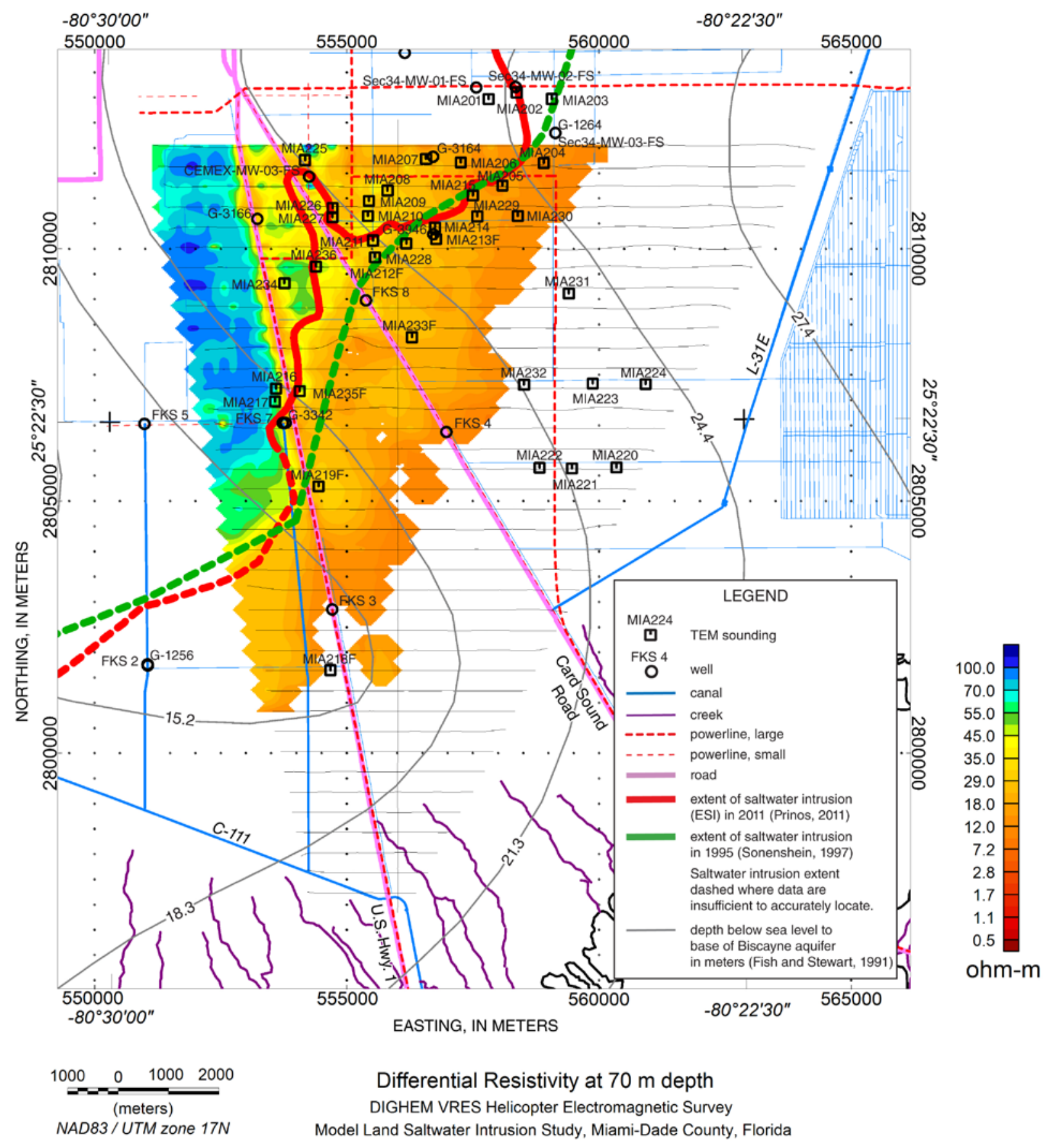

Figure 20. Model Land 70-meter depth differential resistivity depth-slice map. 


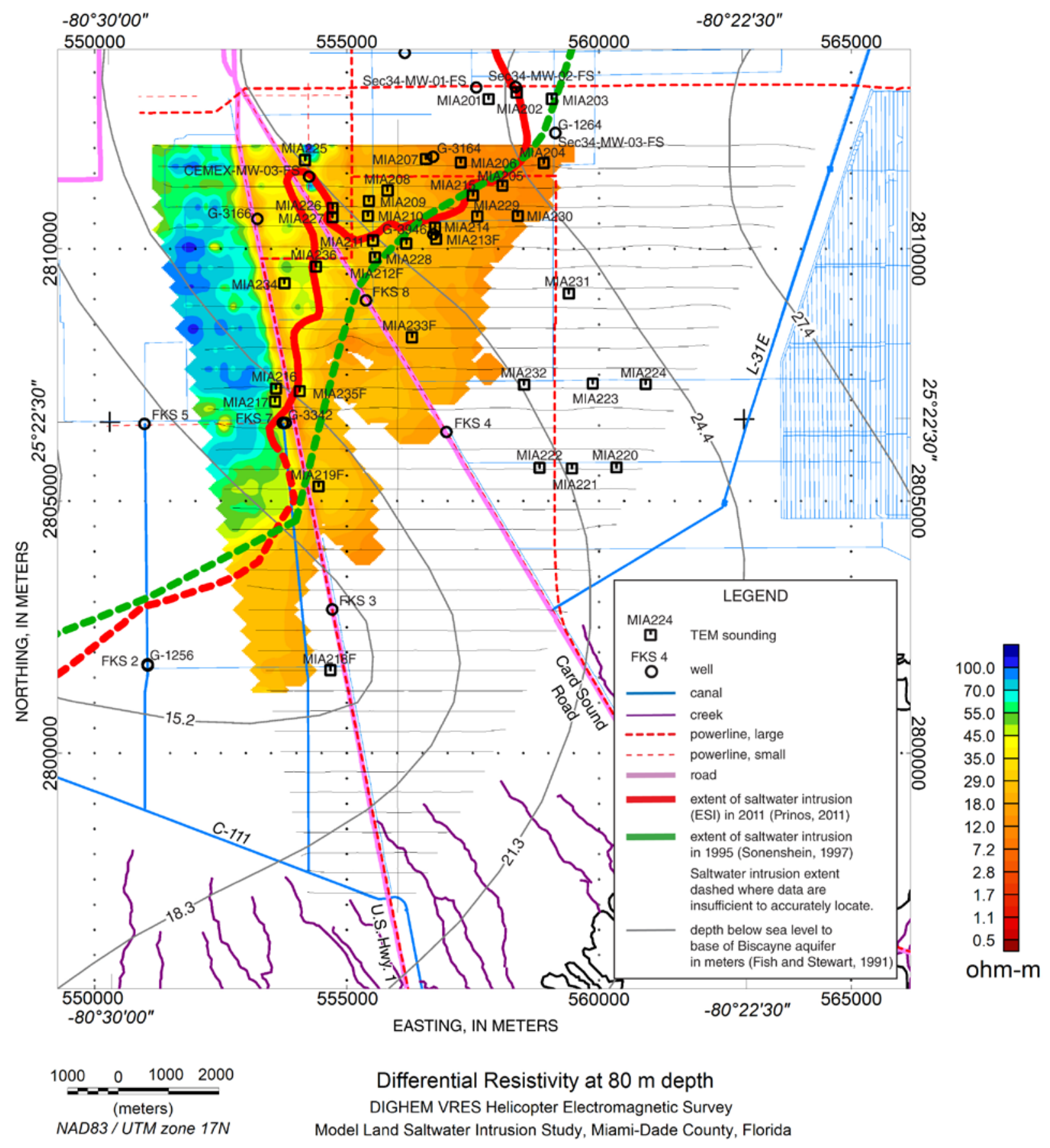

Figure 21. Model Land 80-meter depth differential resistivity depth-slice map. 


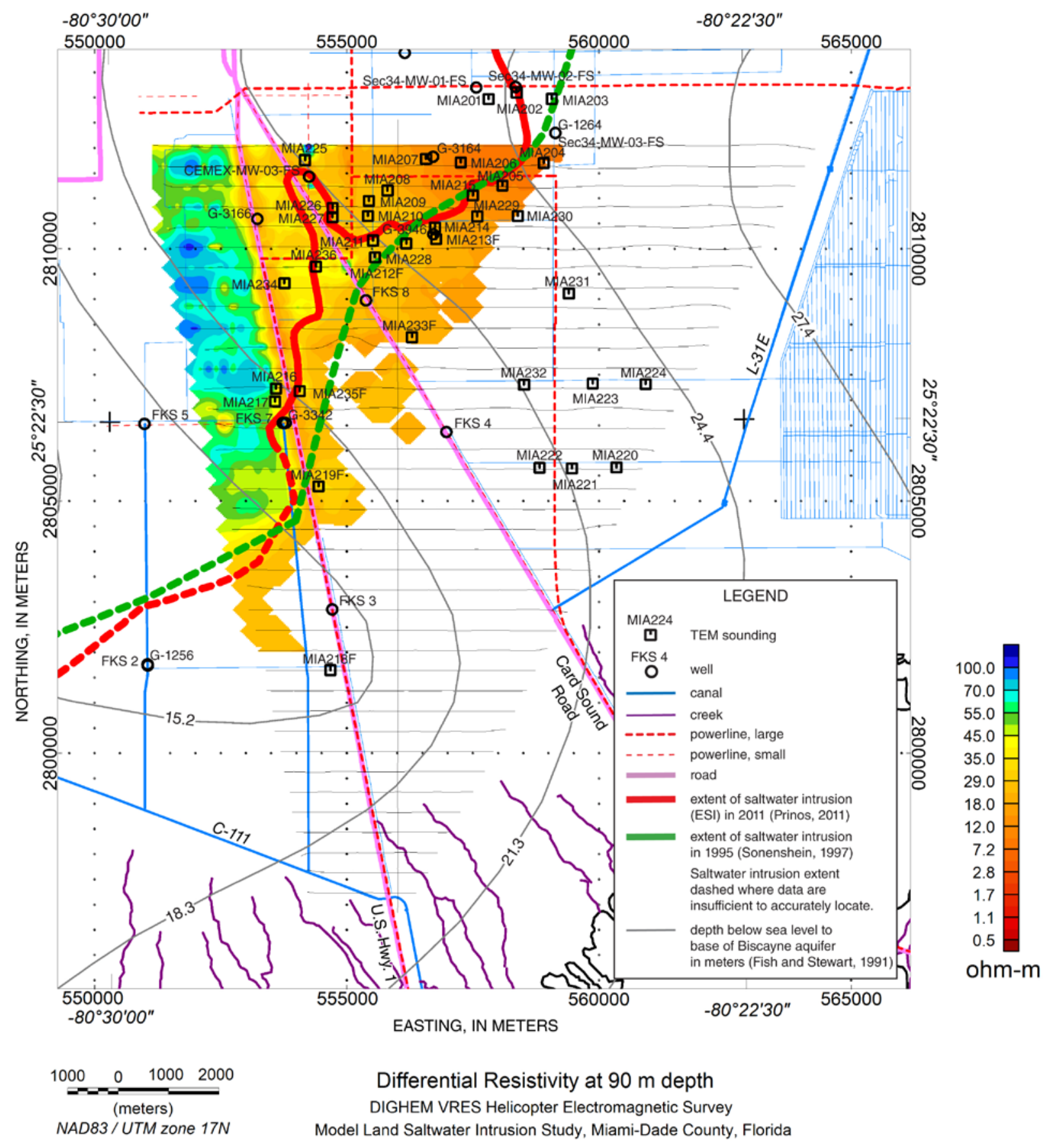

Figure 22. Model Land 90-meter depth differential resistivity depth-slice map. 


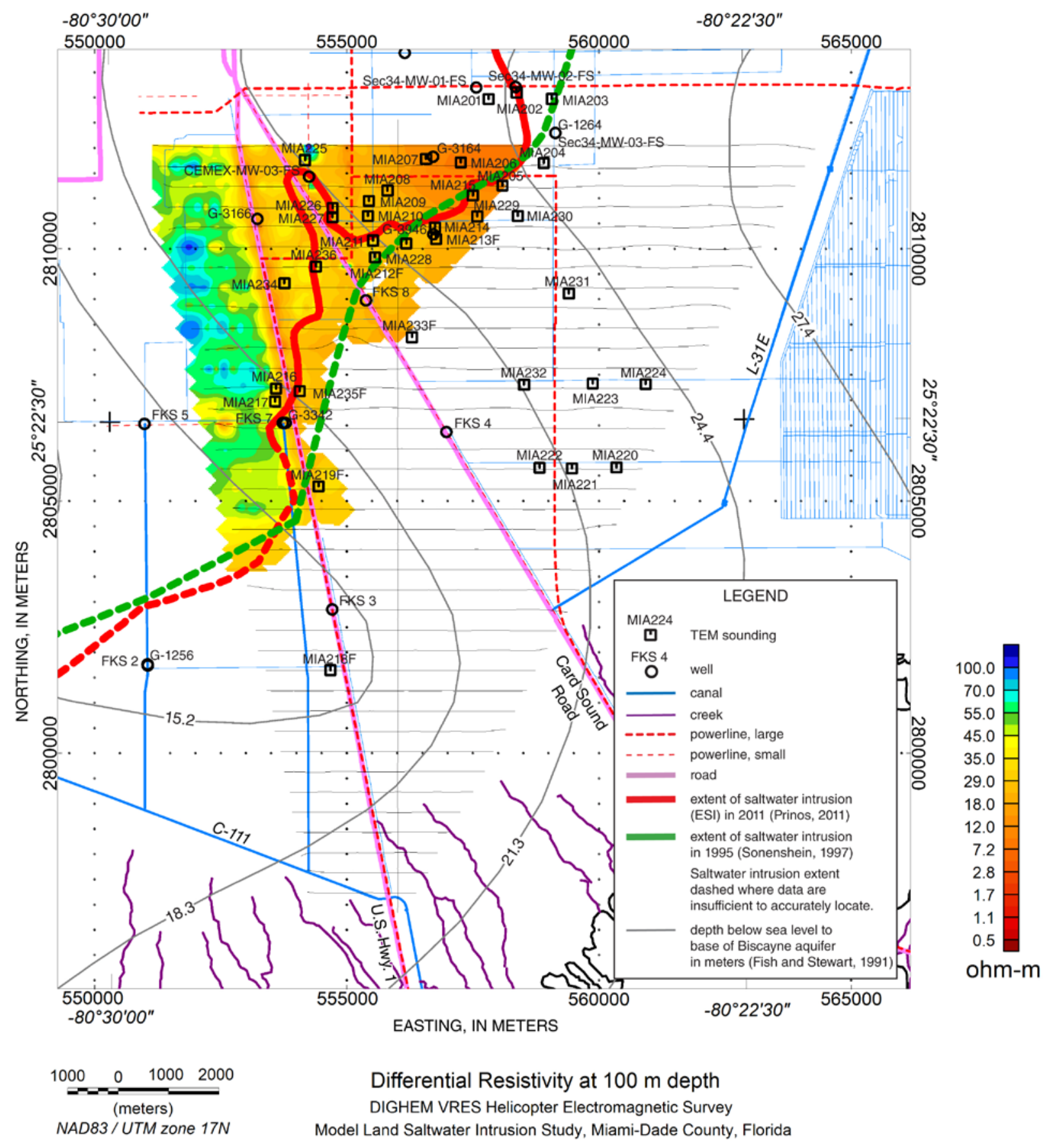

Figure 23. Model Land 100-meter depth differential resistivity depth-slice map. 


\section{Inversion of Helicopter Electromagnetic Data}

The differential resistivity method of Huang and Fraser (1996) is a data transformation method which works very well for HEM data. Another approach for obtaining a geophysical model is inversion, which is a nonlinear parameter-estimation procedure (Oldenburg and Li, 2005). Inversion starts by assuming some sort of electrical resistivity structure called the "model." The electromagnetic response of the model is computed; it is called the "forward model response." The difference between the forward model response and the measured response, called the "misfit," is computed. The sensitivity of the forward model response to changes in the model parameters is also computed. These sensitivities are essentially partial derivatives of the model response with respect to the model parameters. The model parameter sensitivities and misfit are used to adjust the model parameters so as to reduce the misfit. This procedure of adjusting the model and recomputing the response and sensitivities is repeated multiple times until the misfit can no longer be reduced or the number of adjustment steps (iterations) exceeds a specified limit.

The inversion process can be guided so as to favor models that have particular properties. For example, if the models only allow variation of resistivity in the vertical direction (onedimensional or layered-earth models), inversion parameters can be set to favor models that are smooth, that is, models having small changes in resistivity from layer to layer, or models that are closer to some specified resistivity-depth function. Modern inversion routines offer a great deal of flexibility in specifying model constraints.

In many situations the geology is essentially one-dimensional (1-D), that is to say, it varies only with depth over the footprint of the HEM measurement (Beamish, 2003). This is the case in our study area in south Florida where dips are small. The Biscayne aquifer and surficial aquifer system have dips of less than $1^{\circ}$ (Fish and Stewart, 1991). Thus we are justified in using a 1-D model to fit the HEM data. The 1-D inversions are stitched together to make cross sections giving the appearance of a model that varies vertically and horizontally, but in fact the forward and inverse calculations are 1-D.

To invert the HEM data, we used a program developed by the Geophysical Inversion Facility at the University of British Columbia called EM1DFM (Farquharson, 2000; Farquharson and others, 2003). The inversion model is a stack of layers of specified thickness that increase with depth. The model consists of 28 layers with logarithmically spaced layer thicknesses. The first layer is $1 \mathrm{~m}$ thick, and successively deeper layers thicken by a factor of $1.1365\left(=10^{1 / 18}\right)$. The last layer is $26.5 \mathrm{~m}$ thick and starts at a depth of $190 \mathrm{~m}$. The layer thicknesses are fixed while the layer resistivities are adjusted during the inversion process. The inversion process is controlled by a set of parameters. We have used parameters (see the appendix) which have worked well for similar south Florida data sets.

Two reference (or background) models were used for the inversion: one with a resistivity of $10 \mathrm{ohm}-\mathrm{m}$ and the other with a resistivity of $100 \mathrm{ohm}-\mathrm{m}$. The reference model is the resistivity-depth structure expected at a location without benefit of any geophysical information, and it is used to estimate the depth at which the inverted model ceases to be controlled by the data. Using inversion results for the two reference models a depth of investigation (DOI) was estimated by the taking the difference of the inverted model resistivities and dividing it by the difference of the reference model resistivities (Oldenburg and $\mathrm{Li}, 1999$ ). If this ratio, called the DOI metric, is small, the model is controlled by the subsurface conditions, that is, it is sensitive to the data. On the other extreme, when the ratio approaches unity, the model is controlled by the 
reference resistivity values, not the subsurface conditions. The DOI was chosen as the depth where the metric is less than 0.2. Deeper layers are not shown in the inversion cross sections.

The inversion results are generally considered to be more reliable than the differential resistivity transformation because the method is based on an actual forward model calculation. Furthermore, the inversion procedure gives a means of formally assessing the resulting model. Both results are presented for comparison purposes.

\section{Comparison of HEM and TEM Inversion Results}

Fitterman and Prinos (2011) collected 36 TEM soundings in the HEM study area to map the extent of saltwater intrusion. The TEM soundings were collected with a Geonics PROTEM-D system. The TEM inversion models were compared to the HEM inversion results at points on the flight lines nearest the soundings. The maximum distance between soundings and flight lines used for comparisons was $300 \mathrm{~m}$. The comparisons of the TEM and HEM inversion results are shown in the figures below. The comparisons are organized by flight line and sorted by easting along the flight line. There are four traces on each plot: the TEM inversion model (heavy red line), the HEM inversion models using a 10- and 100-ohm-m background resistivity (thin black lines), and the portion of the HEM inversion that meets the DOI criterion described above (heavy black line). The DOI masked model is plotted along the $10 \mathrm{ohm}-\mathrm{m}$ background model, but, in fact, any model between the thin black lines would fit the data equally well.

Discrepancies in HEM and TEM inversion results can be attributed to several causes: inherent differences in sensitivity of the two methods, differences in inversion parameterization, and equivalence resulting in non-uniqueness of models. The TEM method tends to have greater sensitivity to conductive zones (especially thin ones) than HEM methods (Kaufman and Keller, 1983). The HEM inversion models are composed of layers of fixed thickness, whereas the TEM inversion models allow layer thicknesses to vary during the inversion process. The number of layers in the HEM inversion models is fixed at 28, while the TEM inversion models have a userspecified number of layers that is typically in the range of $2-5$. This parameterization difference and the greater sensitivity of the TEM method to conductive zones results in smoothly varying models for the HEM inversions and more blocky models for the TEM inversions. Issues of equivalence are usually less for the TEM results. Because of the greater number of data points used in the TEM inversions (on average 27 points) compared to the HEM inversion (10 points), the effect of equivalence is expected to be less in the TEM models. For these reasons, the results of the TEM soundings are considered to be more reliable. That having been said, we must keep in mind that the resolution of thin layers in the TEM inversion models is often moderate to poor. In some cases, the equivalence behavior of thin conductive layers could only be addressed in the TEM inversions by constraining the layer resistivity to a value obtained from nearby well logs.

The results for flight line 30010 are shown in figure 24 with comparisons to TEM soundings MIA225, MIA207, MIA206, and MIA204. The comparison with sounding MIA225 is not very good. Looking at any of the differential resistivity or depth-slice maps it can be seen that the flight line crosses a power line at the easting of MIA225. Power-line noise adversely affects the HEM inversions. The situation with soundings MIA207 and MIA206, which are on the freshwater side of the ESI line and farther from any power lines, is better. TEM models MIA207 and MIA206 show a steady decrease in resistivity with depth through the first three layers before increasing in the last layer. The HEM models follow a similar pattern; however, they require a slightly more conductive surface layer than the TEM results. Sounding MIA204 is on the saltwater side of the ESI line. The saltwater saturated Biscayne aquifer corresponds to the 
11-m thick, 3.7-ohm-m third layer. The HEM result detects a transition from the resistive surface layer to the $20 \mathrm{ohm}-\mathrm{m}$ zone below; however, it fails to sense the low-resistivity zone detected by the TEM sounding. This may be due to the model smoothness constraint used in the HEM inversion. The comparison of the same four soundings to line 30020 (fig. 25) are similar except for sounding MIA204 (fig. 25d). In this case, the HEM data show a resistivity minimum, albeit at a greater depth and not as conductive as TEM model indicates.

In general, the correspondence between the TEM and HEM inversions is good. For example, in figure $31 \mathrm{~b}$ the model for sounding MIA231 has a 16.6-m thick, $1.9-$-ohm-m layer which agrees quite well with the resistivity minimum in the HEM model. The third layer of the TEM sounding is much higher than the corresponding HEM model; however, the uncertainty in this layer is large so that the disparity in resistivity values is not worrisome. Figure 33a shows the result for sounding MIA233F where the conductive layer is very thin (only $1.2 \mathrm{~m}$ ) and its resistivity is $1.1 \mathrm{ohm}-\mathrm{m}$. The HEM model also requires a conductive zone centered around a depth of $20 \mathrm{~m}$; however, this conductive zone is not as deep and thin. This is a case of equivalence exacerbated by the fact that the HEM data have only 10 data points ( 5 inphase and 5 quadrature values) to resolve the model, while the TEM data have more than 32 data points. This data scarcity makes it harder for the HEM measurements to resolve thin zones, even if they are fairly conductive. Based on the results in figures 24 through 39, the conductive, saltwater saturated zone needs to be at least $20 \mathrm{~m}$ thick for the HEM model to resolve it. There is general agreement between the HEM and TEM results for the resistivity at depth. For TEM models where the resistivity increases in the last layer, the uncertainty in the last basement resistivity can be very large. Examples of this are seen in figures $31 \mathrm{~b}$ and $32 \mathrm{a}$ where the basement resistivity of sounding MIA231 is greater than the second layer resistivity $(1.9 \mathrm{ohm}-\mathrm{m})$, and the third layer resistivity can be in the range of 160 to $7,000 \mathrm{ohm}-\mathrm{m}$. The HEM DOI is about $40 \mathrm{~m}$, so the HEM model is not responsive to the deeper region controlling the later time TEM response.

In several cases, the TEM model has a thin conductive second layer that has no corresponding feature in the companion HEM result (see figs. 26c, 27c, 28c, 28d, 30a, and 31a). In these cases the thin conductive layer was moderately to poorly resolved (Fitterman and Prinos, 2011). While we did not investigate if these features could go undetected in the HEM result, we suspect that this is the case.

The discrepancies between the HEM and TEM models can be attributed to several factors including: (1) differences in the sensitivities of the two methods, (2) differences in the inversion parameterizations used for the two methods, and (3) equivalence and non-uniqueness characteristics of the methods. In general, the TEM method has greater sensitivity to thin conductive zones than the HEM method. On the other hand, the HEM method has greater sensitivity to thin surface layers than the TEM method. The HEM data were inverted with models having 28 layers of pre-assigned thickness, whereas the TEM inversion used fewer layers and allowed the layer thicknesses to vary. This difference in parameterization can influence the final model. While the HEM and TEM methods have similar equivalence behavior, the exact nature of it is different for the two methods. These three factors will contribute to differences in inversion models. 

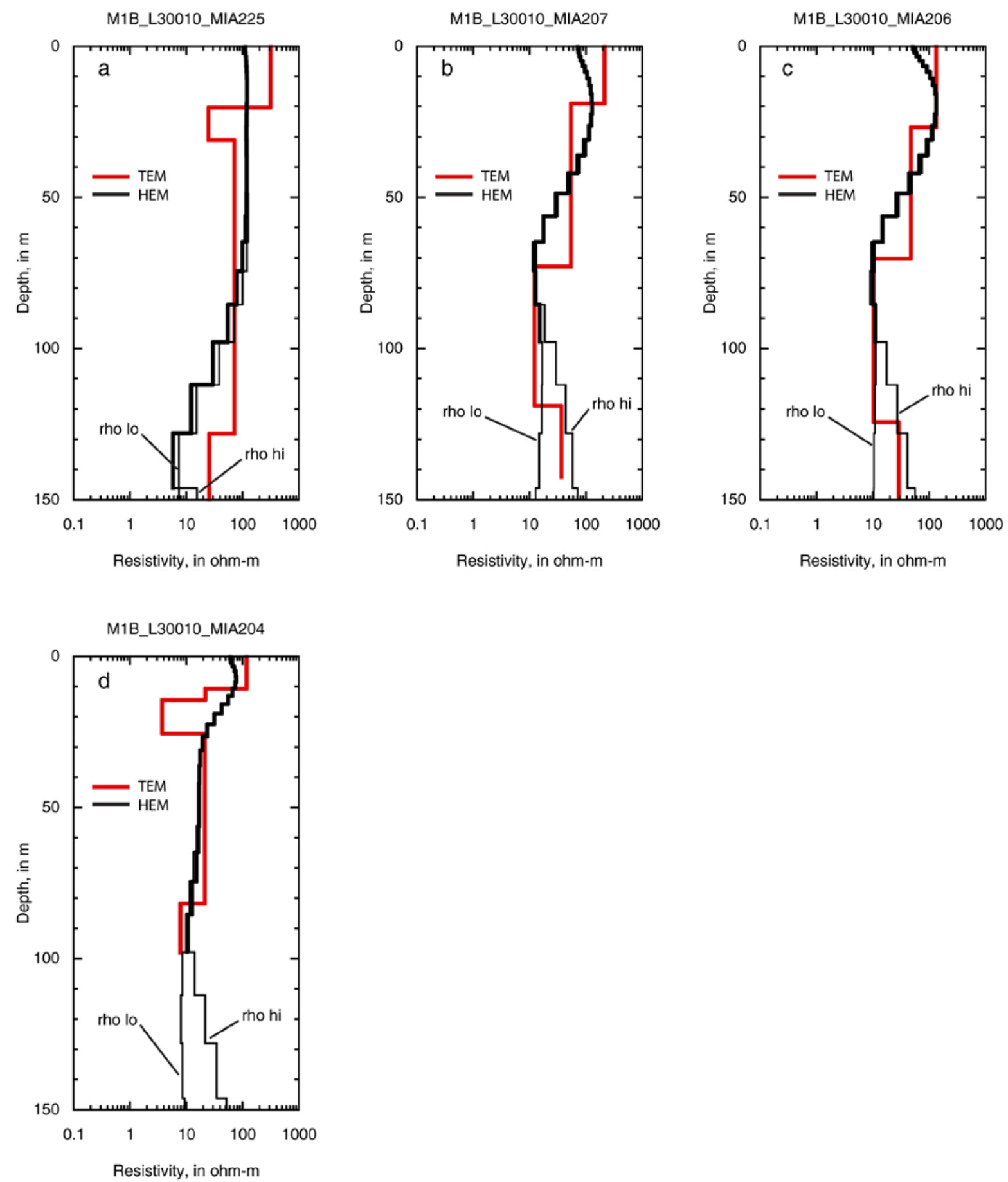

Figure 24. Comparison of HEM inversion for flight line 30010 and TEM sounding models MIA225, MIA207, MIA206, and MIA204. The heavy red line is the TEM model. The HEM model is the heavy black line truncated where the depth of investigation (DOI) metric exceeds 0.2. The thin black lines marked "rho lo" and "rho hi" are the complete models for background resistivities of 10 and $100 \mathrm{ohm}-\mathrm{m}$, respectively. 

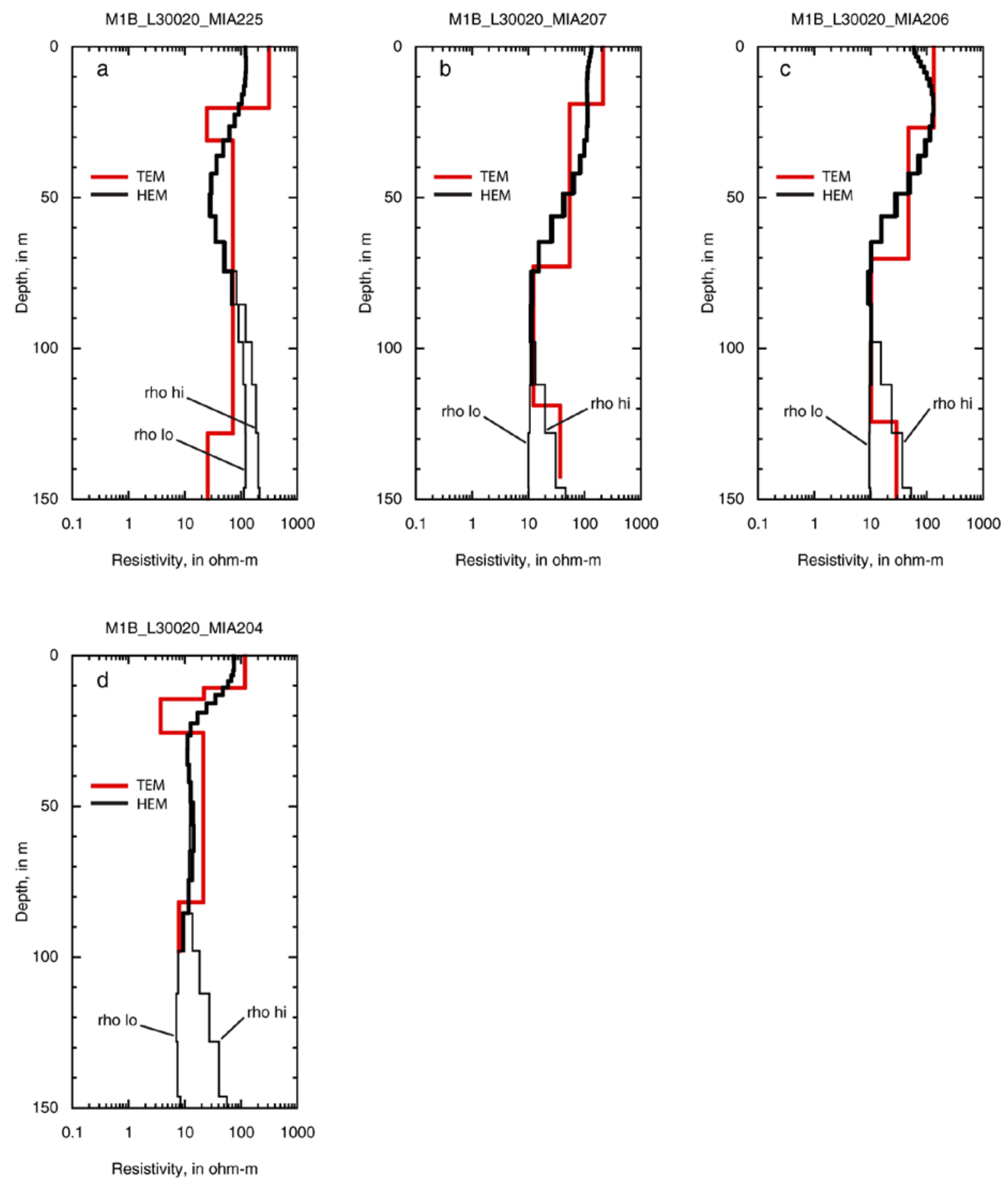

Figure 25. Comparison of HEM inversion for flight line 30020 and TEM sounding models MIA225, MIA207, MIA206, and MIA204. The heavy red line is the TEM model. The HEM model is the heavy black line truncated where the depth of investigation (DOI) metric exceeds 0.2 . The thin black lines marked "rho lo" and "rho hi" are the complete models for background resistivities of 10 and $100 \mathrm{ohm}-\mathrm{m}$, respectively. 

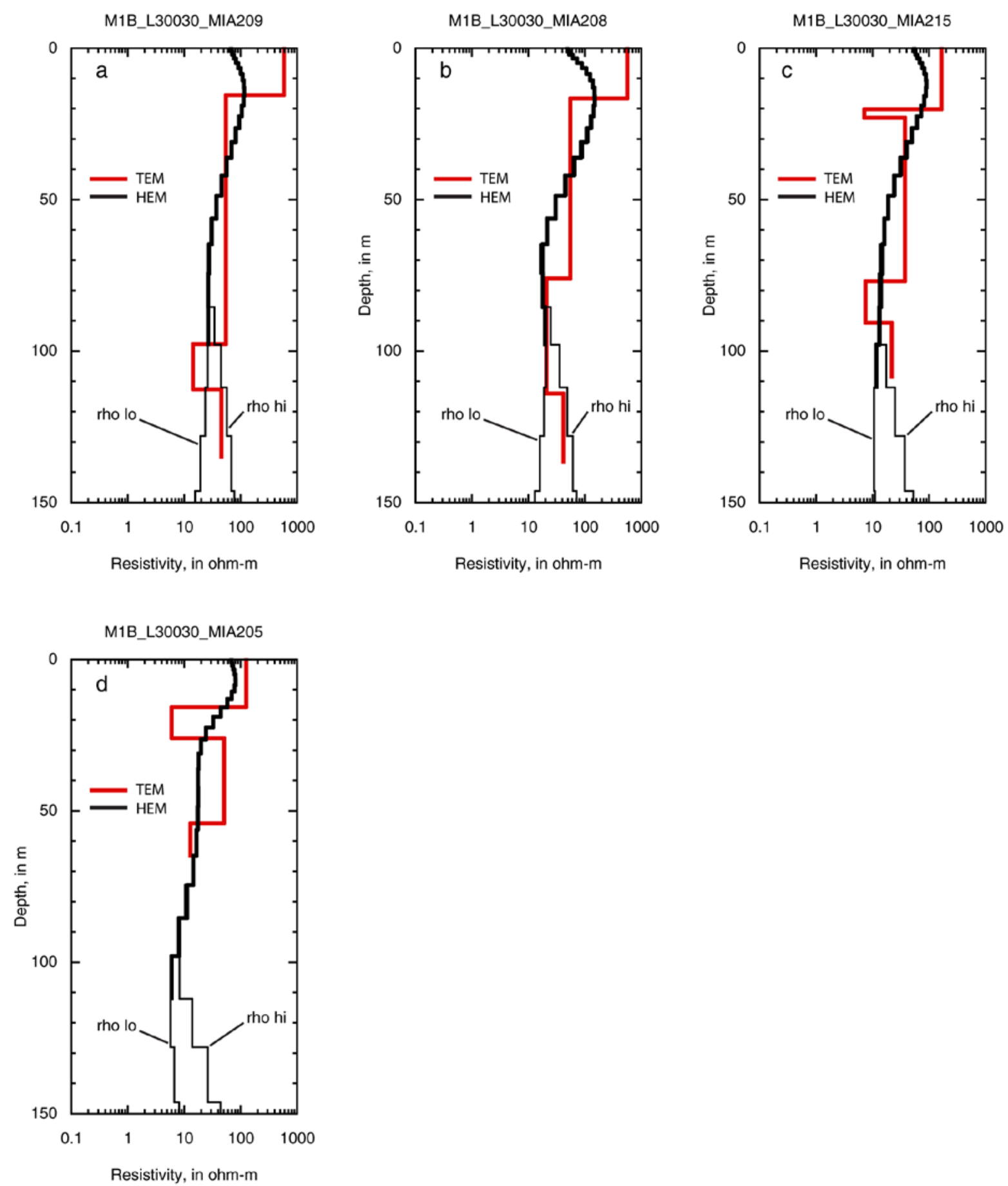

Figure 26. Comparison of HEM inversion for flight line 30030 and TEM sounding models MIA209, MIA208, MIA215, and MIA205. The heavy red line is the TEM model. The HEM model is the heavy black line truncated where the depth of investigation (DOI) metric exceeds 0.2 . The thin black lines marked "rho lo" and "rho hi" are the complete models for background resistivities of 10 and $100 \mathrm{ohm}-\mathrm{m}$, respectively. 

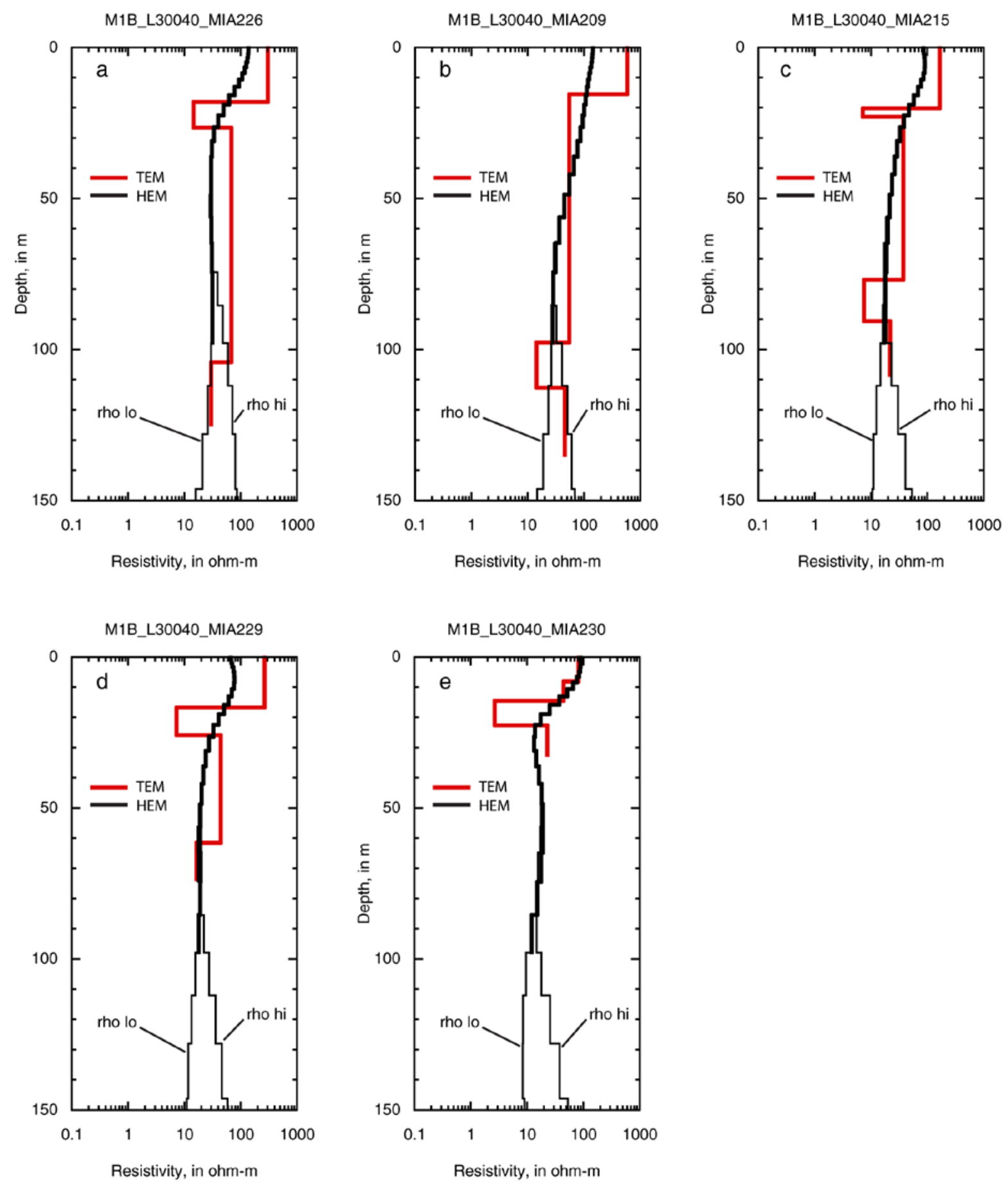

Figure 27. Comparison of HEM inversion for flight line 30040 and TEM sounding models MIA226, MIA209, MIA215, MIA229, and MIA230. The heavy red line is the TEM model. The HEM model is the heavy black line truncated where the depth of investigation (DOI) metric exceeds 0.2 . The thin black lines marked "rho lo" and "rho hi" are the complete models for background resistivities of 10 and $100 \mathrm{ohm}-\mathrm{m}$, respectively. 

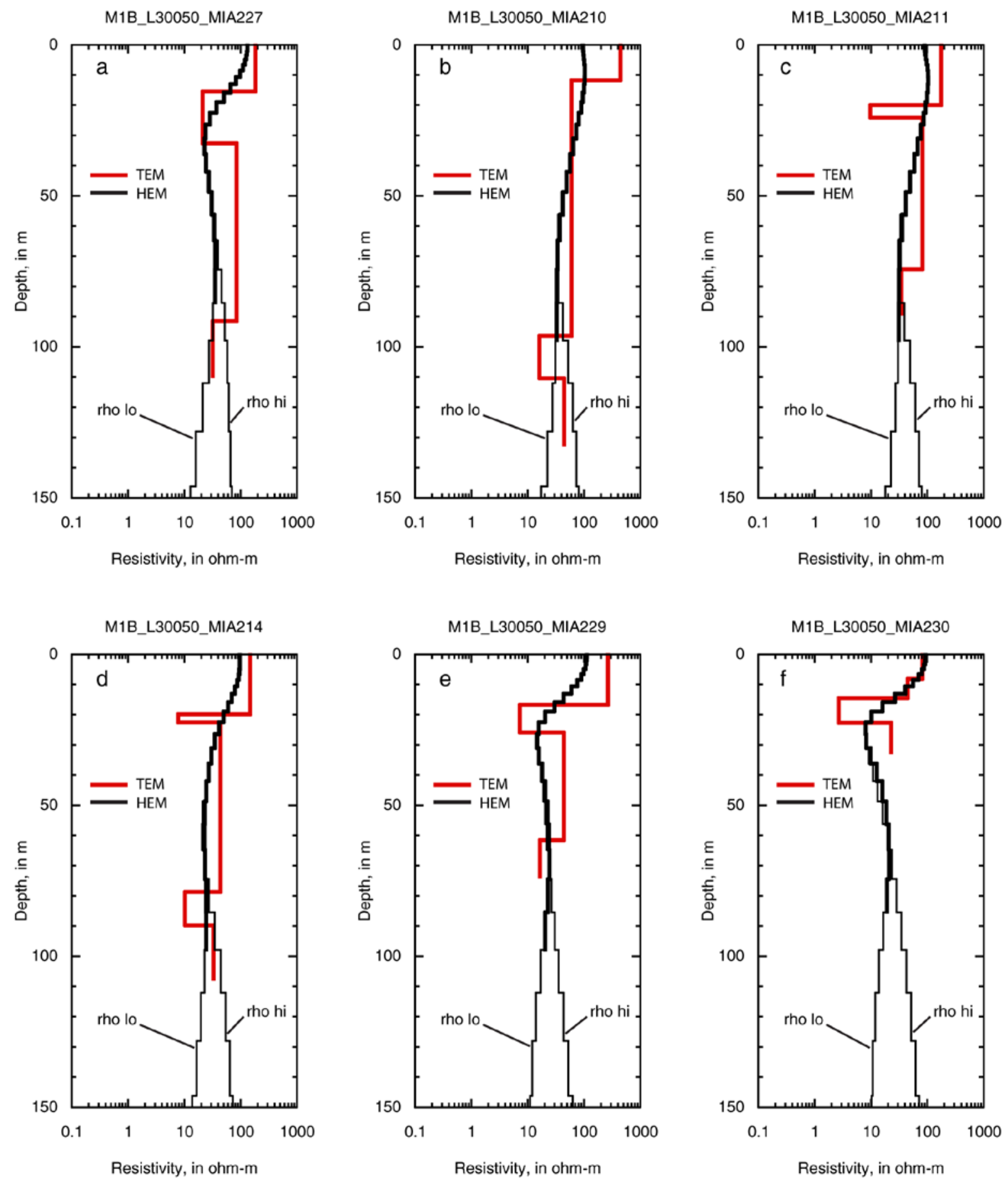

Figure 28. Comparison of HEM inversion for flight line 30050 and TEM sounding models MIA227, MIA210, MIA211, MIA214, MIA229, and MIA230. The heavy red line is the TEM model. The HEM model is the heavy black line truncated where the depth of investigation (DOI) metric exceeds 0.2 . The thin black lines marked "rho lo" and "rho hi" are the complete models for background resistivities of 10 and 100 ohm-m, respectively. 

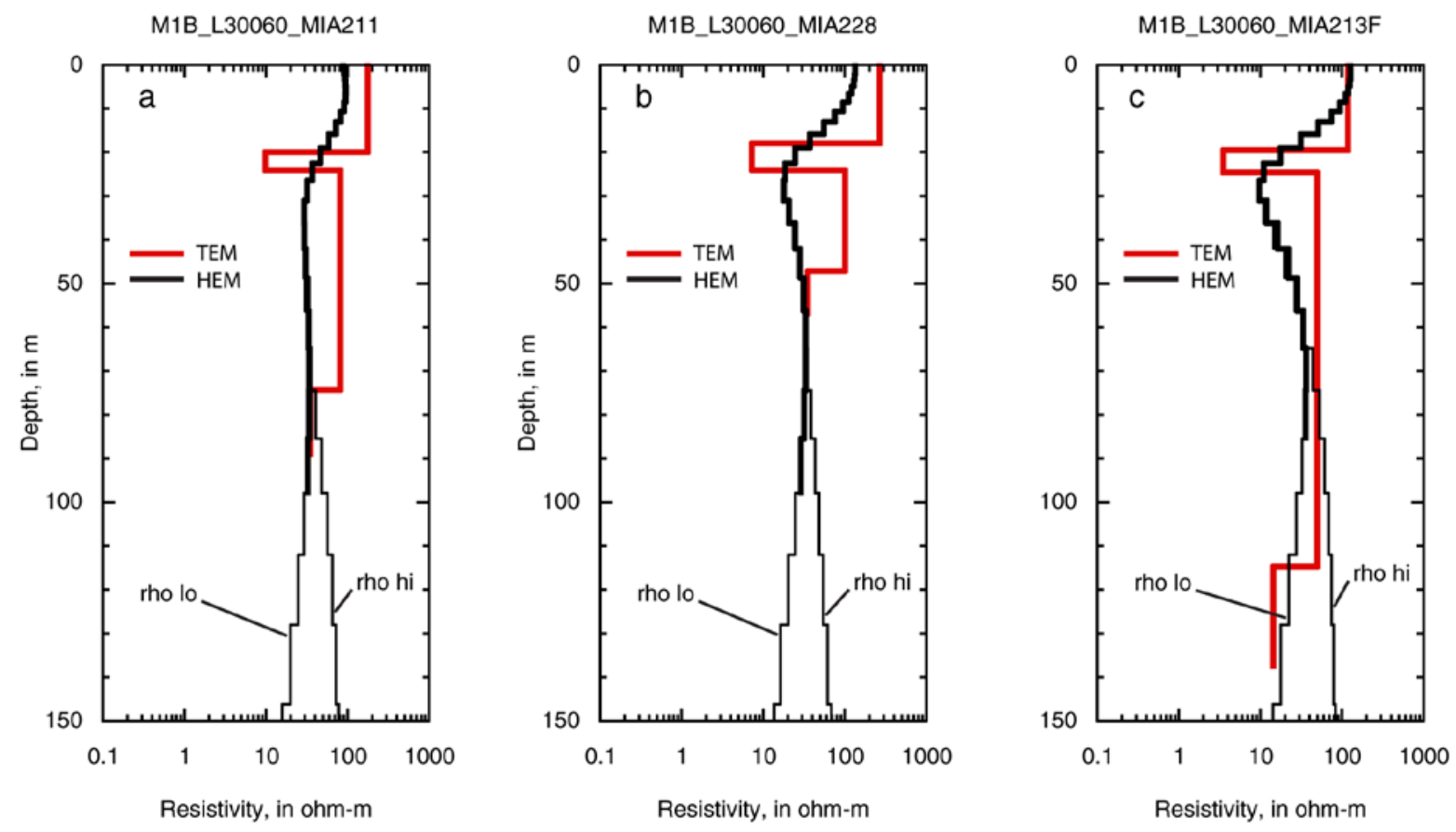

Figure 29. Comparison of HEM inversion for flight line 30060 and TEM sounding models MIA211, MIA228, and MIA213F. The heavy red line is the TEM model. The HEM model is the heavy black line truncated where the depth of investigation (DOI) metric exceeds 0.2 . The thin black lines marked "rho lo" and "rho hi" are the complete models for background resistivities of 10 and 100 ohm-m, respectively. 

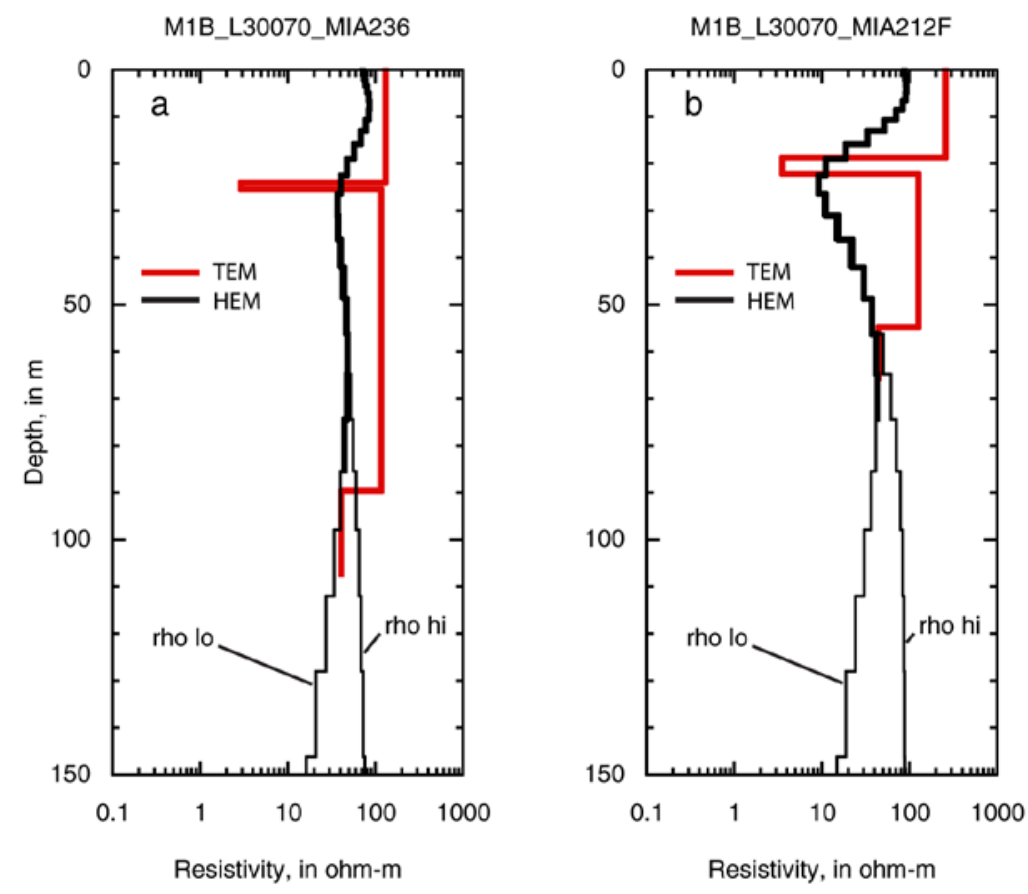

Figure 30. Comparison of HEM inversion for flight line 30070 and TEM sounding models MIA236 and MIA212F. The heavy red line is the TEM model. The HEM model is the heavy black line truncated where the depth of investigation (DOI) metric exceeds 0.2 . The thin black lines marked "rho lo" and "rho hi" are the complete models for background resistivities of 10 and 100 ohm-m, respectively. 

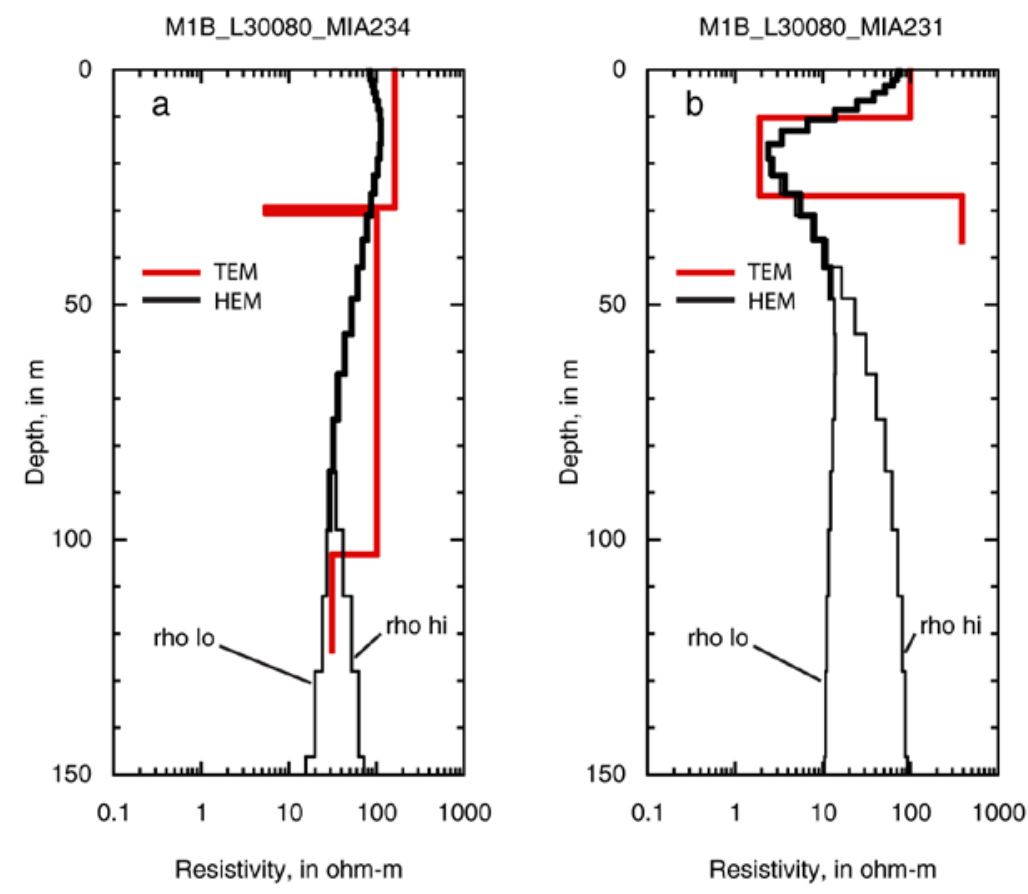

Figure 31. Comparison of HEM inversion for flight line 30080 and TEM sounding models MIA234 and MIA231. The heavy red line is the TEM model. The HEM model is the heavy black line truncated where the depth of investigation (DOI) metric exceeds 0.2. The thin black lines marked "rho lo" and "rho hi" are the complete models for background resistivities of 10 and $100 \mathrm{ohm}-\mathrm{m}$, respectively. 


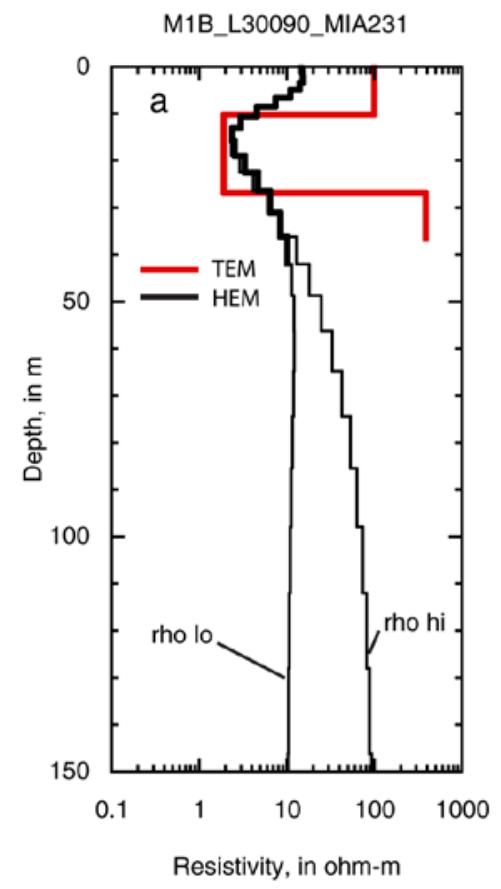

Figure 32. Comparison of HEM inversion for flight line 30090 and TEM sounding model MIA231. The heavy red line is the TEM model. The HEM model is the heavy black line truncated where the depth of investigation (DOI) metric exceeds 0.2. The thin black lines marked "rho lo" and "rho hi" are the complete models for background resistivities of 10 and 100 ohm-m, respectively. 


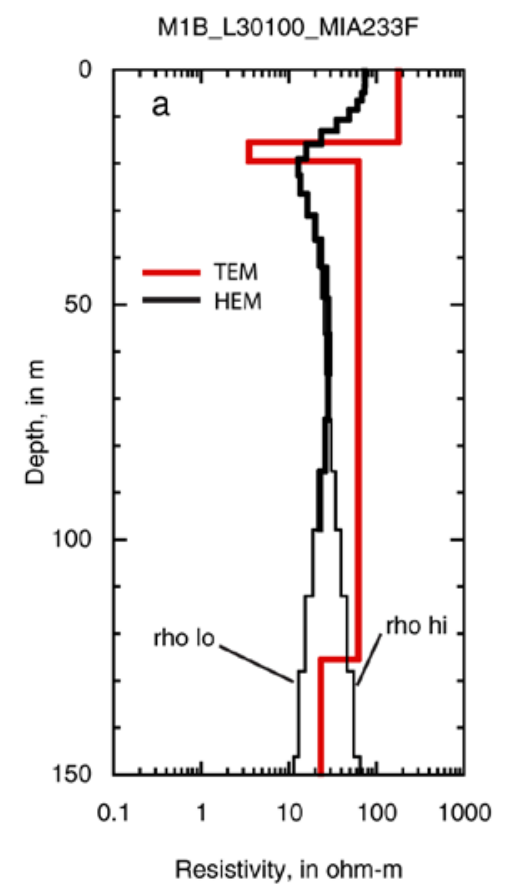

Figure 33. Comparison of HEM inversion for flight line 30100 and TEM sounding model MIA233F. The heavy red line is the TEM model. The HEM model is the heavy black line truncated where the depth of investigation (DOI) metric exceeds 0.2. The thin black lines marked "rho lo" and "rho hi" are the complete models for background resistivities of 10 and 100 ohm-m, respectively. 


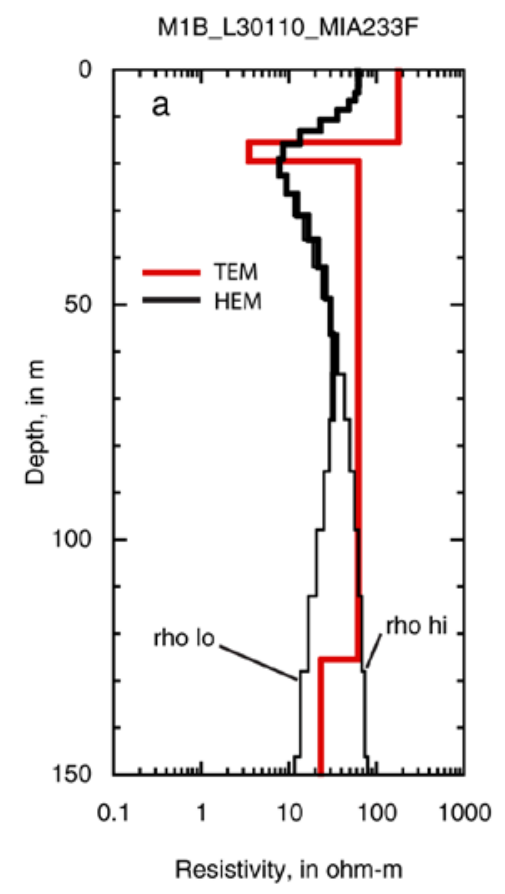

Figure 34. Comparison of HEM inversion for flight line 30110 and TEM sounding model MIA233F. The heavy red line is the TEM model. The HEM model is the heavy black line truncated where the depth of investigation (DOI) metric exceeds 0.2. The thin black lines marked "rho lo" and "rho hi" are the complete models for background resistivities of 10 and 100 ohm-m, respectively. 

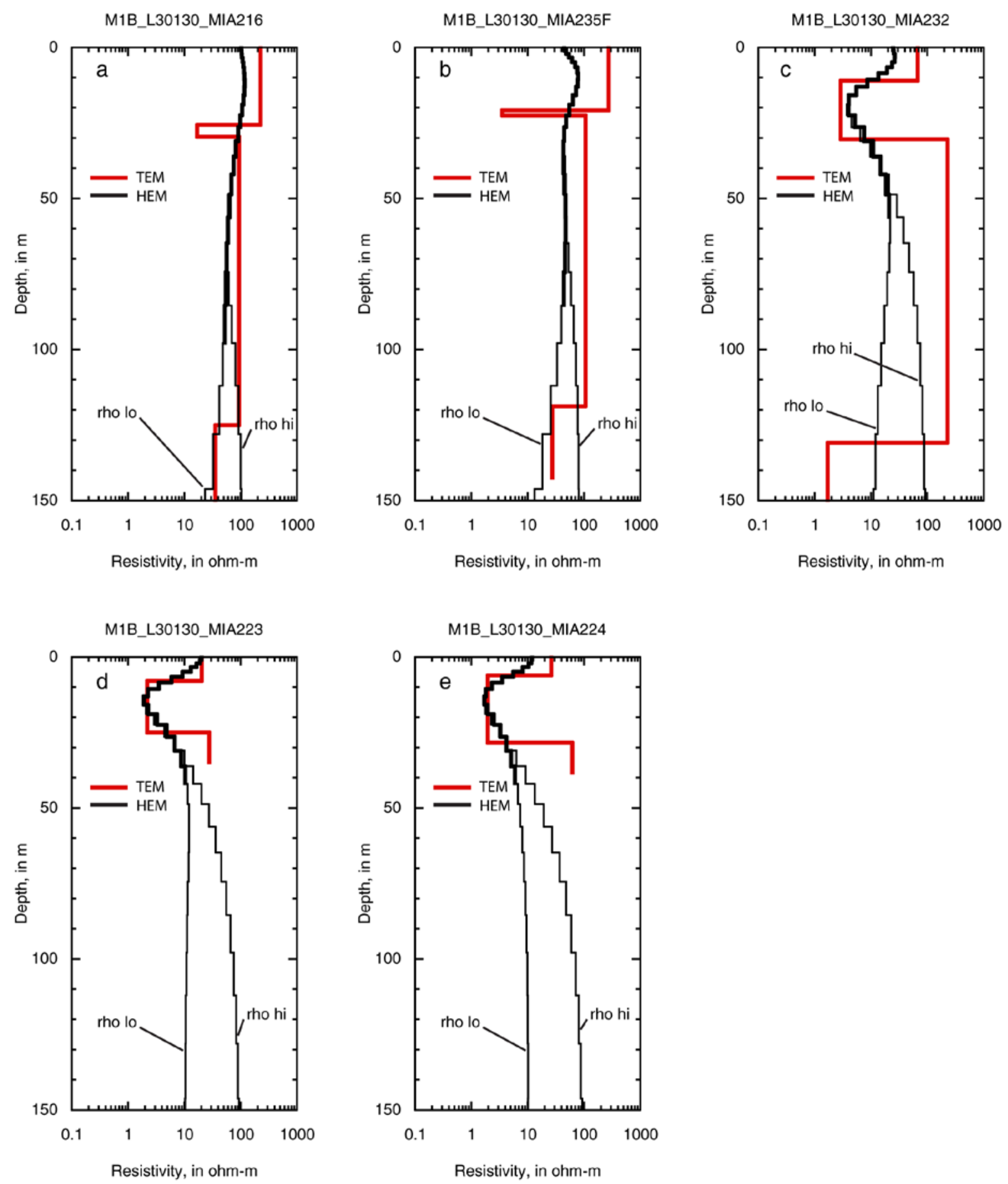

Figure 35. Comparison of HEM inversion for flight line 30130 and TEM sounding models MIA216, MIA235F, MIA232, MIA223, and MIA224. The heavy red line is the TEM model. The HEM model is the heavy black line truncated where the depth of investigation (DOI) metric exceeds 0.2 . The thin black lines marked "rho lo" and "rho hi" are the complete models for background resistivities of 10 and 100 ohm-m, respectively. 


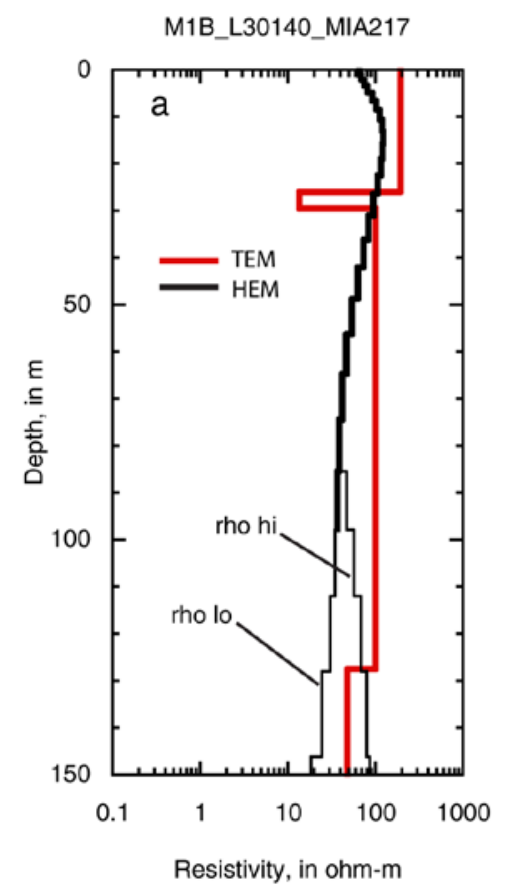

Figure 36. Comparison of HEM inversion for flight line 30140 and TEM sounding model MIA217. The heavy red line is the TEM model. The HEM model is the heavy black line truncated where the depth of investigation (DOI) metric exceeds 0.2. The thin black lines marked "rho lo" and "rho hi" are the complete models for background resistivities of 10 and 100 ohm-m, respectively. 

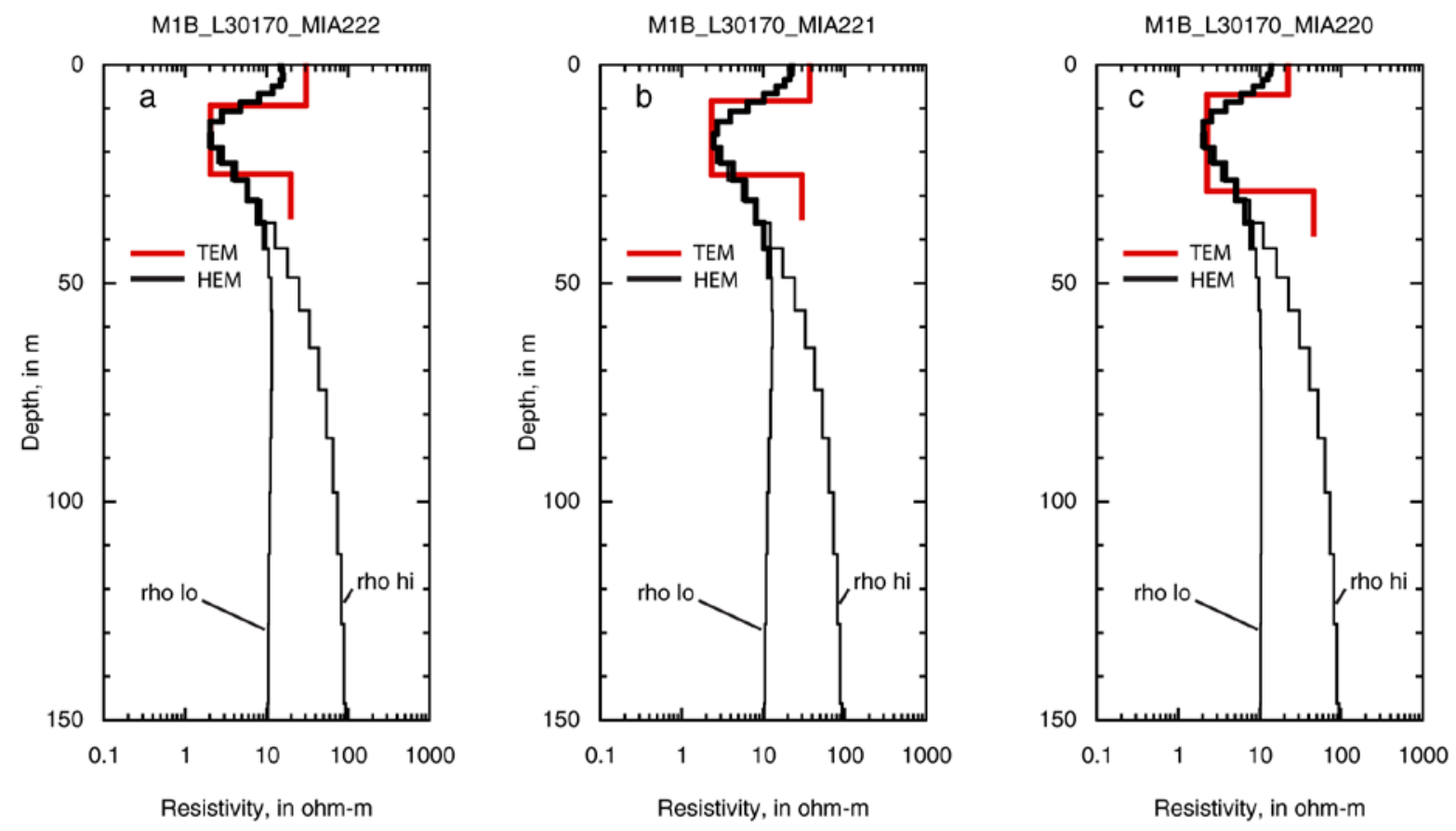

Figure 37. Comparison of HEM inversion for flight line 30170 and TEM sounding models MIA222, MIA221, and MIA220. The heavy red line is the TEM model. The HEM model is the heavy black line truncated where the depth of investigation (DOI) metric exceeds 0.2 . The thin black lines marked "rho lo" and "rho hi" are the complete models for background resistivities of 10 and 100 ohm-m, respectively. 


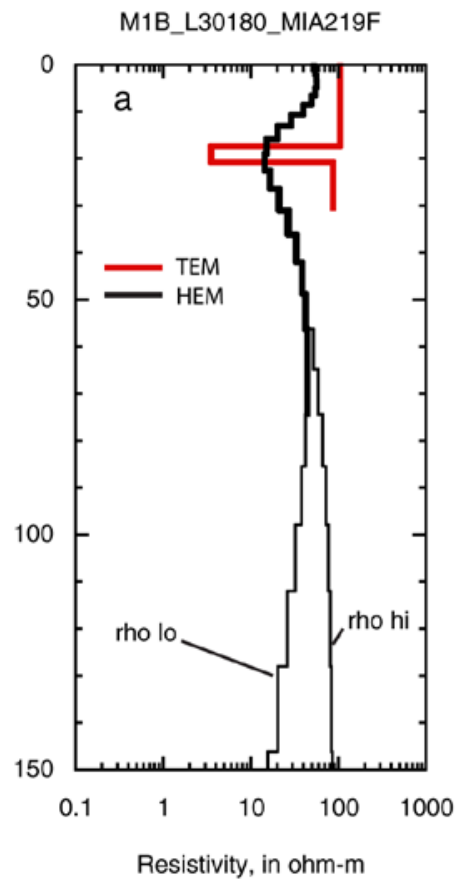

Figure 38. Comparison of HEM inversion for flight line 30180 and TEM sounding model MIA219F. The heavy red line is the TEM model. The HEM model is the heavy black line truncated where the depth of investigation (DOI) metric exceeds 0.2. The thin black lines marked "rho lo" and "rho hi" are the complete models for background resistivities of 10 and 100 ohm-m, respectively. 


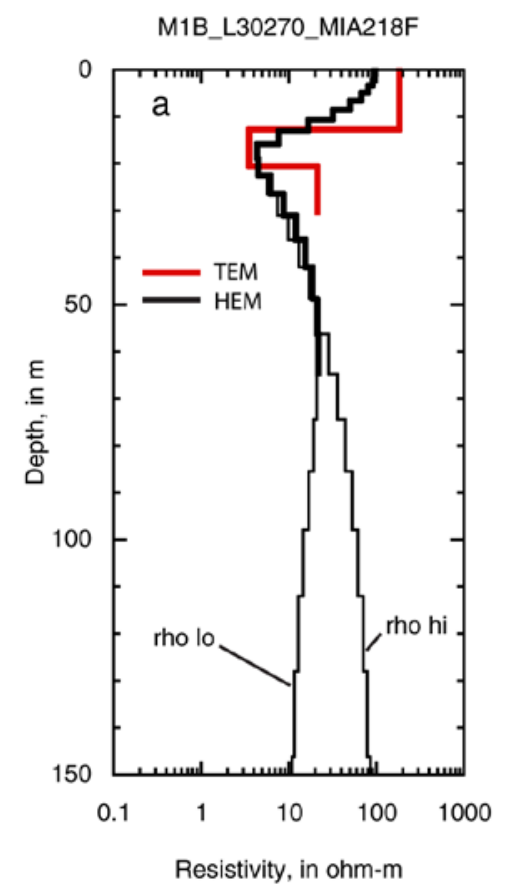

Figure 39. Comparison of HEM inversion for flight line 30270 and TEM sounding model MIA218F. The heavy red line is the TEM model. The HEM model is the heavy black line truncated where the depth of investigation (DOI) metric exceeds 0.2. The thin black lines marked "rho lo" and "rho hi" are the complete models for background resistivities of 10 and 100 ohm-m, respectively. 


\section{Inversion Depth-Slice Maps}

Depth-slice maps created from the inversion results are shown in figures 40 through 50 . In general, the inverted resistivity depth-slice maps show the same regional pattern of resistivity that is seen in the differential resistivity depth-slice maps (figs. 13-23). That is, resistivity decreases across the survey area in the southeast direction toward the coast because of saltwater intrusion. Spatially, the inverted resistivity depth-slice maps are noisier; this creates a wider boundary between the high-resistivity, freshwater-saturated zone and the low-resistivity, saltwater-saturated zone. The noisier character of the depth-slice maps depends upon the specified data errors and the target level of misfit in the inversion. The individual inverted resistivity depth-slice maps are discussed below along with specific differences between them and the corresponding differential resistivity depth-slice map.

The 5-m depth-slice map (fig. 40) exhibits a regional pattern of resistivity decreasing in the southeast direction. Variations from this theme include the low resistivity anomaly associated with the CEMEX quarry. Between U.S. Highway 1 and Card Sound Road, the 55 ohm-m contour is farther northwest than it is in the differential resistivity 5-m depth slice (fig. 13). There is also a pronounced gradient across Card Sound Road southeast of well FKS-4. A slightly more conductive zone is seen near the eastern edge of the survey near the Turkey Point power plant cooling canals. A thin, north-south, higher-resistivity anomaly is seen along SW 137th Avenue from a point south of sounding MIA222 to a point north of sounding MIA231, which corresponds to a power line. This anomaly is seen in all depth slice maps.

In the 10-m depth slice (fig. 41), the CEMEX quarry anomaly and the saltwater front have started to coalesce. The inverted resistivity is not as low as it is in the differential resistivity map (fig. 14). A similar situation is seen in the 20-m depth slice (fig. 42); the inverted resistivities are not as low as the differential resistivities (fig. 15) at the same location. In addition to the SW 137th Avenue power-line anomaly, there is another power-line anomaly along U.S. Highway 1 north of sounding MIA216.

The resistivities in the conductive part of the 30-m depth slice (fig. 43) are not as low as in the differential resistivity map (fig. 16). This is also the deepest depth slice to show a correspondence between the resistivity gradient and the extent of saltwater intrusion. A transitional zone is seen between U.S Highway 1 and Card Sound Road, north of the ESI, that is more obvious than in the differential resistivity map. Moving deeper (40-m depth slice map, fig. 44), the resistivity southeast of the ESI increases slightly due to the slightly fresher water in the deeper portions of the surficial aquifer system below the base of the Biscayne aquifer. Along the eastern edge of the survey, the resistivities are lower to the southwest of Card Sound Road than in the region near the Turkey Point power-plant cooling canals.

The 50-m depth-slice inverted resistivities (fig. 45) are significantly higher than the corresponding ones in the differential resistivity depth-slice (fig. 18). A higher resistivity zone is seen to the west of U.S. Highway 1, north of sounding MIA216. These features persist through a depth of $60 \mathrm{~m}$ before shrinking in size at greater depth. There are also isolated inversion results along U.S. Highway 1 and SW 137th Avenue; these radiate south from the main body of the inversion results. These features, which are coincident with and caused by power-line noise, are present in all of the deeper depths slices, are shown for illustrative purposes only, and are not considered to be geophysically significant. (Note: These low-resistivity power-line features should not be confused with low-resistivity features along U.S. Highway 1 and Card Sound Road caused by changes in water quality. The interpreted region is shrinking with successively deeper maps because of the DOI cutoff criterion (see figs. 47-50).) 


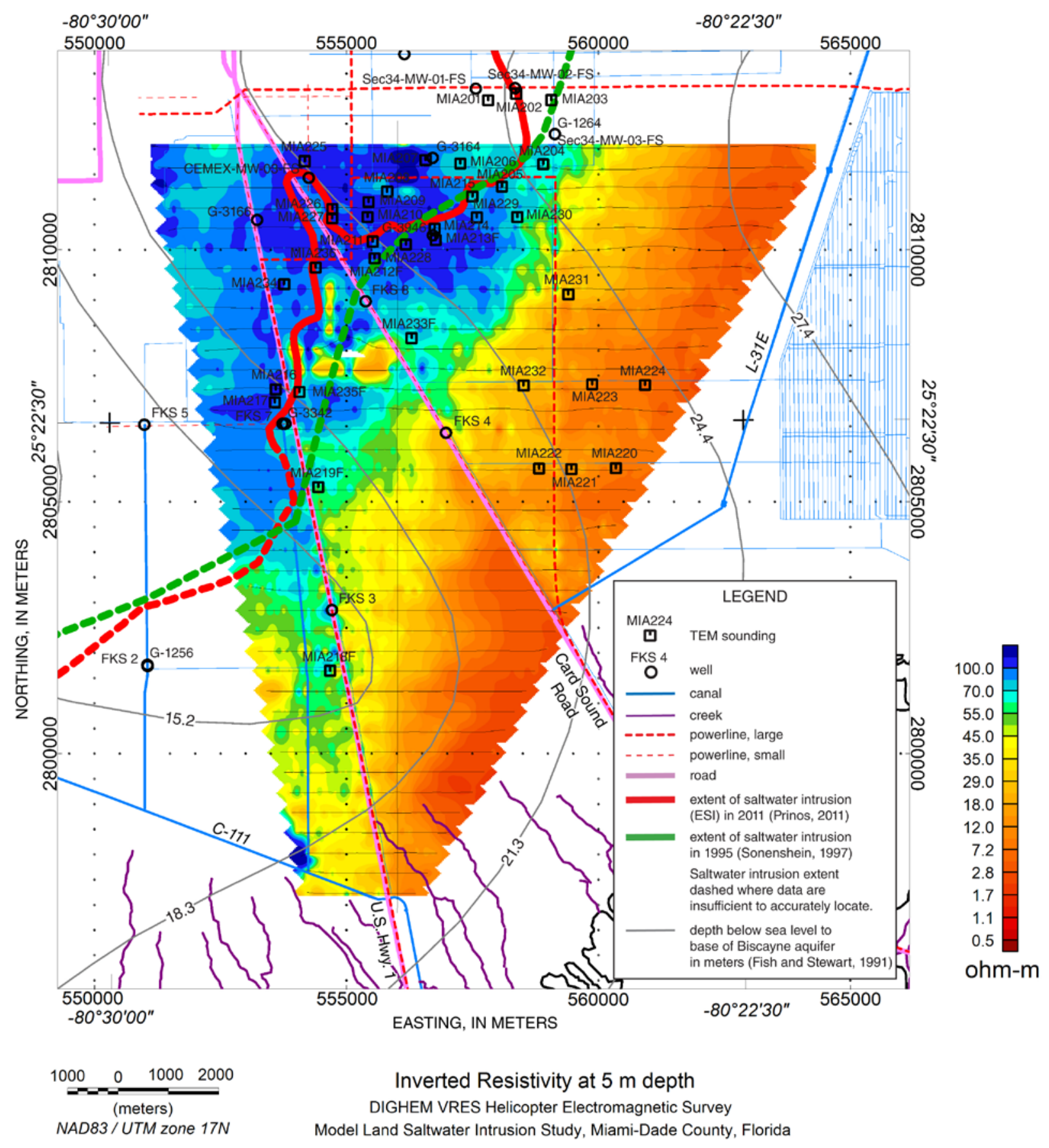

Figure 40. Model Land 5-meter depth inverted resistivity depth-slice map. Contours of the depth to the base of the Biscayne aquifer (Fish and Stewart, 1991) and the extent of saltwater intrusion (Sonenshein, 1997; Prinos, 2011) are shown. 


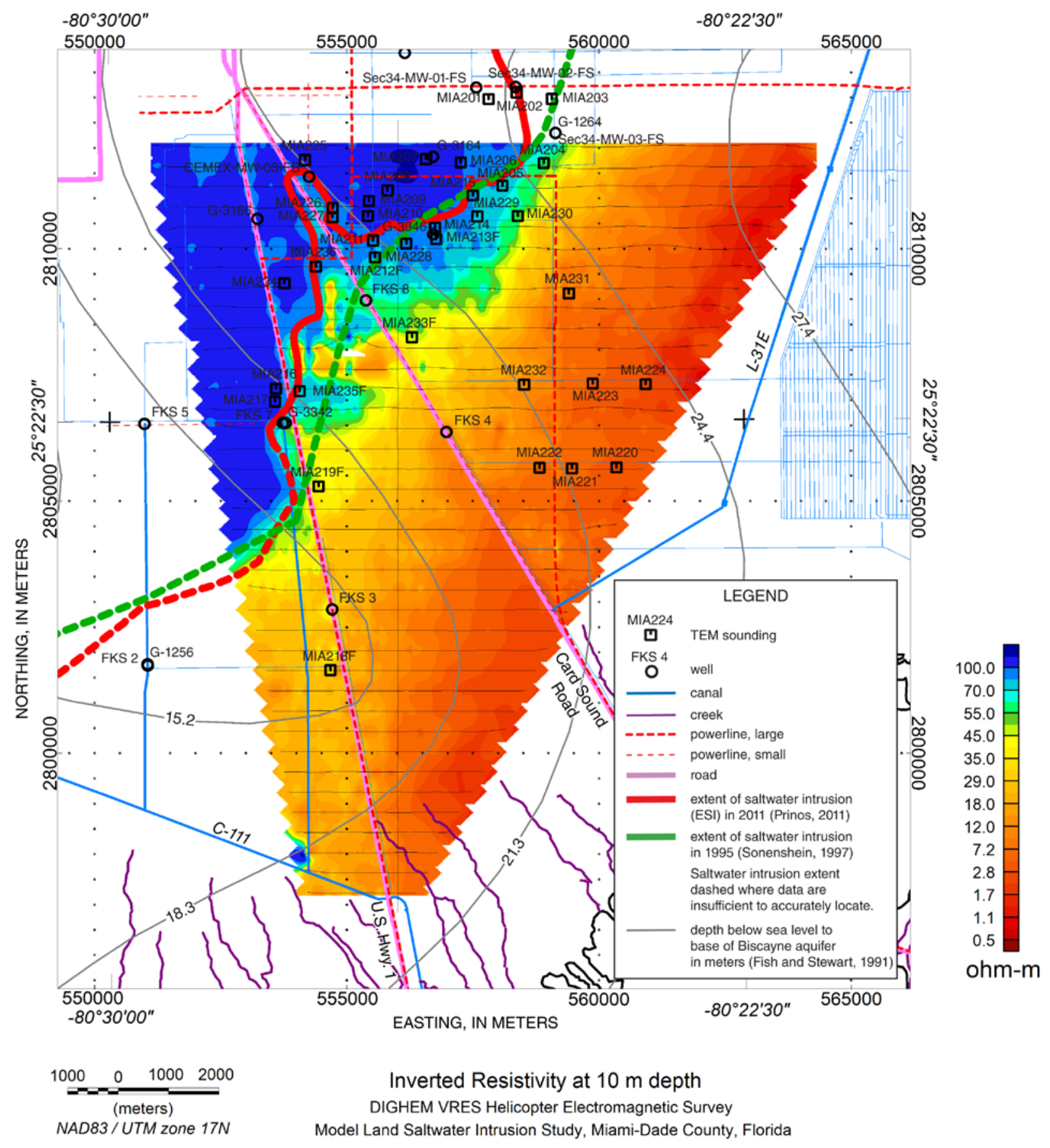

Figure 41. Model Land 10-meter depth inverted resistivity depth-slice map. 


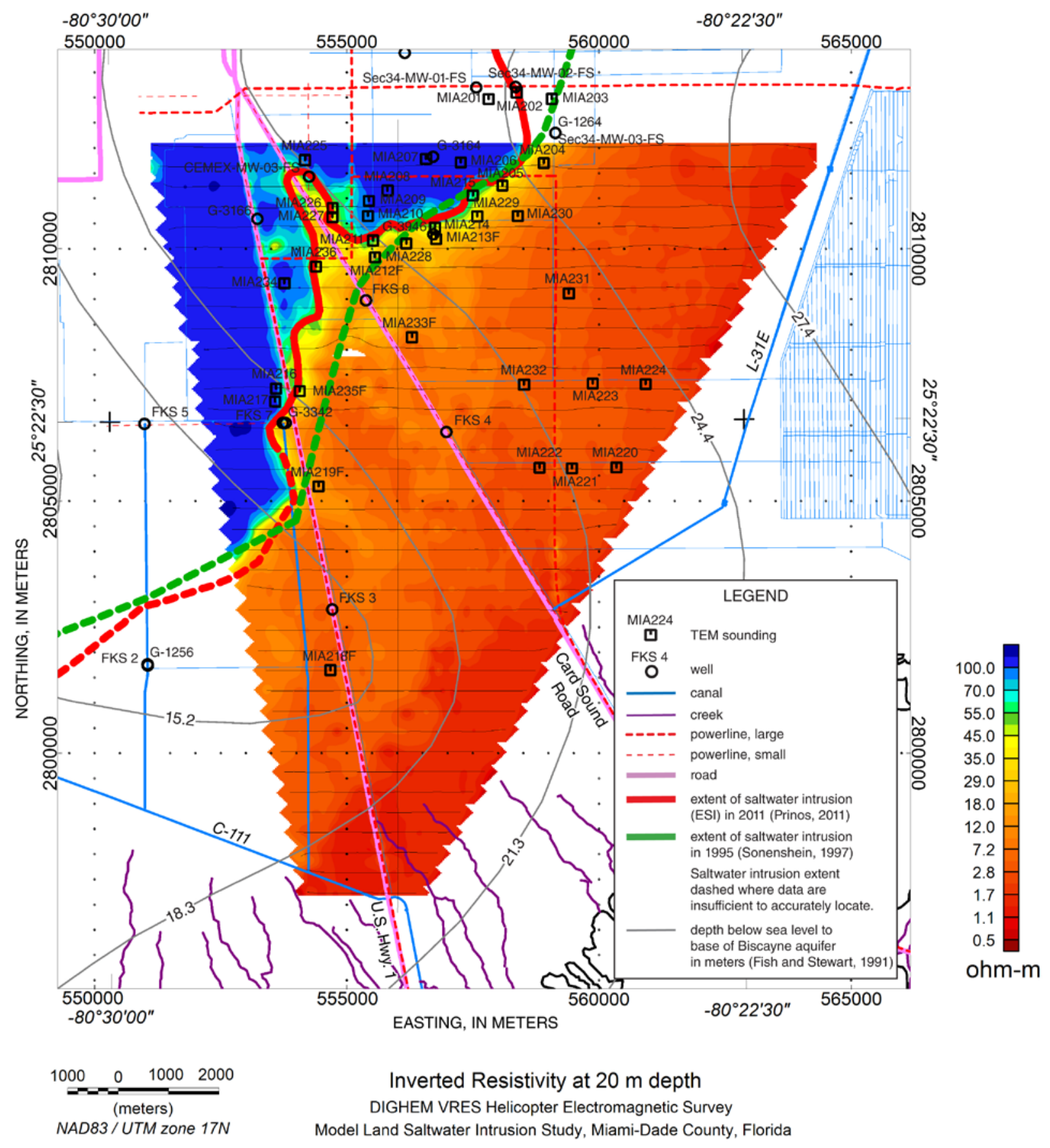

Figure 42. Model Land 20-meter depth inverted resistivity depth-slice map. 


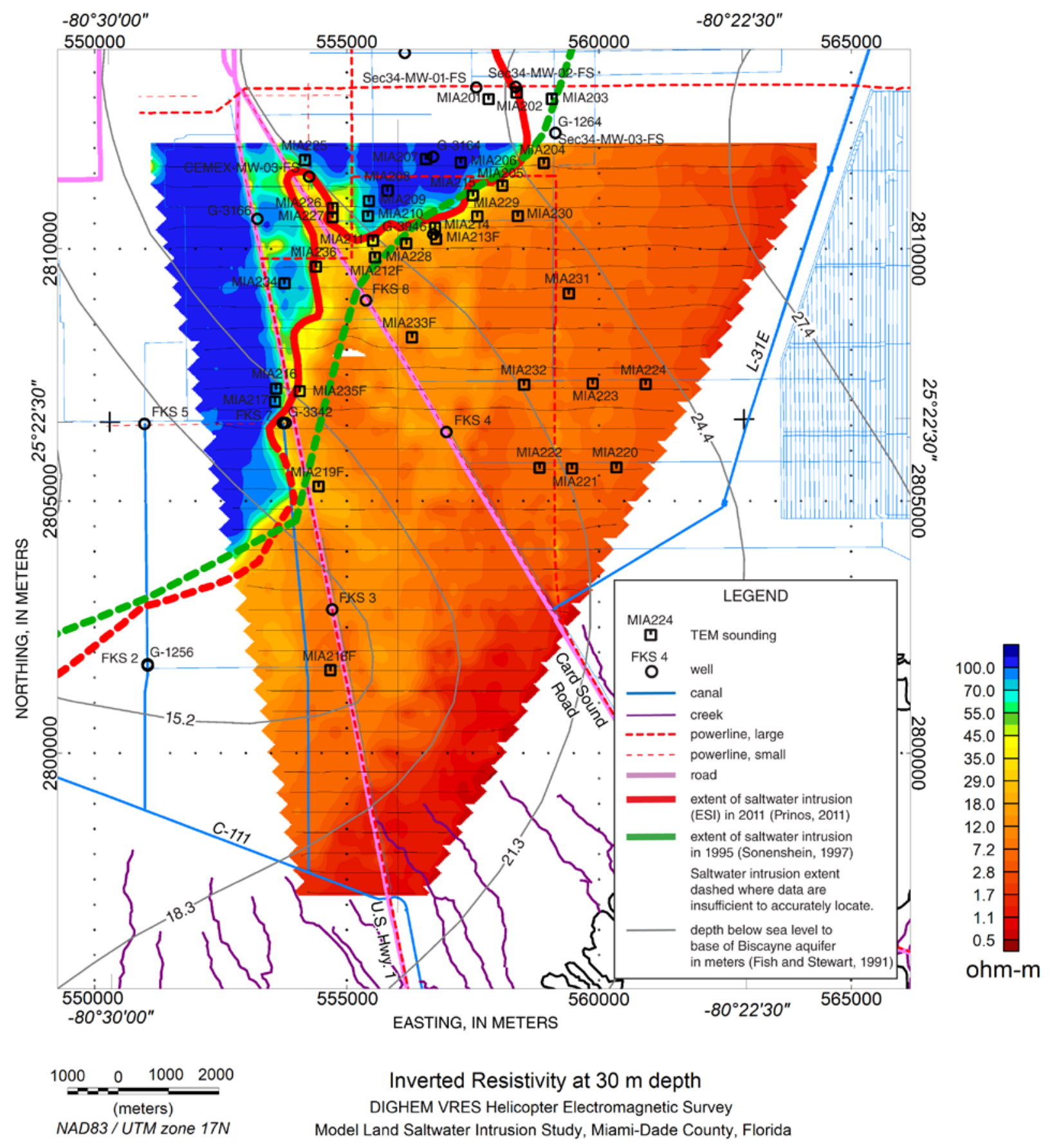

Figure 43. Model Land 30-meter depth inverted resistivity depth-slice map. 


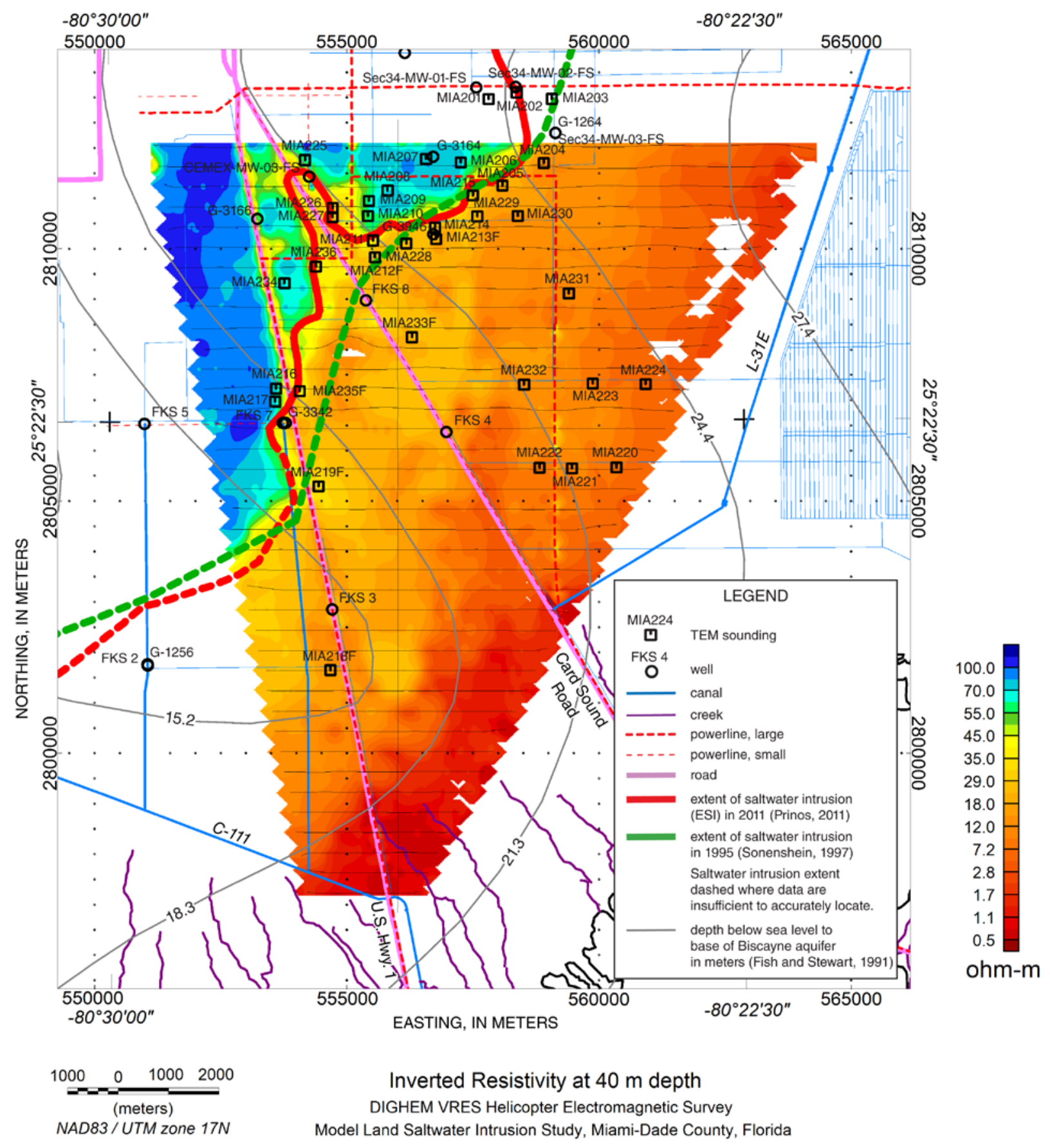

Figure 44. Model Land 40-meter depth inverted resistivity depth-slice map. 


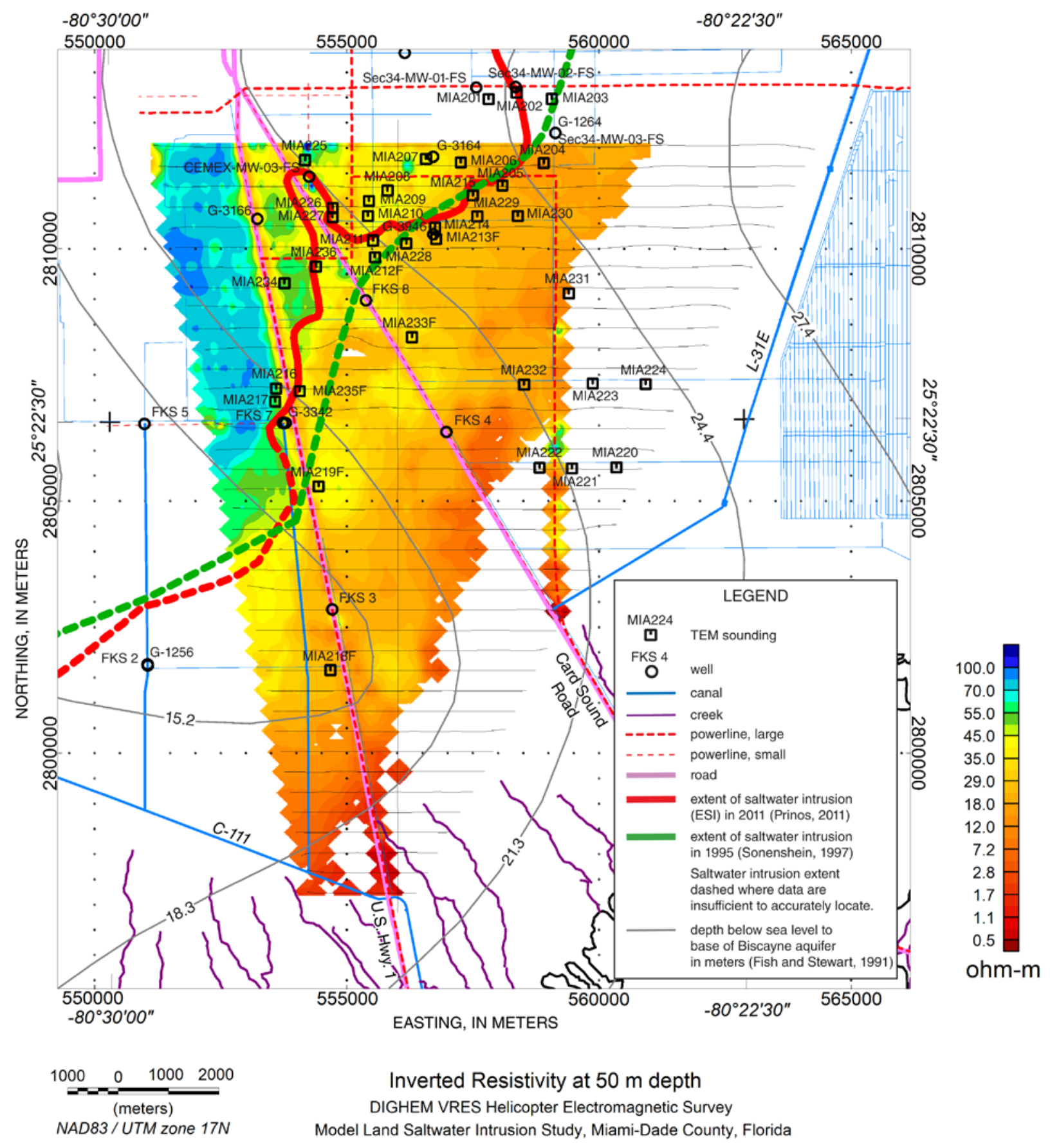

Figure 45. Model Land 50-meter depth inverted resistivity depth-slice map. 


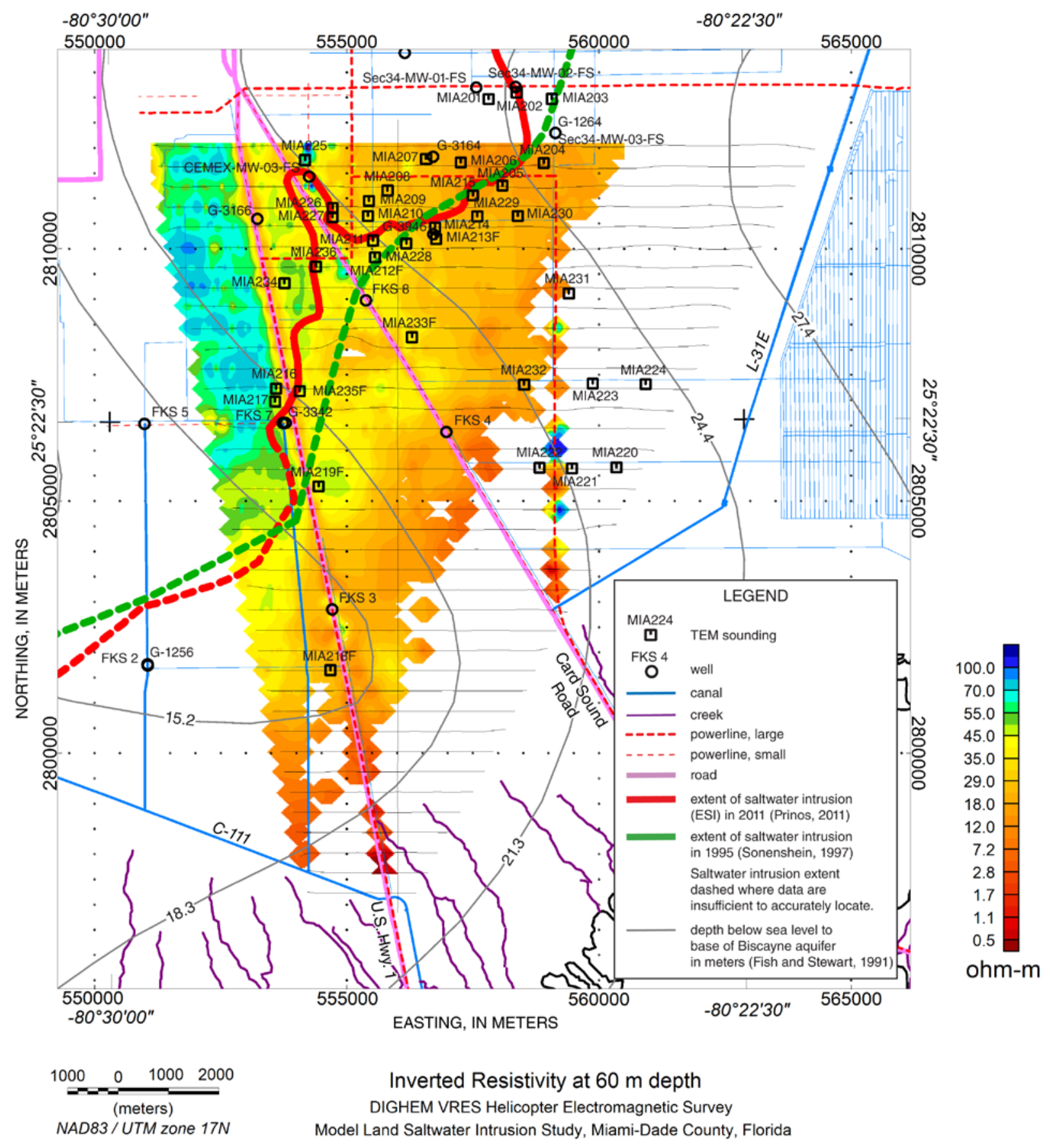

Figure 46. Model Land 60-meter depth inverted resistivity depth-slice map. 


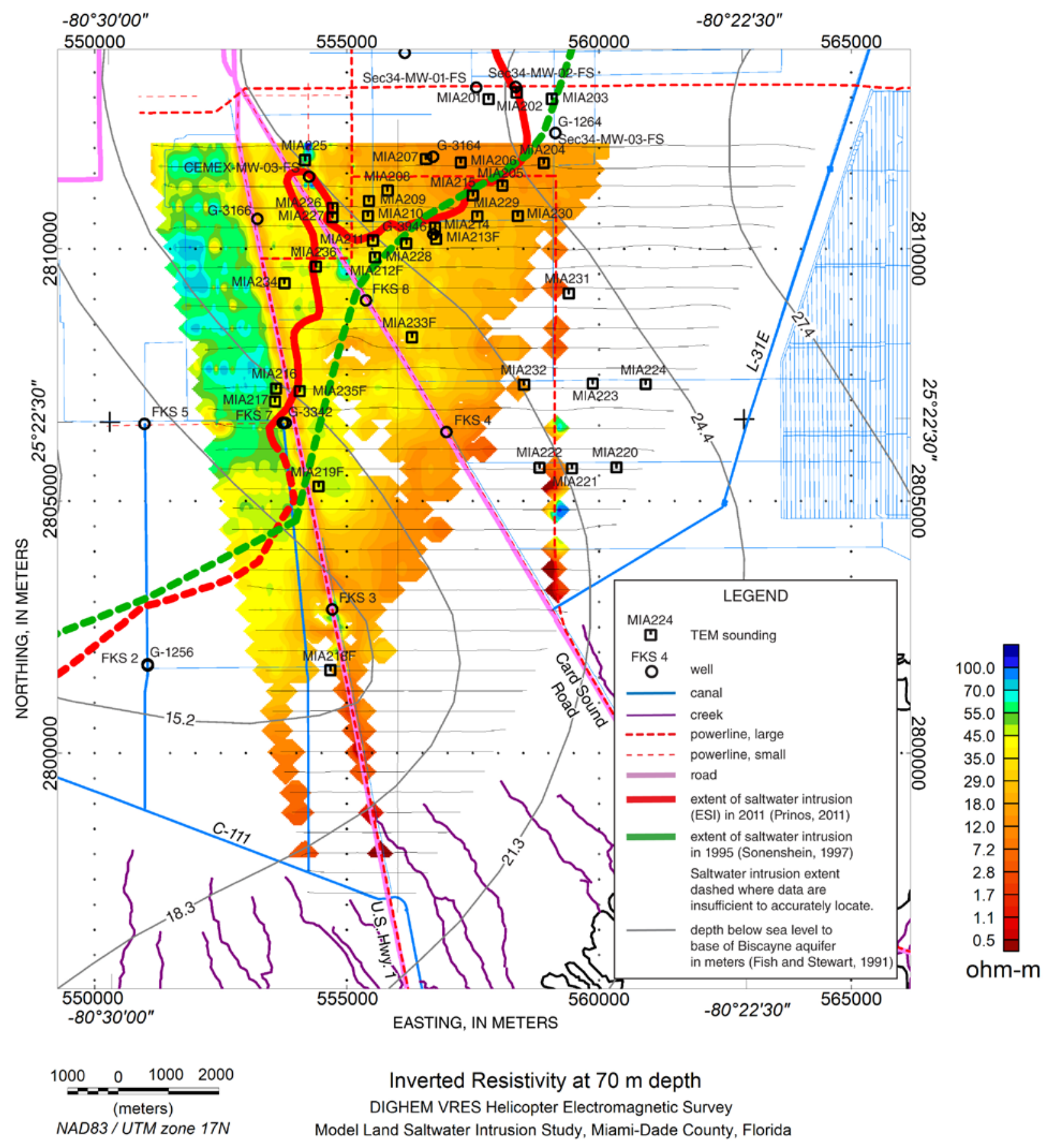

Figure 47. Model Land 70-meter depth inverted resistivity depth-slice map. 


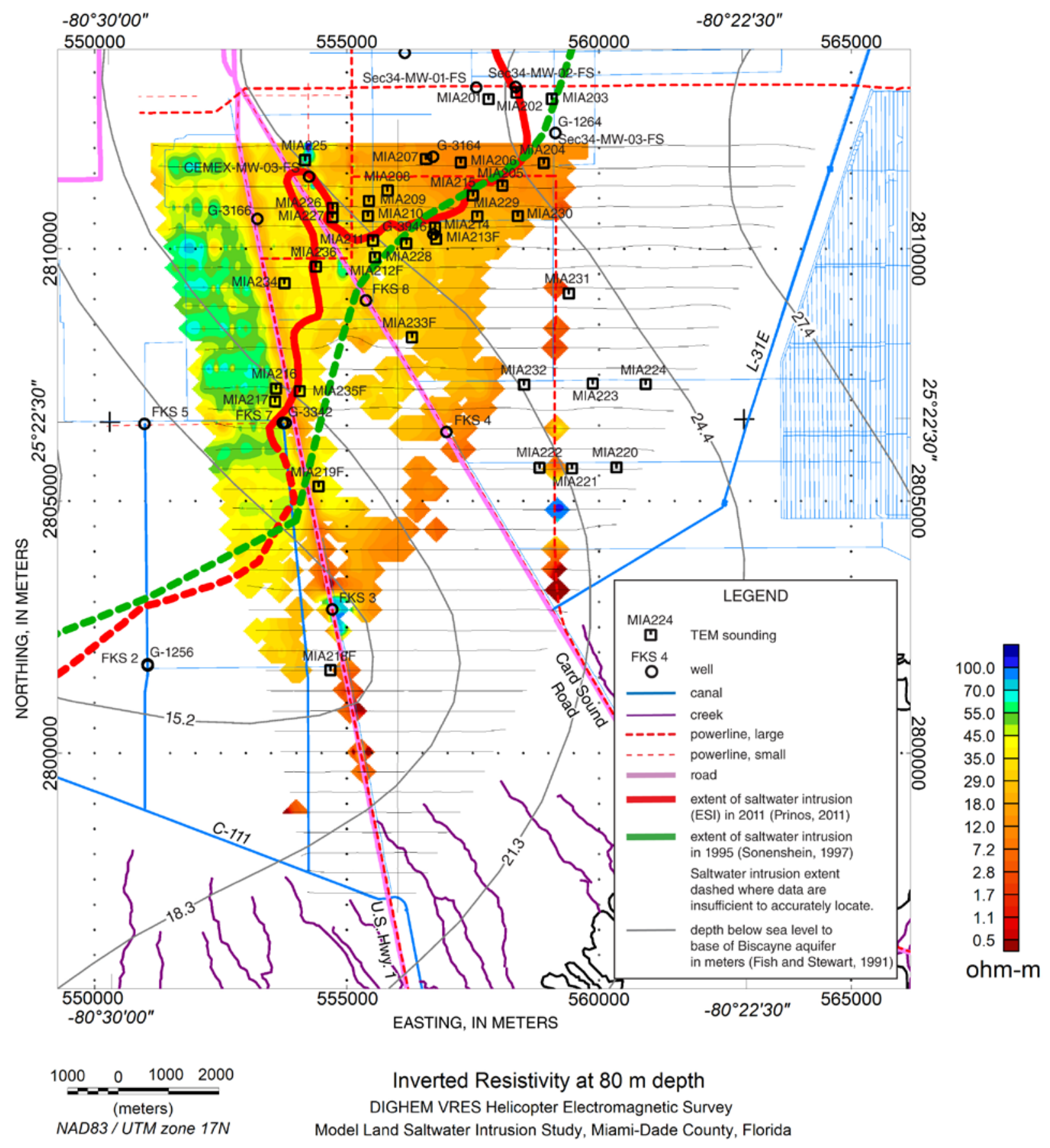

Figure 48. Model Land 80-meter depth inverted resistivity depth-slice map. 


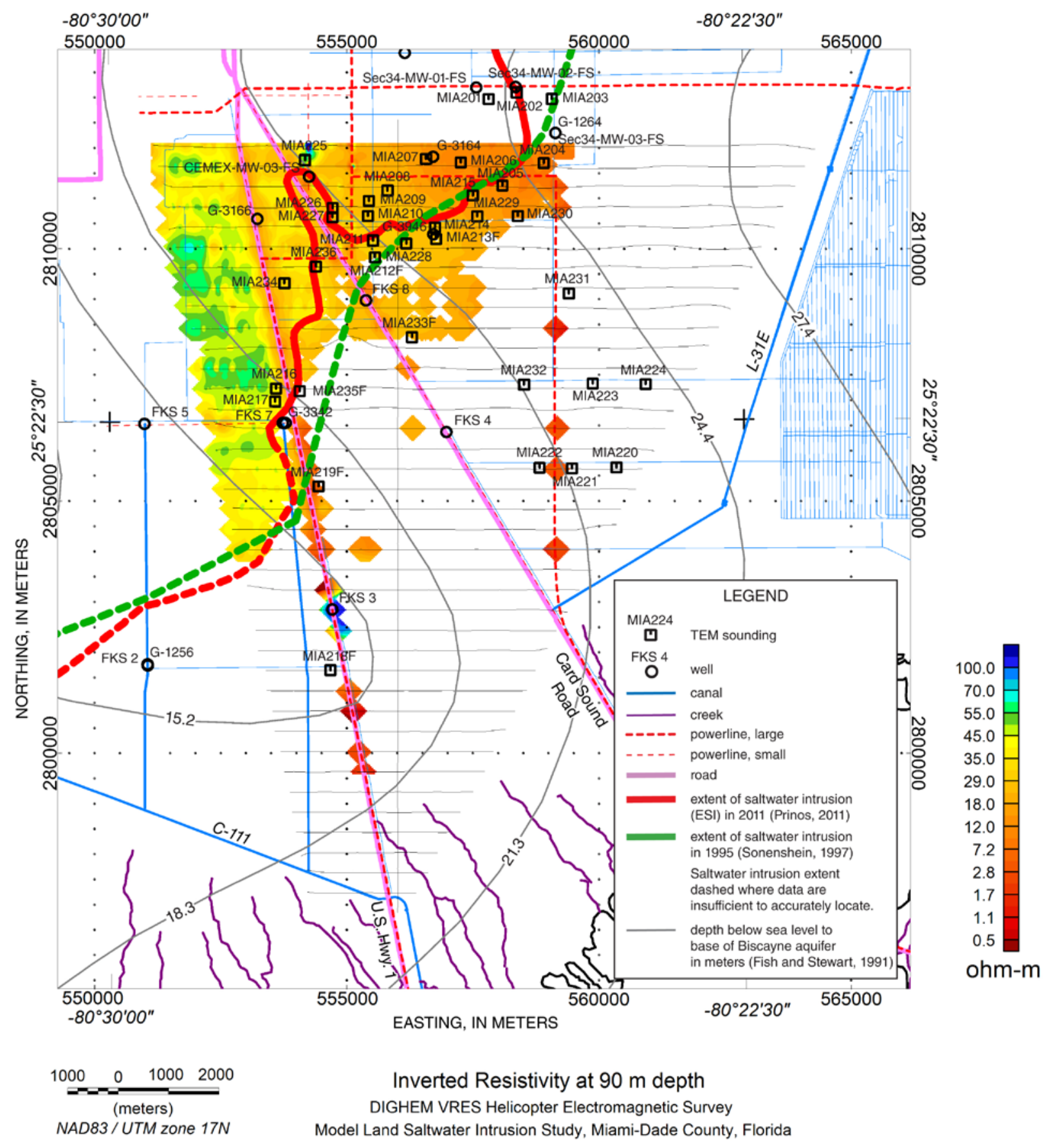

Figure 49. Model Land 90-meter depth inverted resistivity depth-slice map. 


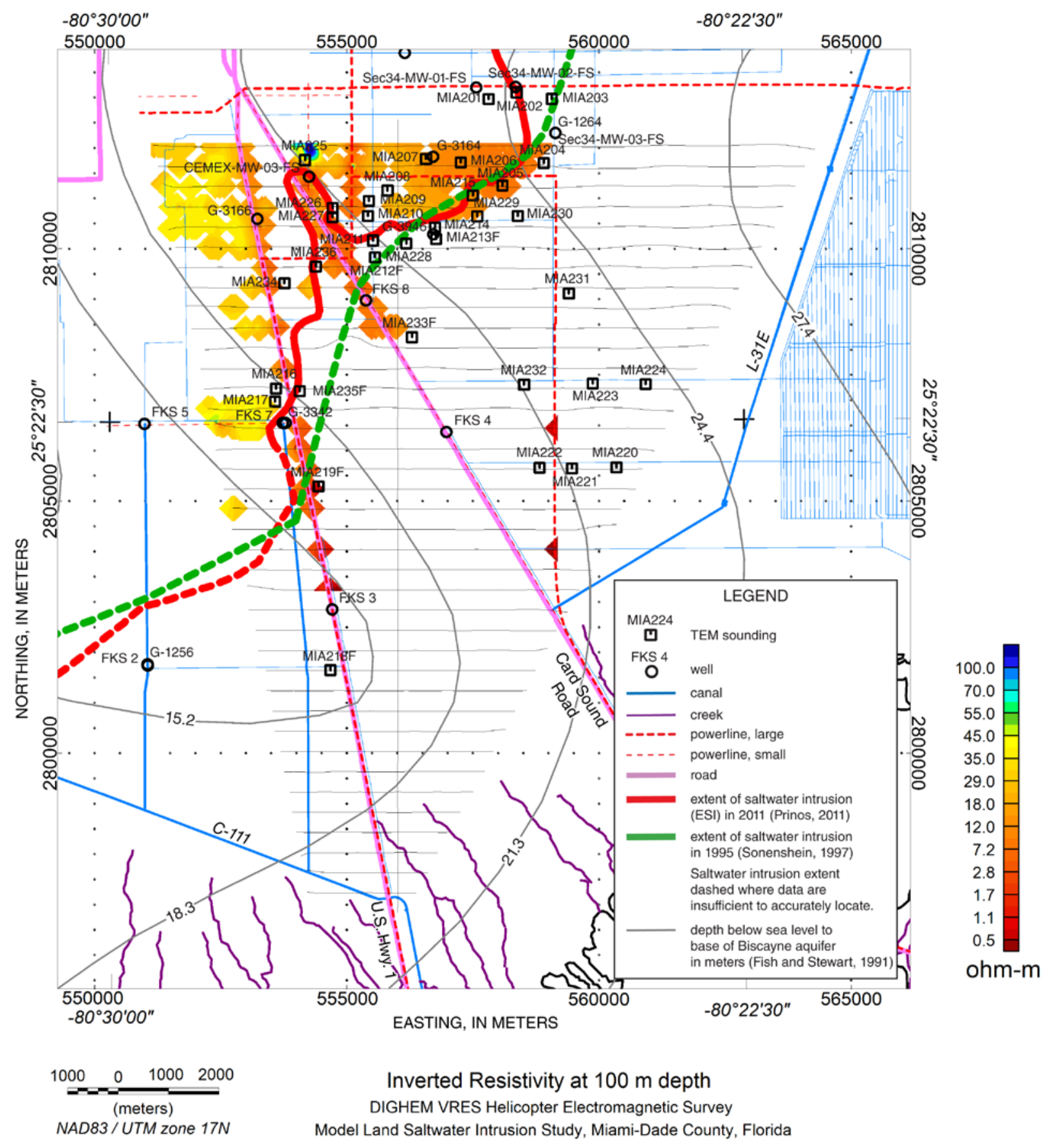

Figure 50. Model Land 100-meter depth inverted resistivity depth-slice map. 


\section{Inversion and Differential Resistivity Cross Sections}

The HEM cross sections are plotted as plates, one for each flight line. Figure 51 shows a typical plate with a description of its various elements. The top panel consists of the five differential resistivity maps including the location of the flight path displayed in the cross sections. These maps show the locations of TEM soundings, wells, roads, canals, power lines, and contours (all unlabeled) on the base of the Biscayne aquifer, as well as the ESI. The color scale for all maps and the two cross sections are the same and is found to the right of the cross sections. The symbols and colors are the same as used in the differential resistivity and depthslice maps described previously.

The small second panel shows the uncalibrated, power-line monitor amplitude. The amplitude increases near power lines, which indicates increased noise in the data. The third an fourth panels are the differential- and inverted-resistivity cross sections, respectively. The trace above the cross sections is the HEM bird altitude. Increases in altitude usually occurred when power lines were crossed or at the end of flight lines. Increased altitude reduces the electromagnetic response of the ground. Increased bird altitude combined with increased electromagnetic noise makes inversion results less reliable. In the cross sections, there are two nearly horizontal gray lines. The solid line is the base of the Biscayne aquifer, and the dashed line is the base of the surficial aquifer system from Fish and Stewart (1991). Fish and Stewart could not identify the base of the surficial aquifer system at distances greater than about $5 \mathrm{~km}$ south of Florida City (Fish and Stewart, 1991, p. 35, fig. 13). Thus, the base is not shown on cross sections south of line 30110 . Also shown on the cross sections are color coded resistivitydepth models from TEM soundings and induction logs. These are included if a sounding or well is within $300 \mathrm{~m}$ of the flight line.

The bottom two panels of the plate show strip maps of the flight path overlain on an orthophoto and digital raster graph (DRG) of the 1:24,000 topographic maps. TEM soundings and wells are marked on the maps as well as the locations of roads, canals, power lines, and the ESI. To the right of the strip maps are orthophoto and DRG maps showing all of the flight lines with the cross section location highlighted.

The cross section from flight line 30080 (fig. 51) is typical for this survey. There is a low resistivity zone on the eastern third of the line in the direction of the ocean. Moving to the west, a thin, high-resistivity surface layer is seen in the middle third of the flight line. The western third of the line has a pronounced deepening of the high-resistivity zone. As the depth section becomes more resistive, the DOI increases, because attenuation of the EM signal is less in highresistivity materials. Two TEM soundings and one induction log are shown on this cross section. In general, the correspondence between the differential- and inverted-resistivity cross sections is good. The differential-resistivity cross sections tend to be smoother than the inverted-resistivity cross sections. This is because the differential cross section is an interpolation between five points, whereas the inverted-resistivity cross section has many layers with resistivity discontinuities between layers. Also, the differential-resistivity cross sections appear to extend to greater depth because no DOI criterion is applied to the results. The pseudodepths are shallower in conductive areas because the electromagnetic energy can not diffuse as deeply as in resistive areas. The differential-resistivity cross sections reflect this fact with the bottom of the model deepening in the freshwater saturated, landward direction. 


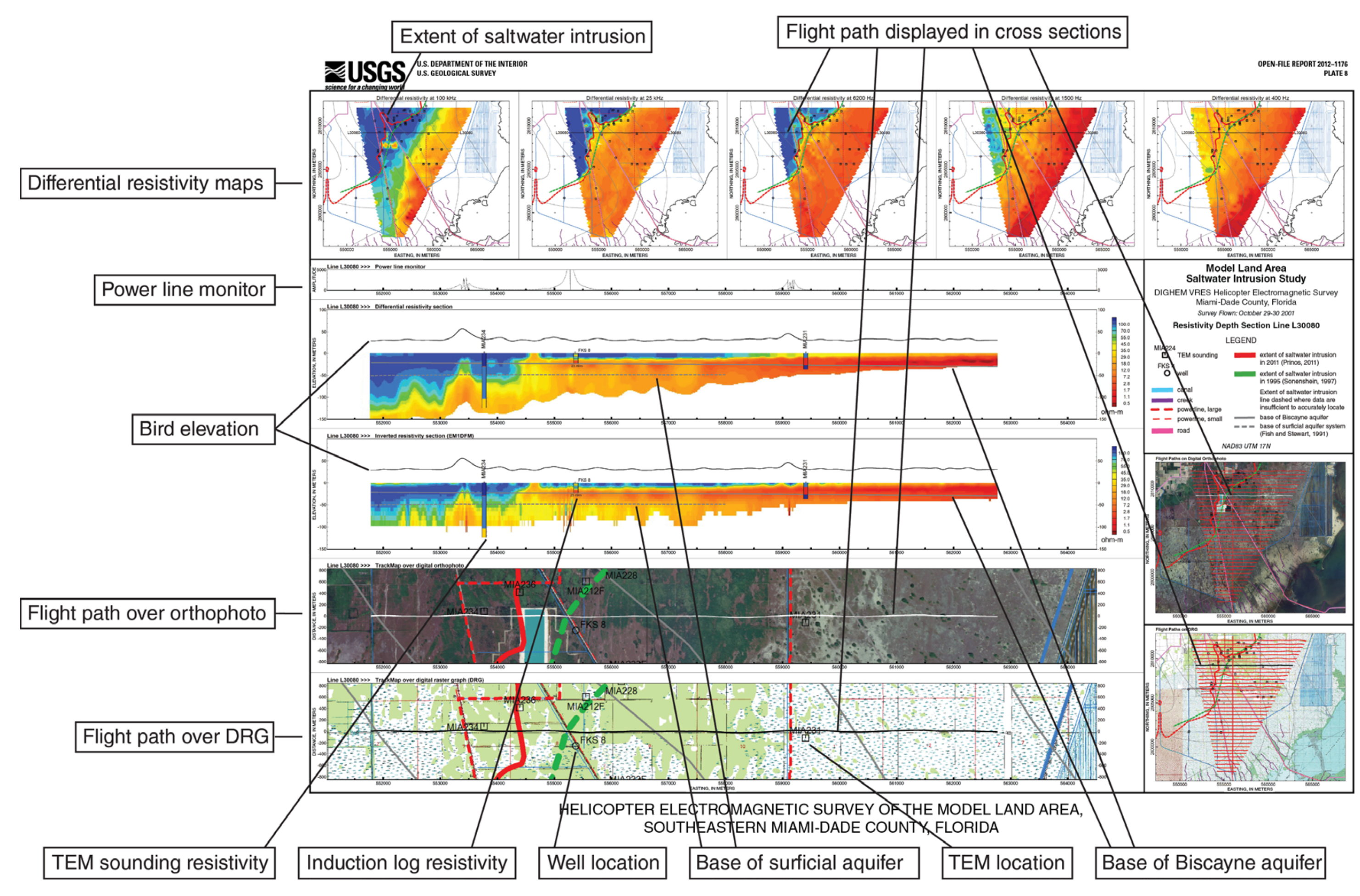

Figure 51. Description of HEM resistivity cross sections. The top panel contains five differential resistivity maps, one for each measurement frequency. Each map shows the flight line (black line) displayed in the cross sections below. All flight lines are shown as red lines in the digital orthophoto and digital raster graph (DRG) maps at the lower right. The second panel is the uncalibrated amplitude of the power-line monitor. Values increase when the HEM bird is near a power line. The third and fourth panels are resistivity cross sections. The upper cross section is derived from the differential-resistivity analysis, and the lower cross section is the produced by the EM1DFM inversion. The bird

elevation is shown as a black trace above both cross sections. Interpreted resistivity depth from TEM soundings and induction-log resistivity is shown as color-coded columns. Soundings and well logs are no more than $300 \mathrm{~m}$ from the flight line if displayed in the cross section. The color scale for the cross sections and differential resistivity maps is shown to the right of the cross sections. The fifth and sixth panels are orthophoto and DRG strip maps, respectively, that show the locations of the flight line, TEM soundings, and wells. Also shown are canals, power lines, roads, and the extent of saltwater intrusion. 
There are 39 cross sections included with this report. All are oriented east-west with the exception of tie line 39010, which runs north-south through the middle of the survey. We have divided the cross sections into five groups that have similar features. The groups, which form east-west bands across the survey area, are described below.

The descriptions below refer to the inverted-resistivity cross sections unless otherwise noted.

\section{Description of Inversion Results: Flight Lines 30010 Through 30060}

This group of flight lines covers the northern $2 \mathrm{~km}$ of the survey area. In this area, the ESI goes from a north-south orientation to a more east-west orientation, and it includes the tongue of saltwater intrusion that aligns with Card Sound Road ${ }^{6}$. The western $7 \mathrm{~km}$ of the first line (30010) is landward of the ESI. Near 558600 E (UTM easting), the flight line crosses the ESI. The inverted resistivity over the western part of the line has a high resistivity (greater than $100 \mathrm{ohm}-\mathrm{m}$ ), which is indicative of freshwater saturation for the full thickness of the Biscayne aquifer and most of the surficial aquifer. Near $558600 \mathrm{E}$ the high-resistivity zone becomes thinner, eventually disappearing about $2 \mathrm{~km}$ farther east. This transitional pattern is mimicked through line 30040 , which is $1.2 \mathrm{~km}$ to the south. From the transition to the eastern edge of the survey, a very low resistivity (less than $10 \mathrm{ohm}-\mathrm{m}$ ) zone extends through the base of the Biscayne aquifer. The resistivity transition is in agreement with the results of TEM sounding MIA204 (see fig. 24d).

Power-line monitor anomalies are noted near $554200 \mathrm{E}$ and $555100 \mathrm{E}$, but only the latter anomaly has an associated bird-altitude anomaly; this indicates that the power-line towers were small.

Where the flight line crosses U.S. Highway 1 and Card Sound Road, the conductive lower layer becomes shallower. The absence of a power-line anomaly at these locations suggests that the anomalies are real and not artifacts of electromagnetic noise or bird altitude. This anomaly is seen on line 30010 near $552875 \mathrm{E}$ and moves eastward on line 30060 to $553250 \mathrm{E}$. The source of this anomaly is probably relict saltwater and is discussed in the "Interpretation of Results" section of this report. South of line 30060 the presence of a power-line anomaly along U.S. Highway 1 makes determination of the cause of a similar conductive anomaly more tenuous.

Going from line 30040 to 30060 , the flight line moves from the landward to the seaward side of the ESI between $554700 \mathrm{E}$ and $557000 \mathrm{E}$. The resistivity cross sections reflect this fact: The zone above the base of Biscayne aquifer becomes conductive in this interval.

\section{Description of Inversion Results: Flight Lines 30070 Through 30130}

The second tier of cross sections is centered around the CEMEX quarry near $555000 \mathrm{E}$. The western 1-2 km of these lines are over the freshwater-saturated Biscayne aquifer, as indicated by a resistivity of over $75 \mathrm{ohm}-\mathrm{m}$. The middle $3-4.5 \mathrm{~km}$ of the profiles has a thin freshwater-saturated zone with a thickness of $15 \mathrm{~m}$ or less. This freshwater zone overlays a conductive zone at the base of the Biscayne aquifer with a resistivity of $10 \mathrm{ohm}-\mathrm{m}$ or less; this is indicative of the presence of saltwater. The first line in this block is north of the CEMEX quarry. On this flight line, there is no anomaly in the upper $15 \mathrm{~m}$, as the bird passes through eastings corresponding to the quarry. Line 30080 goes across the quarry as seen in the orthophoto strip

\footnotetext{
${ }^{6}$ Locations of roads and canals mentioned in this section can be found in figure 2 .
} 
map, and the conductive zone rises up to the surface. The inverted resistivity from the surface to about $10 \mathrm{~m}$ depth going across the quarry pits is approximately $20 \mathrm{ohm}-\mathrm{m}$, which is a factor of 4 to 5 less than in the areas adjoining the pits. The resistivity jump is due to the porosity increasing to 100 percent in the pit (due to an absence of rock). Based on the relationship between water resistivity and chloride content for Biscayne aquifer waters (see fig. 4), the water in the pit is fresh with an estimated chloride content of $60 \mathrm{ppm}$.

Comparison of the HEM interpretation for lines 30070 through 30110 with nearby TEM soundings is very good (see figs. 30 through 34). On the west end of line 30130 the comparison between the HEM and TEM interpretations is not as good (figs. 35a and 35b). Looking at the strip maps in Plate 13 a power line can be seen just east of soundings MIA216 and MIA217 along U.S. Highway 1 . The bird-altitude trace has almost a 30-m deflection. The power-line monitor amplitude, however, is not as large as seen in other locations. Fitterman and Prinos (2011, fig. 9) compare soundings MIA216, MIA217, and MIA235F with the induction log from well FKS-7. The TEM data show a thin conductive zone that is likely caused by saline water at the base of the Biscayne. The well was not deep enough to establish the depth, thickness, and resistivity of the conductive layer from the well log. The HEM result does not show this feature either because it is too thin for the HEM data to resolve or because of power-line noise in the data. Nonetheless, the HEM interpretations show the conductive basement zone becoming shallower under the roadway, suggesting that the anomaly seen in the northern group of flight lines persists to the south.

Power-line anomalies are also seen in the bird altitude and power-line monitor traces at Card Sound Road (556500 E) and SW 137th Avenue (559200 E). The inverted resistivities do not appear to be influenced by the presence of the power lines.

\section{Description of Inversion Results: Flight Lines 30140 Through 30210}

In this group of flight lines, the ESI runs roughly north-south and crosses about 1.2 to $1.5 \mathrm{~km}$ from the western end of the flight lines. The eastern $3.5 \mathrm{~km}$ of all lines are very conductive (less than 10-15 ohm-m) in the first 10 to $20 \mathrm{~m}$. The remaining western portion of the lines has a moderately to highly resistive $(45-100 \mathrm{ohm}-\mathrm{m})$ surface layer that varies in thickness from 5 to $20 \mathrm{~m}$. This layer becomes thicker to the west. The western end of the lines is accompanied by a pronounced thickening of the resistive surface unit as the ESI is crossed.

Starting on line 30200 and continuing southward the resistive surface layer is thicker on the west side (greater than $10 \mathrm{~m}$ ) of U.S. Highway 1 than on the east side ( 5 to $7.5 \mathrm{~m}$ ). The surface layer is more resistive to the west of the highway by a factor of 2, suggesting that the presence of the road affects the water quality in the near surface. Possible explanations of this effect will be discussed below.

Two power-line anomalies are observed: the first at U.S. Highway 1, and the second at SW 137th Avenue. Both are characterized by an increase in altitude and power-line monitor level. A third, smaller power-line monitor anomaly is seen at Card Sound Road, and there is no corresponding altitude anomaly. The first two power-line anomalies produce vertical striping in the inversion results, whereas the third anomaly does not.

\section{Description of Inversion Results: Flight Lines 30220 Through 30290}

This tier of flight lines lies completely seaward of the ESI. The eastern third to half of these cross sections is very conductive from the surface to below the base of the Biscayne aquifer. The western portions of the lines are very conductive near the base of the Biscayne and 
then become slightly less conductive at depth. This agrees with Fish and Stewart (1991) who presented well information showing that freshwater is found in the base of the surficial aquifer, which is separated from the Biscayne aquifer by a semiconfining unit. This pattern of higher resistivity in the surficial aquifer is very clear in lines 30230 through 30280 and is more pronounced to the west of U.S. Highway 1.

The most southern TEM sounding (MIA218F) agrees quite well with the HEM inversion (see fig. 39a for a detailed comparison).

The SW 137th Avenue power-line anomaly continues from flight line 30220 through flight line 30240 at easting $559100 \mathrm{E}$.

\section{Description of Inversion Results: Flight Lines 30300 Through 30380}

This flight-line tier contains the most southerly eight lines of the survey. The most characteristic feature is the thin, moderately resistive, near-surface layer on the west side of U.S. Highway 1 . This feature ends close to the bird altitude anomaly associated with the power line that is adjacent the road. This layer is no more than $10 \mathrm{~m}$ thick and has a resistivity in the range of 20 to $70 \mathrm{ohm}-\mathrm{m}$, becoming less resistive to the south. At depth the inverted resistivity is very low (1-12 ohm-m), and it decreases to the south. Some striping of the inversion result is seen as the U.S. Highway 1 power line is crossed.

\section{Description of Inversion Results: Flight Line 39010}

Line 39010 is the only north-south flight line. It was flown as a tie line to help in removing errors produced by instrumental drift. Going from south to north there is a gradual increase in resistivity throughout the section as distance from the coast increases. The southernmost $2.5 \mathrm{~km}$ is highly conductive all the way to the surface. North of northing 2802000 $\mathrm{N}$, a high-resistivity surface layer appears that becomes increasingly thicker to the north. At northing $2810400 \mathrm{~N}$, the resistive surface layer dramatically thickens as the interface between the invading saltwater and the freshwater is crossed. To the south of the ESI, the freshwater extends halfway through the Biscayne aquifer, whereas to the north of the ESI, it extends below the base of the surficial aquifer.

\section{Interpretation of Results}

The HEM data give a very detailed picture of the subsurface resistivity structure, which can be related to water quality, thereby mapping the extent of saltwater intrusion. In general, the ESI is controlled by the balance of freshwater and saltwater heads and flows in the aquifer. Prior to the construction of drainage canals in Miami-Dade County, water levels were likely sufficient to prevent saltwater encroachment (Parker and others, 1955); however, as canals were constructed to drain the land for development, the balance of fresh and saltwater in the HEM survey area was disrupted. In addition to the canals, borrow ditches were dug to obtain building material for train grades and roadways that crossed marsh land. These features radically altered the hydrology of Miami-Dade County and the study area. The increased drainage has resulted in the potential for groundwater levels to decline below sea level in the study area, particularly during droughts.

The effect of canals on the encroachment of seawater into the Biscayne aquifer has been documented by Parker and others (1955), who review the history of saltwater intrusion in south Florida going back to 1907 . While most of Parker and others' work is concerned with the area 
from Miami northward, they include a discussion of saltwater intrusion in the Homestead area. Figure 52 shows a map of canals and chloride data collected in 1941 and 1945 (Parker and others, 1955, fig. 188). All of the canals shown in the figure were uncontrolled at that time, except for the North and Florida City Canals. Freshwater in the area had chloride levels of 20 ppm or less. Chloride data collected in 1941 show very elevated chloride values near the coast with values decreasing in the landward direction.

Until 1944, the route of U.S. Highway 1 was along the present day alignment of Card Sound Road. The 1941 chloride-content data show sampled values that decreased with increasing distance from the coast. The area experienced a severe drought in 1945 when the water table was below sea level in many places. Chloride data from this period have values in excess of those of seawater as far inland as Florida City (see fig. 52). At high tide, seawater flowed up the uncontrolled canal toward Florida City and infiltrated the ground.

Evapotransporation increased the chloride concentration to levels exceeding those of seawater. Subsequent infiltration of freshwater from rain events flushed the salt downward to the base of the Biscayne aquifer.

During the drought of 1971, water levels in the southern half of Miami-Dade County again declined to below sea level (Meyer, 1974, p. 23). It is likely that saltwater once again flowed inland along the unregulated Card Sound Road Canal and U.S. Highway 1 borrow ditches. Another unusually dry period occurred in 2009 during the current study. Data from groundwater-monitoring stations indicate that by May 15, 2009, groundwater levels in this area had declined to 0.01 to $0.1 \mathrm{~m} \mathrm{NGVD29}$ (USGS, 2012). Many of the groundwater-monitoring wells in this area recorded period-of-record minimum water levels during this period. Even though groundwater levels had not declined below sea level, tides were sufficient to drive sea water up the Card Sound Road Canal at least far as $12.4 \mathrm{~km}$ inland to the location of well FKS 8 . At this location, canal salinity was measured to be $38.6 \mathrm{ppt}$ on May 18, 2009, up from freshwater values of $0.3 \mathrm{ppt}$ in December, 2008.

The effects of the landward flow of seawater facilitated by the uncontrolled canals are evident in the results of the HEM survey. In particular, the low-resistivity feature that follows Card Sound Road (see fig. 15) and brings the ESI to within $2 \mathrm{~km}$ of Florida City near the junction of Card Sound Road and U.S. Highway 1 is likely caused by: (1) the movement of seawater up the Card Sound Road Canal and (2) the reductions of freshwater head in the aquifer caused by this canal's unregulated drainage. As evidenced in the HEM survey results, saltwater occurs at shallower depths beneath the Card Sound Road Canal than it does in adjacent areas even north of the ESI line. This is likely the result of the reduction in freshwater head associated with canal drainage. Given available information, including some collected for this study, plans were developed by State, county, local, and private organizations to regulate flow in the Card Sound Road Canal. 


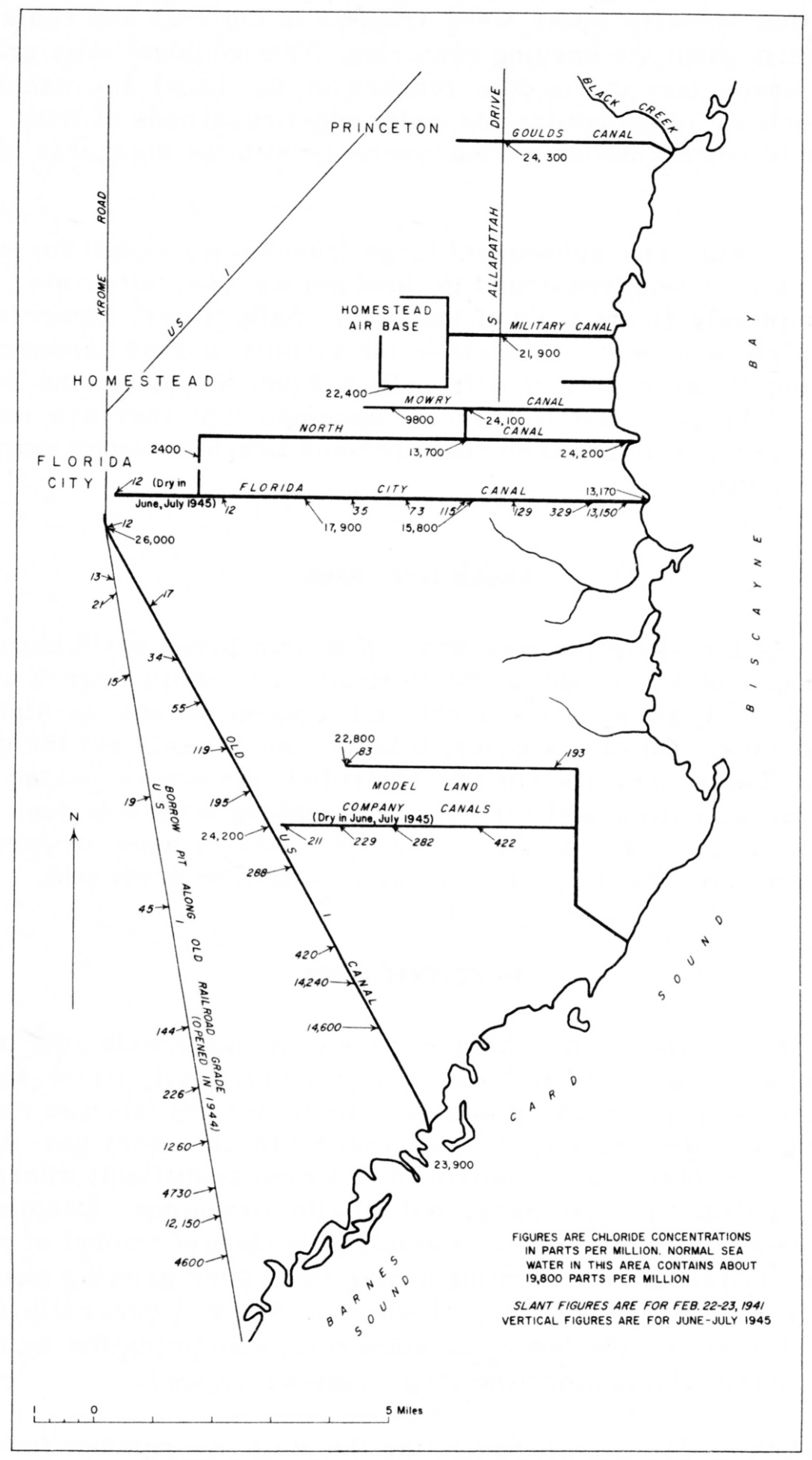

Figure 52. Map of Homestead area showing chloride concentration in canals in February, 1941, and June and July, 1945 (Parker and others, 1955, fig. 188). 
A similar, but less dramatic, low-resistivity feature is associated with U.S. Highway 1. Present day U.S. Highway 1 runs along an old railroad embankment that led to the Keys (Parker and others, 1955). Borrow ditches were dug on either side of the train grade to obtain materials needed to build it. The borrow ditch to the east of the train grade was deeper than the ditch on the west side, and the distance along it to Barnes Sound was shorter than on the west side. The ditches end about $10 \mathrm{~km}$ (6 mi) from Florida City. Chloride data, which were collected in 1941, but not in 1945, show a steady increase to the north (see fig. 52). Values indicative of saltwater contamination occur south of the canal terminus. Observations after the extreme drought of 1945 showed strong contamination at points less than $10 \mathrm{~km}$ from Florida City. This indicates that seawater moved landward beyond the reach of the ditch because of drought-produced low water levels. The resistivity low along U.S. Highway 1 in flight lines 30010 through 30100 is interpreted to be the relict saltwater that flowed along the roadway during periods of low water table.

The Card Sound Road Canal and U.S. Highway 1 appear to influence the surface and groundwater flow in the study area. In the northern half of the study area, flight lines 30020 through 30180 show that resistive materials extend to a greater depth west of U.S. Highway 1 than they do on the east side of the highway. In many instances, this transition is very abrupt. Although more detailed examinations are necessary, this observation may suggest that the eastward flow of surface and shallow groundwater is impeded or diverted southward by U.S. Highway 1, and that the triangle between U.S. Highway 1 and the Card Sound Road Canal has been isolated from this potential source of recharge. Furthermore, the direct leakage of saltwater from the Card Sound Road Canal and its uncontrolled drainage of the area could account for enhanced saltwater encroachment occurring between U.S. Highway 1 and the Card Sound Road.

Parker and others (1955) mention that mangroves, which only thrive in brackish and salty waters, are found growing $3.2 \mathrm{~km} \mathrm{(2} \mathrm{mi)} \mathrm{farther} \mathrm{north} \mathrm{on} \mathrm{the} \mathrm{east} \mathrm{side} \mathrm{of} \mathrm{U.S.} \mathrm{Highway} 1$ than on the west side. They interpret this to indicate that the differences in chloride concentration across the road are not transient conditions. The HEM data support this interpretation. From flight line 30280 southward, the near surface on the west side of the road is more resistive than on the east side of the road, in accord with the interpretation of fresher water being located to the west. While this might have originally been due to the east-side ditch being deeper and having a shorter run to the ocean as suggested by Parker and others, it is not likely to explain the present situation, as the ditches were likely filled in when the road was built in 1944. An alternative explanation is that the flow of surface water from the north was blocked from the east side of the road by the embankment formed by the roadway itself. The fresh-water inflow maintained a lower salinity on the west side, while evapotransporation on the east side increased the salinity during dry periods. Over the course of time, a salinity gradient developed across the road. A similar, though less dramatic, situation is seen across parts of Card Sound Road with the triangle of land between the two roads being more conductive.

Fish and Stewart (1991) reported that the surficial aquifer below the Biscayne aquifer contained pore water that was fresher than the pore water at the base of the Biscayne at well G-3324 near TEM sounding MIA218F. The HEM inverted resistivity depth-slice maps for depths of 20,30, and $40 \mathrm{~m}$ confirm this decrease in resistivity with depth. The region where this is seen is rather large; it falls to the northwest of a line between soundings MIA218F and MIA232 and extends northwest to the ESI line. There are slight variations in this pattern that might reflect differences in the permeability of the semiconfining unit at the base of the Biscayne aquifer. 


\section{Conclusions}

The HEM inversion results give a very good picture of the subsurface resistivity to a depth of about $50 \mathrm{~m}$ in conductive areas and to nearly $100 \mathrm{~m}$ in resistive areas. The decreased depth of investigation in conductive areas is a characteristic of frequency-domain electromagnetic methods. Through the use of relationships between formation resistivity, pore water resistivity, and pore chloride content, the HEM results can be interpreted in terms of water quality. This linkage between the geophysical resistivity model and a hydrologically significant water-quality model is essential to transforming the results into a valuable tool for hydrologic purposes. Because the spatial sampling density of the HEM data is three orders of magnitude larger than the sampling density of the wells and TEM soundings, the detail of the interpretive products generated from the HEM data is extraordinary. The extent of saltwater encroachment obtained from these data agrees nicely with well and surface geophysical results (Fitterman and Prinos, 2011). Saltwater intruded zones less than $20 \mathrm{~m}$ thick were not well resolved by the HEM data, which may be due, in part, to the inversion scheme used. The TEM soundings can resolve conductive zones as thin as a few meters at depths of 10 s of meters, a feat not possible with the HEM data. However, the resistivity of the first $5 \mathrm{~m}$ below the surface are better determined by the HEM data than the TEM data because of the shallow penetration depth of the 100-kHz HEM data. The depth of investigation of the two methods is comparable; however, the TEM data have greater vertical resolution than the HEM data, in part because of the greater number of data points at each measurement site.

One of the significant advantages of the HEM data set is the very high spatial sampling density. This survey contains nearly 100,000 data points. In contrast, well coverage is limited to 17 sites, and the number of TEM soundings is only slightly better at 36 . The images produced by the HEM data are unrivalled by other electromagnetic methods. In the right environment, HEM surveying to map saltwater intrusion is an ideal method that allows rapidly covering large tracts of land. On a unit area basis it is less expensive and faster than ground-based electromagnetic methods. It has the added advantage of usually not requiring the land owner's permission to access land. The use of an HEM survey on undeveloped land that might become the target of development should be considered so that pre-development background conditions can be determined. Should development occur, these data would be of great value in assessing, developing, and protecting groundwater resources.

The HEM method does have its drawbacks. Surveys can not be flown in urban areas due to safety restrictions concerning the carrying of sling loads. Power lines pose a problem in two regards: safety and electromagnetic noise. The helicopter must fly high enough for the bird to clear the power lines, which reduces data sensitivity. Noise from the power lines introduces uncertainty in the interpretation.

\section{Acknowledgments}

The authors gratefully acknowledge the assistance of the FPL Turkey Point security office in obtaining permission from the Federal Aviation Administration to fly the helicopter survey near the Turkey Point nuclear power plant in the days following September 11, 2001. 


\section{References Cited}

Archie, G.E., 1942, The electrical resistivity log as an aid to determining some reservoir characteristics: Transactions of the American Institute of Mining, Metallurgical, and Petroleum Engineers, v. 146, p. 54-62.

Beamish, D., 2003, Airborne EM footprints: Geophysical Prospecting, v. 51, no. 1, p. 49-60.

Brown, R.H., and Parker, G.G., 1945, Salt water encroachment in limestone at Silver Bluff, Miami, Florida: Economic Geology, v. 60, no. 4, p. 235-262.

Cunningham, K.J., Wacker, M.A., Robinson, E., Dixon, J.F., and Wingard, G.L., 2006, A cyclostratigraphic and borehole-geophysical approach to development of a three-dimensional conceptual hydrogeologic model of the karstic Biscayne aquifer, southeastern Florida: U.S. Geological Survey Scientific Investigations Report 2005-5235, 75 p. (Also available at http://pubs.usgs.gov/sir/2005/5235/.)

Cunningham, K.J., Sukop, M.C., Huang, H., Alvarez, P.F., Curran, H.A., Renken, R.A., and Dixon, J.F., 2009, Prominence of ichnologically influenced macroporosity in the karst Biscayne aquifer-Stratiform "super K" zones: Geological Society of America Bulletin, v. 121, no. 1/2, p. 164-180.

Farquharson, C.G., 2000, Background for program "EM1DFM"—-Version 1.0: Vancouver, British Columbia, University of British Columbia Geophysical Inversion Facility, 20 p.

Farquharson, C.G., Oldenburg, D.W., and Routh, P.S., 2003, Simultaneous 1D inversion of looploop electromagnetic data for magnetic susceptibility and electrical conductivity: Geophysics, v. 68 , no. 6 , p. 1857-1869.

Fish, J.E., and Stewart M., 1991, Hydrogeology of the surficial aquifer system, Dade County, Florida: U.S. Geological Survey Water-Resources Investigations Report 90-4108, 50 p, 11 sheets.

Fitterman, D.V., and Deszcz-Pan, M., 1998, Helicopter EM mapping of saltwater intrusion in Everglades National Park: Florida Exploration Geophysics, v. 29, p. 240-243. 2002, Helicopter electromagnetic data from Everglades National Park and surrounding areas-Collected 9-14 December 1994: U.S. Geological Survey Open-File Report 02-101 (on CD-ROM), $38 \mathrm{p}$.

2003, Estimating water quality along the southwest Florida coast for hydrologic models using helicopter electromagnetic surveys, in Torres, A.E., Higer, A.L., Henkel, H.S., Mixson, P.R., Eggleston, J.R., Embry, T.L., and Clement, G., eds., U.S. Geological Survey Greater Everglades Science Program-2002 Biennial Report: U.S. Geological Survey Open-File Report 03-54, p. 88-89. [Including USGS abstracts of presentations made at the Joint Science Conference on Florida Bay and Greater Everglades Ecosystem Restoration (GEER), "From Kissimmee to the Keys," April 13-18, 2003, Palm Harbor, Fla.)

Fitterman, D.V., Deszcz-Pan, M., and Stoddard, C.E., 1999, Results of time-domain electromagnetic soundings in Everglades National Park, Florida (on CD-ROM): U.S. Geological Survey Open-File Report 99-426, 152 p.

Fitterman, D., and Labson, V.F., 2005, Electromagnetic induction methods for environmental problems, in Butler, D.K., ed., Near surface geophysics, part 1-Concepts and fundamentals: Tulsa, Okla., Society of Exploration Geophysicists, p. 295-349.

Fitterman, D.V., and Prinos, S.T., 2011, Results of time-domain electromagnetic soundings in Miami-Dade and southern Broward Counties, Florida: U.S. Geological Survey Open-File Report 2011-1299, 289 p. (Also available at http://pubs.usgs.gov/of/2011/1299/.) 
Fraser, D.C., 1972, A new multicoil aerial electromagnetic prospecting system: Geophysics, v. 37 , no. 3 , p. $518-537$.

1978, Resistivity mapping with an airborne multicoil electromagnetic system:

Geophysics, v. 43, no. 1, p. 144-172.

Hoy, N.D., 1952, Two maps of Dade County, Florida, showing approximate position of the 1,000-ppm isochlor as of 1951 and approximate area of potential salt-water penetration under 1945 conditions: U.S. Geological Survey Open-File Report 52-78.

Huang, H., and Fraser, D.C., 1996, The differential parameter method for multifrequency airborne resistivity mapping: Geophysics, v. 61, no. 1, p. 100-109.

Kaufman, A.A., and Keller, G.V., 1983, Frequency and transient sounding: Amsterdam, Netherlands, Elsevier, 685 p.

Keller, G.V., and Frischknecht, F.C., 1966, Electrical methods in geophysical prospectingInternational series of monographs in electromagnetic waves: Oxford, England, Pergamon, $519 \mathrm{p}$.

Klein, H., 1957, Salt-water encroachment in Dade County, Florida: Florida Geological Survey Information Circular 9, $5 \mathrm{p}$.

, 1965, Probable effect of canal 111 on salt-water encroachment, southern Dade County, Florida: U.S. Geological Survey Open-File Report 65-085, 25 p. plus 6 figures.

Klein, Howard, and Ratzlaff, K.W., 1989, Changes in saltwater intrusion in the Biscayne aquifer, Hialeah-Miami Springs area, Dade County, Florida: U.S. Geological Survey Water-Resources Investigations Report 87-4249, 1 sheet.

Klein, Howard, and Waller, B.G., 1985, Synopsis of saltwater intrusion in Dade County, Florida, through 1984: U.S. Geological Survey Water-Resources Investigations Report 85-4101, 1 sheet.

Leach S.D., and Grantham, R.G., 1966, Salt-water study of the Miami River and its tributaries, Dade County, Florida: Florida Geological Survey Report of Investigations, no. 45, 35 p.

Meyer, F.W., 1974, Availability of ground water for the U.S. Navy well field near Florida City, Dade County, Florida: U.S. Geological Survey Open-File Report 74-1072, 50 p.

Miller, J.A., 1990, Ground water atlas of the United States - Segment 6, Alabama, Florida, Georgia, and South Carolina: U.S. Geological Survey, Hydrologic Investigations Atlas 730-G, $28 \mathrm{p}$.

National Geodetic Survey, 2012, National Geodetic Survey-Frequently asked questions: National Geodetic Survey, accessed July 18, 2012, at http://www.ngs.noaa.gov/faq.shtml.

Oldenburg, D.W., and Li, Y., 1999, Estimating depth of investigation in de resistivity and IP surveys: Geophysics, v. 64, no. 2, p. 403-416.

2005, Inversion for applied geophysics: A tutorial, in Butler, D.K., ed., Near surface geophysics, Part 1 -Concepts and fundamentals: Tulsa, Okla., Society of Exploration Geophysicists, p. 89-150.

Parker, G.G., 1945, Salt water encroachment in southern Florida: Journal of the American Water Works Association, v. 37, no. 6, p. 526-542.

Parker, G.G., Ferguson, G.E., Love, S.K., and others, 1955, Water resources of southeastern Florida, with special reference to the geology and ground water of the Miami area: U.S. Geological Survey Water-Supply Paper 1255, 965 p.

Prinos, S.T., ed., 2011, Approximate inland extent of the saltwater interface in the Biscayne aquifer in 2011, Miami-Dade County, FL: U.S. Geological Survey Arc-GIS shapefile. (Available at http://www.envirobase.usgs.gov/FLIMS/SaltFront/viewer.htm.) 
Prinos, S.T., Lietz, A.C., and Irvin, R.B., 2002, Design of a real-time ground-water level monitoring network and portrayal of hydrologic data in southern Florida: U.S. Geological Survey Water-Resources Investigation Report 01-4275, 108 p.

Sengpiel, K.P., 1988, Approximate inversion of airborne EM data from a multilayered ground: Geophysical Prospecting, v. 36, p. 446-459.

Sonenshein, R.S., 1997, Delineation and extent of saltwater intrusion in the Biscayne aquifer, eastern Dade County, Florida 1995: U.S. Geological Survey Water-Resources Investigation Report 96-4285, 1 sheet.

Sonenshein, R.S., and Koszalka, E.J., 1996, Trends in water-table altitude (1984-1993) and saltwater intrusion (1974-1993) in the Biscayne aquifer, Dade County, Florida: U.S. Geological Survey Open-File Report 95-705, 2 sheets.

Swayze, L.J., 1980, Water-level contour and salt front map, Hialeah-Miami Springs well field area, Dade County, Florida, October 13, 1978: U.S. Geological Survey Open-File Report 80-8, 1 sheet.

UBC Geophysical Inversion Facility, 2000, Background for program "EM1DFM"_-Version 1.0: Vancouver, British Columbia, University of British Columbia, Department of Earth \& Ocean Sciences, $20 \mathrm{p}$.

U.S. Geological Survey, 2012, Annual water data reports: U.S. Geological Survey, accessed July 18, 2012 at http://wdr.water.usgs.gov/.

Wait, J.R., 1951, Oscillating magnetic dipole over a horizontally stratified earth: Canadian Journal of Physics, v. 29, p. 577-592. 1955, Mutual electromagnetic coupling of loops over a homogeneous ground:

Geophysics, v. 20, no. 3, p. 630-637. 1982, Geo-electromagnetism: New York, N.Y., Academic Press, 268 p. 


\section{Appendix 1: EM1DFM Inversion Parameters}

Program EM1DFM was used for inverting the HEM data (Farquharson, 2000). The operation of this program is controlled through a large set of parameters, which are described in detail in the software documentation (UBC Geophysical Inversion Facility, 2000). The purpose of this appendix is not to duplicate that documentation, but simply to indicate the specific inversion parameters used in obtaining the results described in this report.

Inversion used a one-dimensional (1-D) model with 28 layers of fixed thicknesses, as specified in table $1-1$.

Table 1-1. Inversion layer thicknesses and depth to top of layers.

\begin{tabular}{cccccc}
\hline $\begin{array}{c}\text { Layer } \\
\text { number }\end{array}$ & $\begin{array}{c}\text { Layer } \\
\text { thickness } \\
{[(\mathrm{m}]}\end{array}$ & $\begin{array}{c}\text { Depth to } \\
\text { top of layer } \\
{[\mathrm{m}]}\end{array}$ & $\begin{array}{c}\text { Layer } \\
\text { number }\end{array}$ & $\begin{array}{c}\text { Layer } \\
\text { thickness } \\
{[\mathrm{m}]}\end{array}$ & $\begin{array}{c}\text { Depth to } \\
\text { top of layer } \\
{[\mathrm{m}]}\end{array}$ \\
\hline 1 & 1.00714 & 0.00 & 15 & 5.85806 & 36.19 \\
2 & 1.14209 & 1.01 & 16 & 6.64325 & 42.05 \\
3 & 1.29513 & 2.15 & 17 & 7.53369 & 48.70 \\
4 & 1.46868 & 3.44 & 18 & 8.54347 & 56.23 \\
5 & 1.66548 & 4.91 & 19 & 9.68861 & 64.78 \\
6 & 1.88866 & 6.58 & 20 & 10.9872 & 74.46 \\
7 & 2.14174 & 8.47 & 21 & 12.4599 & 85.45 \\
8 & 2.42873 & 10.61 & 22 & 14.1300 & 97.91 \\
9 & 2.75418 & 13.04 & 23 & 16.0239 & 112.04 \\
10 & 3.12334 & 15.79 & 24 & 18.1717 & 128.06 \\
11 & 3.54198 & 18.92 & 25 & 20.6074 & 146.23 \\
12 & 4.01674 & 22.46 & 26 & 23.3695 & 166.84 \\
13 & 4.55512 & 26.47 & 27 & 26.5018 & 190.21 \\
14 & 5.16568 & 31.03 & 28 & & 216.71 \\
\hline
\end{tabular}

The starting model for the inversion was a homogeneous half-space with the same resistivity as the reference model. Inversions were performed with a reference resistivity of 10 and $100 \mathrm{ohm}-\mathrm{m}$; these reference values span the most common range of resistivities in the area. Inversion was done only for resistivity values, not magnetic susceptibilities. Background magnetic susceptibility was set to zero.

No additional user-supplied weights for the model norm were specified.

The inversion type was " 1 ," meaning that a user-specified trade-off parameter was used. The specified value of the trade-off parameter was 20 . A maximum of 25 inversion steps were allowed. The convergence test parameter was set to 0.001 .

Model norm components were as follows: $\mathrm{acs}=0.001, \mathrm{acz}=1$. These values provide a good tradeoff between relatively smooth models versus ones that conform to the background model.

Inversion parameters not mentioned above used the default values.

Estimated noise used to normalize the HEM data during inversion are given in table 1-2 as a percentage of signal amplitude. These estimates are based on analysis of HEM data sets from south Florida (Richard Irvine, Condor Consulting, Lakewood, Colorado, written commun., 2003). Minimum specified noise level at each frequency to stop inversion iteration was set at 4 ppm. 
Table 1-2. Estimated noise in HEM data based on calibration-site measurements. Noise is given as a percentage of the signal amplitude.

\begin{tabular}{cccccc}
\hline $\begin{array}{c}\text { Coil } \\
\text { pair }\end{array}$ & $\begin{array}{c}\text { Coil } \\
\text { geometry }\end{array}$ & $\begin{array}{c}\text { Nominal } \\
\text { frequency [Hz] }\end{array}$ & $\begin{array}{c}\text { Actual } \\
\text { frequency (Hz] }\end{array}$ & $\begin{array}{c}\text { Inphase } \\
\text { noise } \\
\text { [percent] }\end{array}$ & $\begin{array}{c}\text { Quadrature } \\
\text { noise } \\
\text { [percent] }\end{array}$ \\
\hline 1 & HCP & 400 & 340 & 5 & 7 \\
2 & HCP & 1,500 & 1,529 & 7 & 5 \\
3 & HCP & 6,200 & 6,227 & 7 & 7 \\
4 & HCP & 25,000 & 27,340 & 10 & 7 \\
5 & HCP & 100,000 & 106,200 & 20 & 10 \\
\hline
\end{tabular}

